\title{
Responsible Land Administration in Disaster Risk Management
}

Approaches for Modelling, Integrated Governance and Policy Transfer of People, Land, and Disasters 



\title{
RESPONSIBLE LAND ADMINISTRATION IN DISASTER RISK MANAGEMENT
}

\author{
APPROACHES FOR MODELLING, INTEGRATED GOVERNANCE AND POLICY \\ TRANSFER OF PEOPLE, LAND, AND DISASTERS
}

DISSERTATION

\begin{abstract}
to obtain
the degree of doctor at the University of Twente, on the authority of the rector magnificus, prof.dr. T.T.M. Palstra,

on account of the decision of the Doctorate Board, to be publicly defended on Thursday 26 September 2019 at 14.45 hrs
\end{abstract}

by

Eva-Maria Unger

born on 17 March 1986

in Oberwart, Austria 
This thesis has been approved by:

Prof.mr.dr.ir. J.A. Zevenbergen, supervisor

Prof.dr.ir. C.H.J. Lemmen, supervisor

Dr. R.M. Bennett, co-supervisor

ITC dissertation number 366

ITC, P.O. Box 217, 7500 AE Enschede, The Netherlands

ISBN 978-90-365-4858-8

DOI 10.3990/1.9789036548588

Cover designed by Eva-Maria Unger

(adapted from the painting drawn at Children's Convention organized by Plan International Nepal in November 1997, at Kathmandu Airport)

Printed by ITC Printing Department

Copyright (C 2019 by Eva-Maria Unger

\section{UNIVERSITY OF TWENTE.}

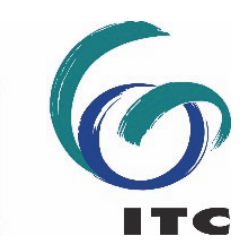


Graduation committee:

\section{Chairman/Secretary}

Prof.dr.ir. A. Veldkamp University of Twente

\section{Supervisor(s)}

Prof.mr.dr.ir. J.A. Zevenbergen University of Twente

Prof.dr.ir. C.H.J. Lemmen University of Twente

\section{Co-supervisor(s)}

Dr. R.M. Bennett

Swinburne University of Technology

\section{Members}

Prof.dr. V.G. Jetten

University of Twente

Prof.dr. K. Pfeffer

University of Twente

Prof.dr.ir. J. Crompvoets

KU Leuven

Dr. D. Mitchell

RMIT University of Technology

Prof.dr.ir. P.J.M. van Oosterom TU Delft 



\section{Acknowledgements}

This may be the most challenging task in writing this thesis - the acknowledgements acknowledging all those people that have accompanied and guided me on this journey which honestly feels like a lifetime. Please when reading this acknowledgment keep in mind that the names are not in any particular order and if somebody feels forgotten, please be assured that it was not on purpose.

So many people have touched my life and supported me in one way or another during this $\mathrm{PhD}$ journey. Some were directly involved and made a significant contribution, some were indirectly involved and made an equally significant impact. It was the culmination of all of you that shaped this research. The journey itself I would say was pretty intense and made me grow as a person - there were huge ups and even more intense downs but somehow through all the support and inspiration I got from you - I - WE made it.

To start, I would like to thank my supervisor team Jaap Zevenbergen, Rohan Bennett and Christiaan Lemmen, this thesis would not have been possible without your guidance and support. Jaap, it was you who convinced me to become a PhD student at ITC next to my fulltime job in Austria. I would say it was destiny that we met sitting next to each other at the UN-Habitat GLTN dinner during the World Urban Forum in Naples talking about research possibilities. And it was your guidance, pressure and deadlines I needed in order to complete this thesis. Rohan it was you who sharpened my thoughts with your witty English and linguistic expertise. Your guidance through discussions and in-depth questions shaped this research deeply. Chrit, you joined the supervisory team a little later, but your guidance was invaluable for this thesis. Our fruitful and sometimes intense discussions let me flourish and think outside the box. But the most important characteristic of you was that I could always count on your kind and continuous support. There are simply no words to express this gratitude - the three of you were the activators that got me writing and this thesis without your inspiration, expertise and dedication to research and science would not exist. Thank you for this opportunity and continuously seeing the spark in me - I think I can conclude that this supervision has led to valuable friendships.

Kees, thank you for being the best manager I've ever had, giving me a job at Kadaster, providing me opportunities on the global stage, and supporting my research is already exceeding everything I could have wished for in my professional career. CheeHai, you are a true mentor in the most subtle way. Thank you for being a continuous supporter and providing me with guidance and inspiration. Ganesh Prasad Bhatta, another true inspiration, with your kindness, all-time-smile and your dedication to your country, Nepal: your leadership is a living example of Responsible Land Administration. Paula, I don't know where to put you - because you are all in one - friend and colleague - so I will mention you twice - as you deserve it. You were my strongest support during our FIG YSN leadership, during this PhD research and when I was arriving in the Netherlands. You are a brilliant, truthful and also my most organised friend.

Travelling to Nepal with my best friend Eva after the 2015 earthquakes made me realize all the misery, grief and despair of natural disasters. This realization, the workshop in 
Kathmandu and all those dedicated Young Surveyors of Nepal triggered an inner call to conduct the fieldwork for this research in Nepal. Therefore, my deep appreciation to all my friends and colleagues I met and I worked with during this time in Nepal. Those days are firmly fixed in my mind. All of you: Raja Ram Chhatkuli, Shristee Singh Shrestha, Padma Sunder Joshi, Bishnu Khadka, Jagat Deuja, Uma Shankar Panday, Janak Raj Joshi, Sharada Shiwakoti, Swostika Dahal, Dewi Shiwakoti, Hom Pathak, Shristi Paudel, Jordan Friis, Biplov Bhandari, Shivajee KC, Reshma Shrestha, Ramesh Dahal and Uttam Pudasaini, have provided me with another home in Nepal. It is your friendly smiles, hospitality and the fascinating landscape that will stay with me forever. Last but not least, in the context of Nepal, I would like to acknowledge and appreciate all the stakeholders engaged in the fieldwork in the three sites of Phulappa, Bulungkhani and Jilu - including all the local municipality officials and the community members for their collaborative spirit and support.

Thank you also to my ITC PGM colleagues Divyani Kohli, Liza Groenendijk, Monika Lengoiboni, Mila Koeva, and Dimo Todorovski. I am also deeply grateful to Loes Colenbrander, Petra Weber and Benno Masselink who were supportive in every PhD related issue.

Since I was always fulltime employed while conducting my PhD research, I want to say special thank you to my friends and colleagues at Kadaster: Pauline van Elsland, Tamara Hagendijk-Slappendel, Janine Bender, Kholoud Saad, Christelle van den Berg, Gert Noeverman, Gert Jansonius, Martien Tomberg, Co Meijer, Paul Saers, Suzanne Valkman, Bastiaan Reydon, Marije Louwsma, Mathilde Molendijk, Ernst-Peter Osterbroek, Martinus Vranken, Ton van Helvert, Haico Vegt, Karin Knip, Guus Spitzen, Dorine Burmanje, and Frank Tierloff. I feel very fortunate to work in such an environment with a highly inspirational, open minded and purpose-driven team. Thank you also to my friends and colleagues at my previous employer, the Federal Office of Metrology and Surveying (BEV). Thank you in particular to Stefan Klotz, Julius Ernst, Wernher Hoffmann, Gunther Rabl, Martin Mueller-Fembeck, Gerhard Muggenhuber, Erich Imrek, Gert Steinkellner, August Hochwartner, Edin Pezerovic, Rupert Kugler, Schildberger Bernhard, and Christa Petz who provided me foundational knowledge and the drive to grow professionally.

I have had brilliant teachers and professional peers who I met along the way and who shaped my thinking through mentoring, coaching, promoting my work and ideas or just simply giving their time. In this regard thank you, Gerhard Navratil, Reinfried Mansberger, Christoph Twaroch, Sayeh Kassaw Agegnehu, Wondimagegen Tesfaye, Greg Scott, John Gitau, Danilo Antonio, Oumar Sylla, Joep Compvroets, Brent Jones, Keith Hofgartner, David Mitchell, Peter van Oosterom, Peter van Tongeren, Alicia Silva, Tjeerd Witts, Simon Ulevund, Athina Trakas, Jean-Francois Beaupre, David Betge, Mikael Lilje, and Rudolf Staiger.

This section will not be complete without highlighting the Austrian Society of Geoinformation and Surveying (OVG) and the International Federation of Surveyors (FIG). Both organisations were the ignitors of my international career and the fertilizer of my professional network. FIG feels like a family and Louise Friis Hansen, Claudia 
Stormoen Pederson, Maria Bargholz, Kate Fairlie, Cecilia Linden, John Hohol, Mike Barry, and Paul van der Molen for me - you were the centre and important parts of this family. Of course, I am forever grateful for all the FIG Young Surveyors who were my source of inspiration in every kind of matter during my ten years of involvement, which also impacted this research tremendously. I am so thankful to have been able to combine my research experiences with the STDM Training of Trainers, YSN Conferences and sessions, and the Volunteer Community Surveyors Program and for that I am forever grateful to everybody who supported me along the way.

Stepping aside from all the 'professional' acknowledgments I indulge now in some personal gratitude. I feel the luckiest person to have a great family and friends who always supported my dreams and ideas and to keep me going. Mama (Margaretha), Papa (Josef) and Josef (brother), the three of you have instilled so many values and qualities in me which I am forever grateful for. Thank you for the immeasurable amount of love that you have showed me and the support you gave me throughout the years. Eva, (sister in law) thank you for providing me time with the two little ones, Clara and Luise. You are truly a bundle of joy - and I hope that we will catch a lot more rainbows together. Tante Erika and Onkel Helmut your guidance from early on shaped and grounded me. Never will I forget all the valuable lessons you provided me and the evening 'Haselnuss Pudding' or English teaching sessions. I also would like to thank my extended family - all aunties and uncles and cousins - naming all of you would be too much but I would like to thank Tante Renate and Onkel Ferdinand - thank you for joining the defence. Eva, Andi, Mel and Paula how on earth can I ever be without you. The four of you are my corner stones and your support throughout anything and everything is not measurable. I know that I can always count on you and that this friendship will always be solid as a rock (wie ein Fels in der Brandung).

I feel fortunate to have friends all over the world who shared their visions, ideas, life experiences and simply the most valuable we all have - time. Thank you Kerstin Steiner, Julia Hutter, Julia Egermann, Julie Morgenbesser, Sabine Gottwald, Georg Topf, Anita Ernst, Barbara Kullnig, Claudia Lukschander, Monica Ashton, Anna Legath, Suerme Ucan, Mike Miler, Bernd Lukits, Lukas Fingerle, Margaux \& Guy, Margot Megens, Yasemin Tanriverdi, Louise Richardson, Cobus Bosman, Joachim Eberhardt, Noah Eberhardt, Günter Schneider, Melle Nikkels, Suzanne de Jong, Divyani Kohli, Anna Shnaidman, Edgar Barreira, and my Bali surfer gang (Cynthia \& Nick, Pierre, Julia, Julie, Lisa, Rick \& Alexia, and Ele.

Finally, I would like to say a special thank you for those who were providing their beautiful cosy homes during my stays in the Netherlands Margot, Yasemin, and family Bennett (Sarah, Rohan, Eve, Edmund, Edith and John) and to those who were involved in the finalization of this thesis by either working on the summary or advising me on the cover till late in the evenings. Thank you: Kerstin, Eva, Andi, Rohan, Divyani, Chrit, Margot and Paula.

I sincerely sincerely sincerely thank all of you - With love and gratitude, Eva 


\section{Table of Contents}

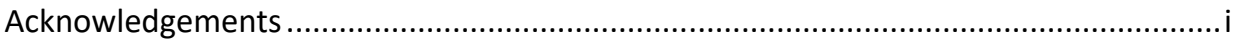

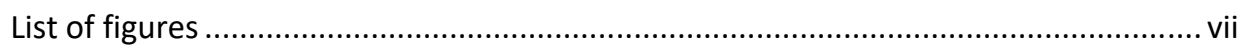

List of tables .......................................................................................................... vii

Chapter 1 Introduction ........................................................................................ 1

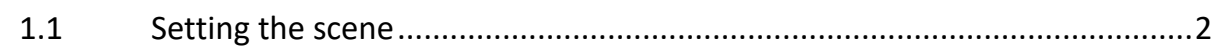

1.2 Defining the research problem .................................................................

1.3 Research formulation, general and specific research objectives .................6

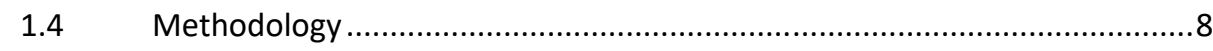

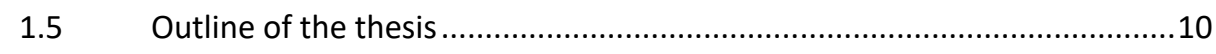

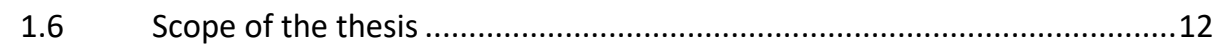

Chapter 2 On the need of responsible LA in DRM................................................ 13

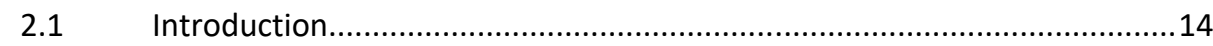

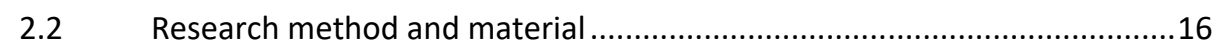

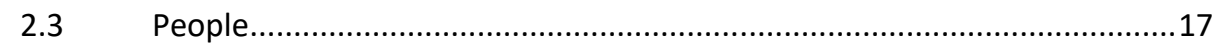

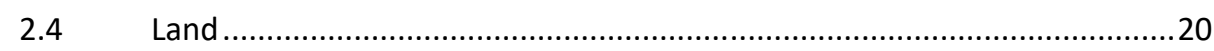

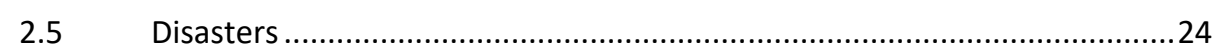

2.6 Consolidating the links between responsible LA and DRM ........................26

2.7 Potential example applications of the framework ....................................28

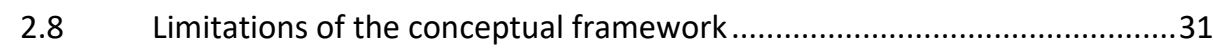

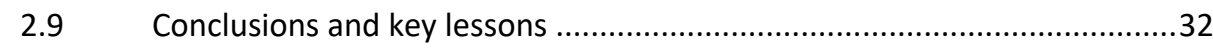

Chapter 3 Adapting LADM for disaster prone areas and communities...........................35

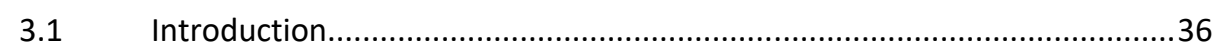

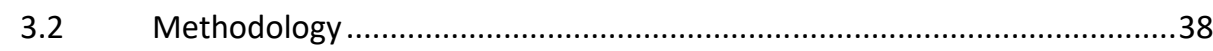

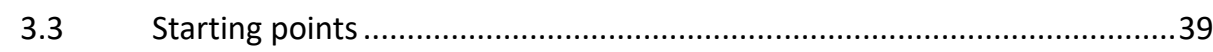

Elements of an integrated LA-DRM model..............................................42

3.4.1 Individual and community defined vulnerabilities pre- and post-disaster...........44

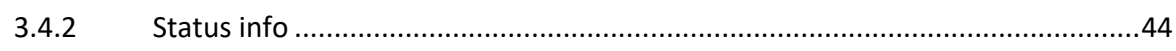

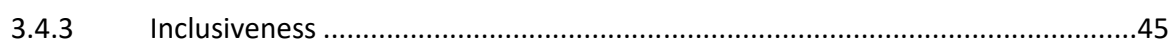

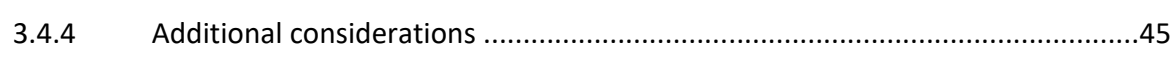

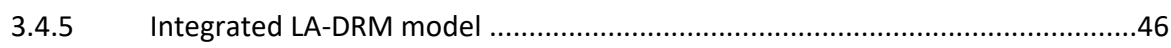

3.5 Potential and limitations of the LA-DRM model .....................................47

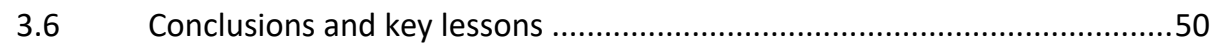

Chapter 4 Application of FFP LA tools and approaches in a post-disaster context ........51

iv 


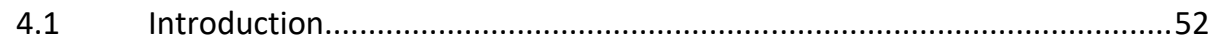

4.2 Land administration challenges in Nepal ...............................................53

4.3 Land and post-earthquake challenges in Nepal ......................................55

4.4 Case study areas in the Dolakha region .................................................56

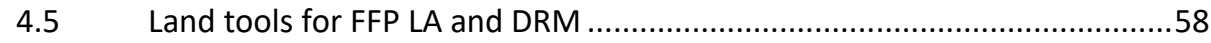

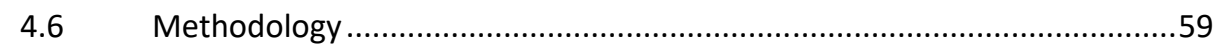

4.7 Overview of different roles in the FFP LA spatial framework......................62

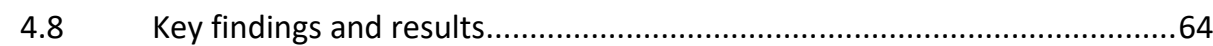

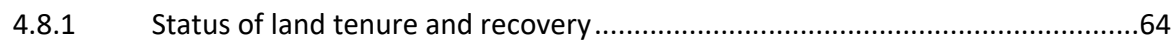

4.8.2 Relevance of farm tenure for DRM ...............................................................66

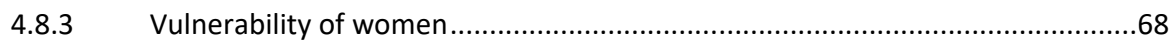

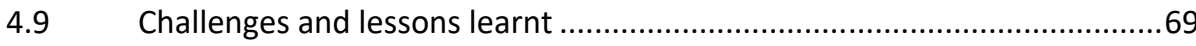

4.10 Conclusions and Recommendations .......................................................... 70

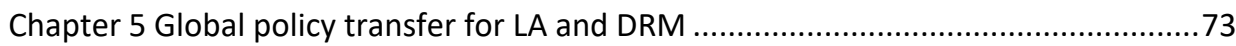

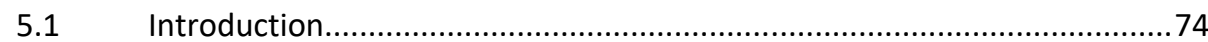

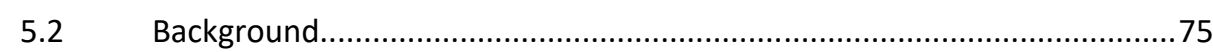

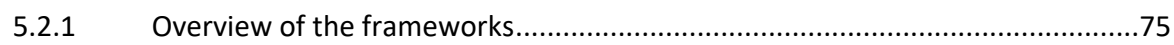

5.2.2 The policy transfer challenge ..........................................................................76

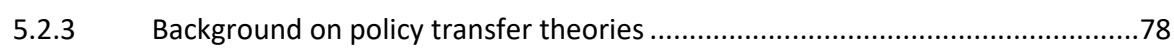

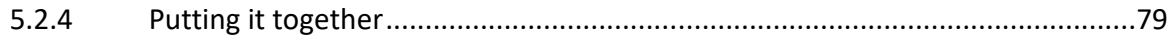

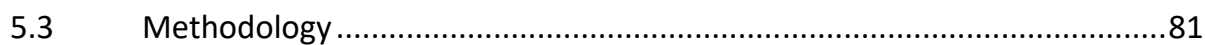

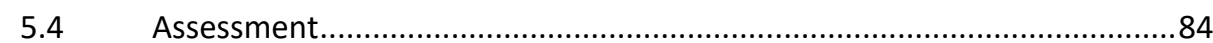

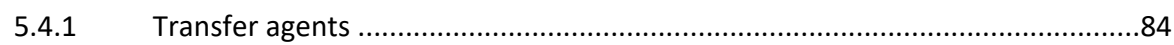

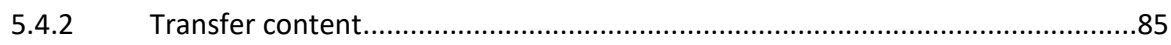

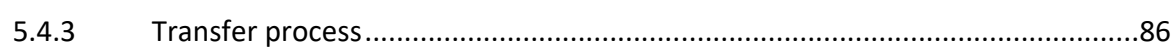

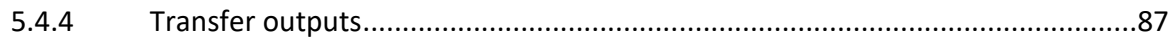

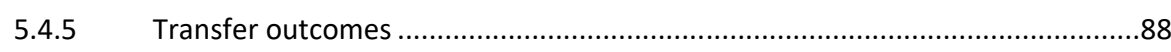

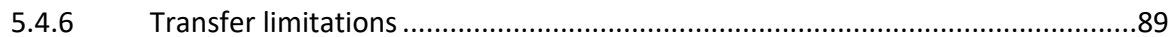

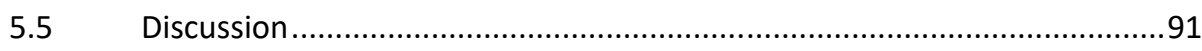

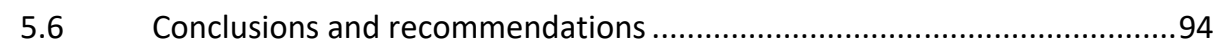

Chapter 6 Towards responsible LA in DRM: summary and conclusion ........................97

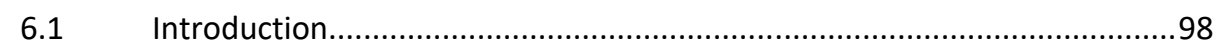

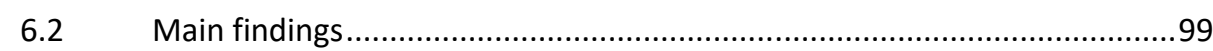

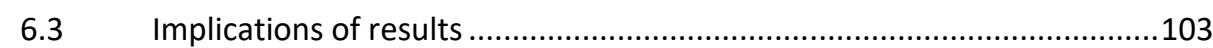

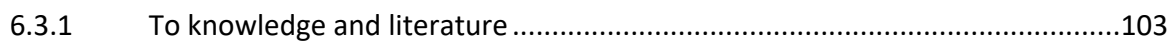

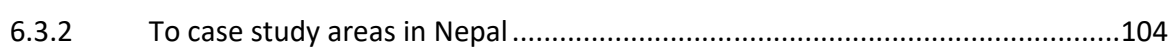


6.3.3 To meeting other societal challenges and needs ..........................................105

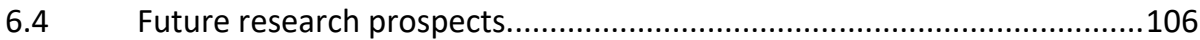

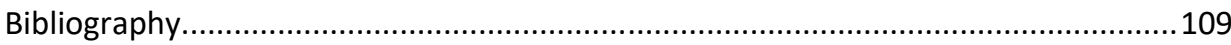

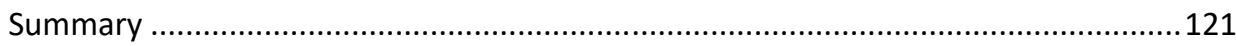

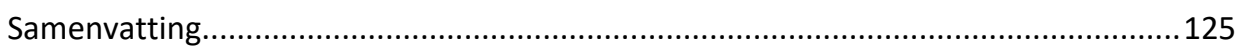

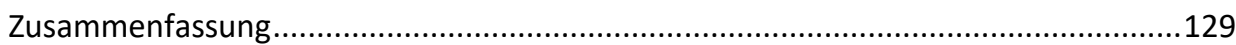

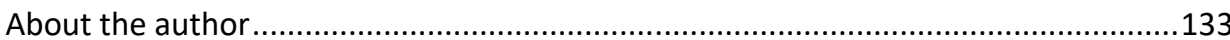




\section{List of figures}

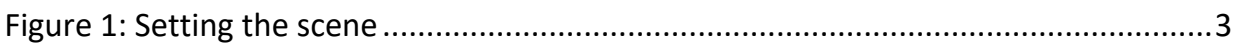

Figure 2: Overview - fundamental drivers for the research objectives ..........................6

Figure 3: Overview - research methodology of specific research objective.....................9

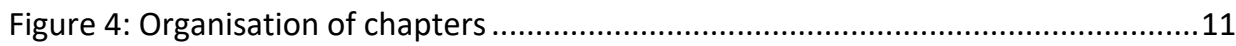

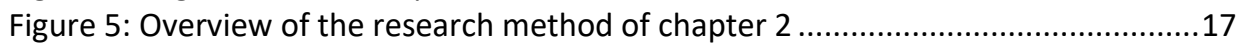

Figure 6: Conceptual framework on the need for responsible LA in DRM .....................27

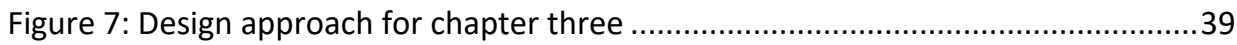

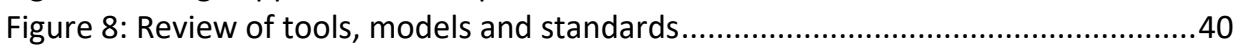

Figure 9: LADM/STDM as a base for the LA-DRM model ...........................................41

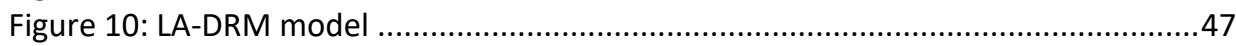

Figure 11: DRM phases and potential of the LA-DRM model.....................................49

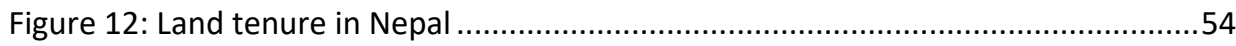

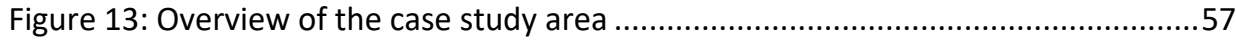

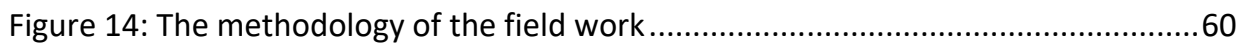

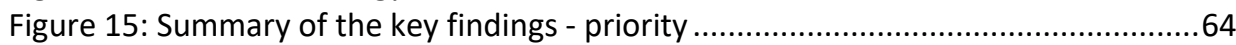

Figure 16: House status in case study areas.............................................................65

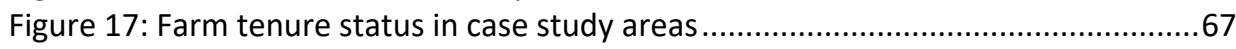

Figure 18: Summary of the key findings - gender..................................................68

Figure 19: Policy transfer - local (national, regional and community) to global level ....77

Figure 20: Research setting: LA - DRM - Global Policy ..............................................8

Figure 21: Assessment parameters and modes adapted from (Stone, 2004) ................82

Figure 22: The nine strategic pathways of the IGIF source (UN-GGIM, 2018) ...............90

Figure 23: Alignment between SFGISD and FELA .....................................................90

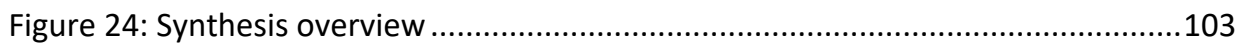

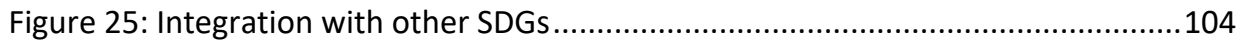

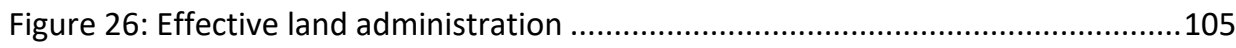

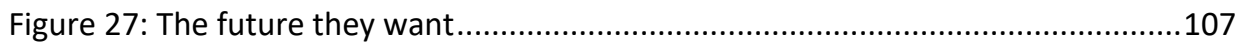

\section{List of tables}

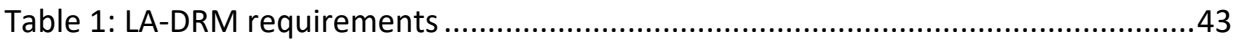

Table 2: Different roles in the FFP LA spatial framework ...........................................63

Table 3: Policy transfer assessment questions and modes adapted from (Stone,2004)83

Table 4: Policy transfer assessment parameters adapted from (Stone, 2004) ..............91 
Chapter 1

Introduction 


\subsection{Setting the scene}

In 2015 global agreements were reached intending to shape international policy responses to the major social, economic, and environmental challenges of the $21^{\text {st }}$ century. With the adoption of - the Sendai Framework for Disaster Risk Reduction (March 2015), the agreement on the 2030 Agenda for Sustainable Development (September 2015), and the Paris Agreement on Climate Change (December 2015) there was recognition at the highest governance levels on the undeniable and fundamental relationship between land administration (LA) and disaster risk management (DRM), and hence the sustainable development of humankind.

The Sendai Framework for Disaster Risk Reduction 2015-2030 establishes a roadmap for reducing disaster loses by 2030 (WCDRR, 2015). The 2030 Agenda for Sustainable Development defines 17 goals at its core, which is an urgent call for action by all countries for a global partnership to achieve sustainable development (UN, 2015). The Paris Agreement on Climate Change aims to strengthen the global response to climate change (UNFCCC, 2019).

All three initiatives respond to the challenge that an estimated $70 \%$ of the population is living in unrecognised (by government) or undocumented people-to-land relationships (Enemark, et al., 2014). Meanwhile, since 2000, approximately 200 million people have been affected by natural hazards (UNISDR, 2019). Further contemporary drivers such as increasing damage caused by natural disasters worldwide, rural to urban migration, rapid urbanization and further impacts of a changing climate, all generate new vulnerabilities and an increased marginalisation of already vulnerable people (Mitchell \& McEvoy, 2019).

Addressing tenure insecurity and disaster risk, in a holistic way (Figure 1), by strengthening the resilience of people and communities - via sound administration and management tools - are necessary conditions for reaching the goals of the 2030 Agenda for Sustainable Development. Among those affected, higher income countries have suffered in terms of absolute economic losses, but people in low and middle-income countries experience effects to their overall livelihoods. As shown in the case study conducted in this thesis, the devastation on people's livelihood and their people-to-land relationship caused by the 2015 earthquakes in Nepal reinforces the argument that integration of responsible LA in DRM approaches is needed. 


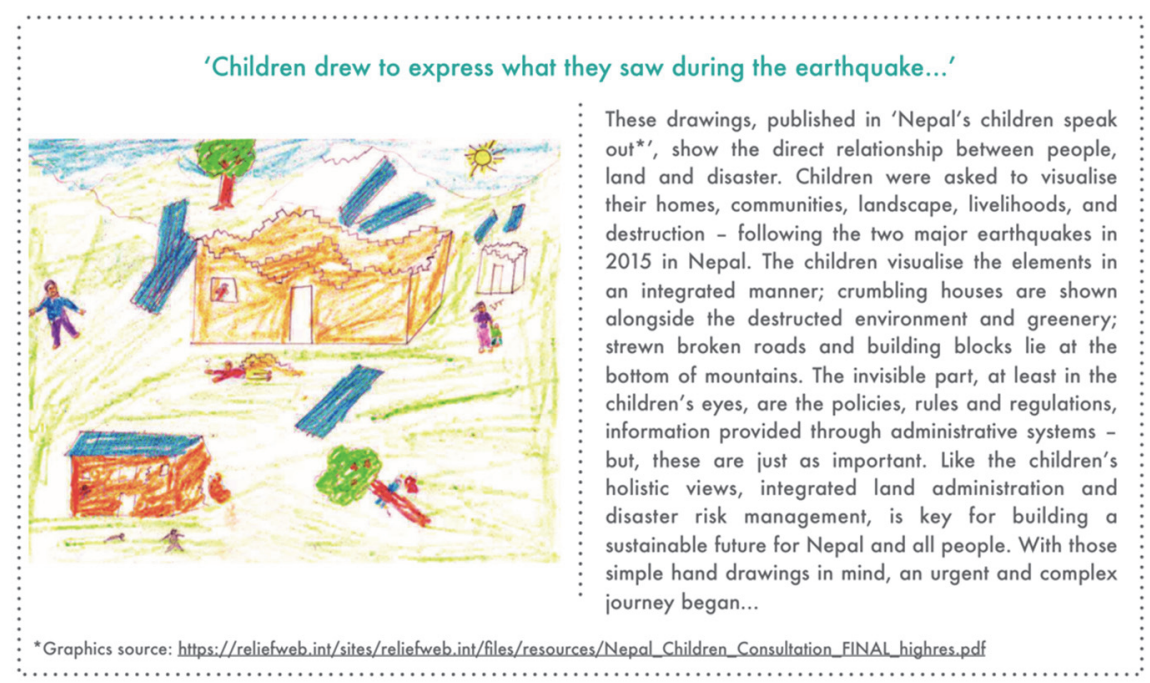

Figure 1: Setting the scene

\subsection{Defining the research problem}

Local level challenges relating to land and disasters, provide the foundational problem to which this research seeks to respond. Those challenges are coupled with the global agenda and are drivers for change in the domains of LA and DRM. Further studies on important building blocks in both domains LA and DRM have been undertaken but an integrated implementation is lacking. A gap currently exists between the challenges experienced by local individuals and communities in relation to land issues and disasters on the one side and the frameworks and policies established at the global level on the other side. Whilst the importance of the latter should not be understated, there is a need to go beyond global policy statements to ensure that those policies reach national and local levels and are implementable through the provision of technical tools and capacity. This requires research developing the theoretical, methodological, conceptual, and technical relationships between the domains of LA and DRM.

Going beyond this initial problem statement, the research problem is further refined by four underlying problems, described, justified, and addressed in more detail in each of the following chapters. To understand the research flow, a snapshot of the problems is provided here. 


\section{Absence of a theoretical framework linking DRM and land tenure security provision}

First, the increasing occurrence of natural disasters and the increasing demands for land tenure security are crucial global challenges that have received much attention over the past two decades. The 2030 Agenda for Sustainable Development with its defined Sustainable Development Goals (SDGs), together with the Sendai Framework for Disaster Risk Reduction, stimulate innovative and transformative approaches to secure land and property rights for all (UN, 2015). The Sendai Framework (WCDRR, 2015) specifically calls for investments in research and the development of a methodology and models for disaster risk assessment. Responsible LA and DRM both focus on empowering vulnerable groups to become resilient communities. When LA is implemented responsibly, it underpins good land governance and ultimately supports sustainable LA by providing strategies and tools to document all people-to-land relationships (Zevenbergen, et al., 2015). DRM and especially community-based disaster risk management (CBDRM) aims to evaluate and manage natural disaster risks at the local level - and highlights the role of communities when it comes to disaster risk reduction (ADPC, 2016). Consequently, there is growing agreement on the need to adopt responsible LA approaches, ones that better address the needs of the poor living in disaster prone contexts. Vulnerable communities and exposed lands could benefit from emerging responsible LA, however, thus far, the application of the responsible LA mind-set has gained minimal traction in the DRM agenda - and this is primarily because at the theoretical and conceptual levels, there is a void between the disciplines in terms of the philosophies, theories, and methods applied. Ultimately, responsible LA should enable the poor to minimise vulnerabilities and disaster risks through an inclusive land tenure security approach to prevent, mitigate, prepare and respond to natural disasters. Therefore, an integrated conceptual framework for LA and DRM is needed.

\section{Lack of data models for integrated technical approaches and responses}

Disaster prevention, response and recovery require information about land tenure. Though, in many high-risk contexts, such records are non-existent or not up to date. As a result, vulnerable groups are often passed over by the government during DRM activities. At present there exists no dedicated tool for supporting land tenure recordation of all people-to-land relationships for the purposes of DRM. More specifically, the required supportive data models and standards that could enable integration of concepts from the respective domains of LA and DRM are lacking. Standardized data models could support software and service designs. Well-designed and documented conceptual and logical models support and allow stakeholders to identify areas for improvements. Consequently, the demand for a shared ontology, which allows all stakeholders to act globally, increases with any software development 
and requires alignment and standardisation to achieve data compatibility and interoperability (West \& Fowler, 1999). Within the LA domain, a globally agreed ISO standard exists, the Land Administration Domain Model (LADM) (ISO, 2012). Within DRM many frameworks already exist that are used to develop practical approaches in DRM. However, none of these models deal directly with the overlap between land and disaster related data. Hence the demand for a data model linking the land and disaster related data appears high.

\section{Limited evidence of local initiatives testing an integrated approach with innovative land tools}

To gain credence, any solutions to the abovementioned theoretical, conceptual and methodological gaps would need to be shown in practice. There is a need to tangibly demonstrate how information on people-to-land relationships - documented in a LA system - is crucial in any natural disaster response. In this vein, there is a need to showcase how local level initiatives applying Fit-For-Purpose LA (FFP LA) in the process of earthquake recovery, in such a way that it improves the community resilience. Being more specific, can it be shown that innovative land tools can be used in the postearthquake context to support the recordation and management of customary and informal land rights for communities? One of the FFP LA approaches which involves participatory mapping through and with the community, by identifying visible boundaries on high-resolution satellite imagery, appears to have great potential for DRM. Such local level initiatives may show the way to an efficient and effective mapping of land rights in the context of DRM and may deliver the urgently required data with the agreement of the community on their people-to-land relationships for reconstruction grants and decision making. Further analysis of information collected by grassroot surveyors could identify hinderances caused through the missing people-to-land information. Hence the proof that FFP LA initiatives can deliver an overview of the people-to-land relationships of the poor and vulnerable to access reconstruction grants and secure tenure in the aftermath of a natural disaster is missing.

\section{Lack of policy and tool transfer between LA and DRM at multiple levels}

Policy transfer is a concept that gains importance at the global level, where politically and institutionally speaking, broad agreement exists in policies, goals, and indicators with regard to the achievement of global sustainability (UN, 2015). Methods for transferring the agenda to national level, and beyond, are a logical next step in the implementation of the 2030 Agenda for Sustainable Development and its seventeen Sustainable Development Goals (SDGs). The United Nations initiative on Global 
Geospatial Information Management (UN-GGIM) plays a leading role in the development and diffusion of policy frameworks with regard to geospatial information. Specifically, two frameworks, the Framework for Effective Land Administration (FELA) and the Strategic Framework for Geoinformation Services for Disaster (SFGISD), are under development to tackle global issues in relation to tenure security and natural

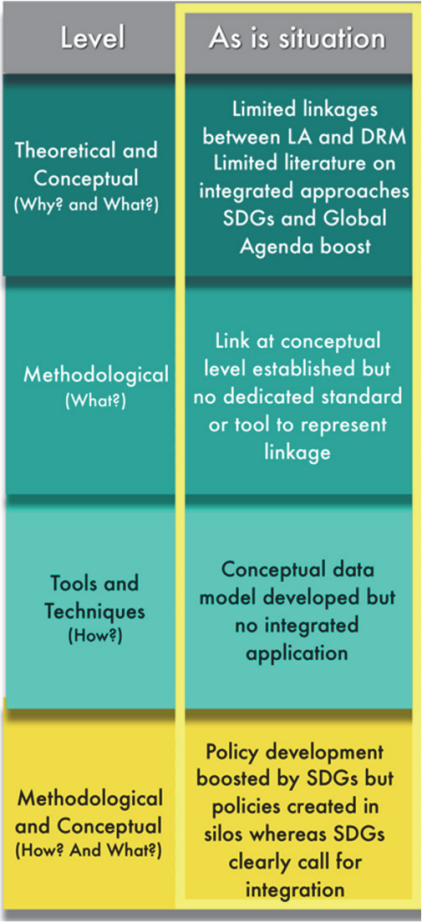
disasters. In order to harmoniously diffuse those global goals and frameworks into national laws and regulations, and to local community initiatives and policies, policy transfer is required to occur between governance layers. However, it remained unclear what approach, the network or institutional mode, is being used to ensure harmonisation of policies between the two domains, and whether those policies are transferring down to national and community levels successfully.

Combined, the four abovementioned problems or 'as is situation', as shown in Figure 2 impede, and will continue to impede, sound LA in disaster risk contexts, and ultimately the achievement of global policies and agreements. The four problems form the kernel of the research problem underpinning this thesis. The ways to respond to the problem in terms of research objectives, questions and intended methods are now discussed.

Figure 2: Overview fundamental drivers for the research objectives

\subsection{Research formulation, general and specific research objectives}

To address the research problems, the overarching research objective is to understand and demonstrate how responsible LA can be combined with DRM, via concepts and tools, in a way that is people-serving, efficient and effective from the global to local level. To achieve the general research objective, the following specific objectives will be addressed:

1) To illustrate the theoretical linkages within responsible LA in DRM, by developing a conceptual framework explaining the interactions between global change forces, disaster risk drivers, and foundational LA constructs. 
2) To develop a conceptual data model linking the domains of LA and DRM to support resilience to natural disasters.

3) To assess responsible land tools applied in DRM in a post-earthquake context.

4) To assess the opportunities and limitations of policy transfer within LA and DRM.

Where:

'Responsible land administration'

means that LA continuously aligns processes and resources with the dynamics of societal demands (Zevenbergen, et al., 2015).

\section{'Disaster risk management'}

means the systematic process of using administrative directives, organizations, and operational skills and capacities to implement strategies, policies and improved coping capacities in order to lessen the adverse impacts of hazards and the possibility of disaster (Mitchell, 2011).

\section{'Conceptual framework'}

means an overall structure of a set of assumptions, concepts, values and practices that constitutes a way of viewing reality (Bennett, 2007).

\section{‘Conceptual data model'}

is a structured business view of the data required to support business processes, record business events, and track related performance measures. A conceptual data model focuses on identifying the data used in the business but not its processing flow or physical characteristics (Sherman, 2015).

\section{'Resilience'}

means the ability of a system, community or society exposed to hazards to resist, absorb, accommodate, adapt to, transform and recover from the effects of a hazard in a timely and efficient manner, including through the preservation and restoration of its essential basic structures and functions through risk management (Mitchell, 2011). 


\section{'Policy transfer'}

means the process by which actors borrow policies developed in one setting to develop programs and policies within another (Dolowitz \& Marsh, 1996).

\subsection{Methodology}

The overarching method follows a pragmatic research ontology based on the search to solve a series of practical problems through academic inquiry. According to (Morgan, 2014) pragmatism is particularly appropriate for mixed methods research which is also supported by (Johnson \& Gray, 2010). Pragmatist researchers identify interrelations between objective, subjective and intersubjective realities in order to identify the best way forward (Johnson \& Gray, 2010). Therefore, the major rational behind using pragmatism as a guiding paradigm was the action-oriented nature of this research which can be summarized by 'research through design'. The design process is broken into four pieces, whereas each piece uses a different method to produce the required element.

Moving forward, for each specific objective there is a specific research methodology. This remainder of this section provides the overview and the rationale behind the choices for the methodologies adopted to reach each specific objective, as shown in Figure 3. Further details on each methodology are provided in the subsequent chapters. 


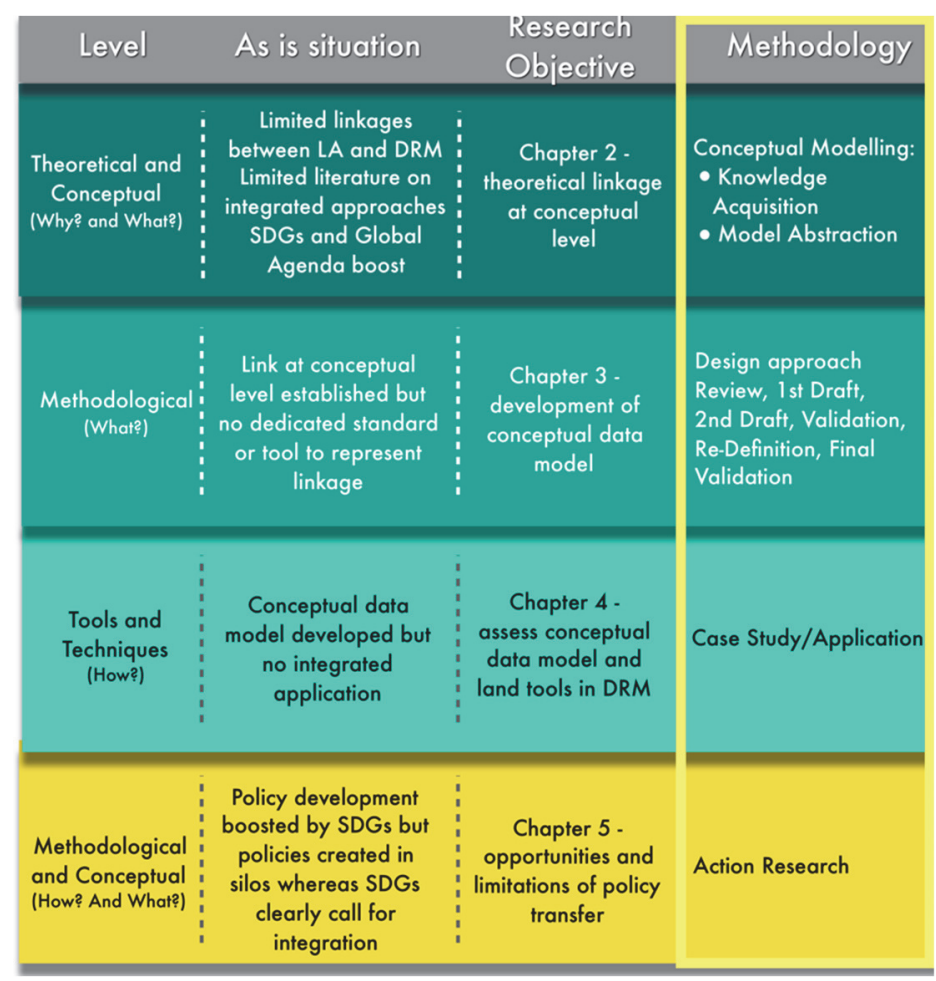

Figure 3: Overview - research methodology of specific research objective

The first objective requires the exploration of the interactions between the three identified and fundamental global change forces (people, land and disaster) and the three disaster risk drivers (vulnerability, exposure and hazard). To reach this objective two processes of conceptual modelling were followed: knowledge acquisition and model abstraction. Justification of the approach is found in similar work relating to model land tenure security (Simbizi, et al., 2014). Regarding knowledge acquisition, a research synthesis approach is used to analyse and consolidate existing evidence and to develop a new inclusive conceptual framework. Steps for model abstraction involve identifying and describing the relationships between the components, identified through knowledge acquisition, graphical modelling as well as considering the model's limitations.

The second objective seeks to develop a conceptual data model linking the domains of LA and DRM using a design approach. Justification of the approach is found in similar research to tenure security (Lemmen, 2012), (Hay, 2014), and (Lemmen, et al., 2015), and related to DRM (Li, et al., 2007), (UNISDR, 2015). Basic steps of the design approach were: to review existing standards, to draft model abstractions, the initial model definition, a first draft model and validation, followed by a re-definition of classes, 
attributes and associations and a final validation. Throughout the design approach, Unified Modeling Language (UML) diagrams, along with textual and graphical description, were used for the representation of all activities, processes, classes, attributes and associations.

The third objective is reached using a case study methodology as defined by (Yin, 2014). The case study method is a well-known and often used method conducting research in the field investigating a contemporary phenomenon. A case study approach is one of the main sources of gaining information and knowledge from practical experiences in the field of LA (Asiama, 2019), (Shreshta, 2019), and (Stubkjær \& Cagdas, 2009). For this reason, a case study in four different communities in Dolakha, Nepal was undertaken. The practical steps in the field involved the design of the case study, conducting the study, analysing the results and reporting the findings.

The fourth objective seeks to assess the opportunities and limitations of policy transfer for two developed frameworks by the United Nations in relation to tenure security and natural disasters. To reach this objective, an action research inspired approach is used, whereby the concept of reflexivity was considered central. The action research inspired approach was used because the researchers were among those involved in the actual (and ongoing) development of the frameworks. To increase objective distance, the assessment parameters used were taken from (Stone, 2004).

\subsection{Outline of the thesis}

The thesis is organized in six chapters, based on the four sub-objectives, towards achieving the overall objective as seen in Figure 4. Chapters two to five form the core of this thesis, with each addressing one sub-objective. The chapters are derived from a series of published ISI journal papers and an UN-Habitat publication. Each chapter provides a background to the sub-objective, the methodology used to achieve the subobjective, results and the discussion of the results, and ends with a conclusion. The research is undertaken in four stages - (1) problem analysis, (2) data model development, (3) data model application, data collection and analysis and (4) assessment of policy transfer mechanisms. 


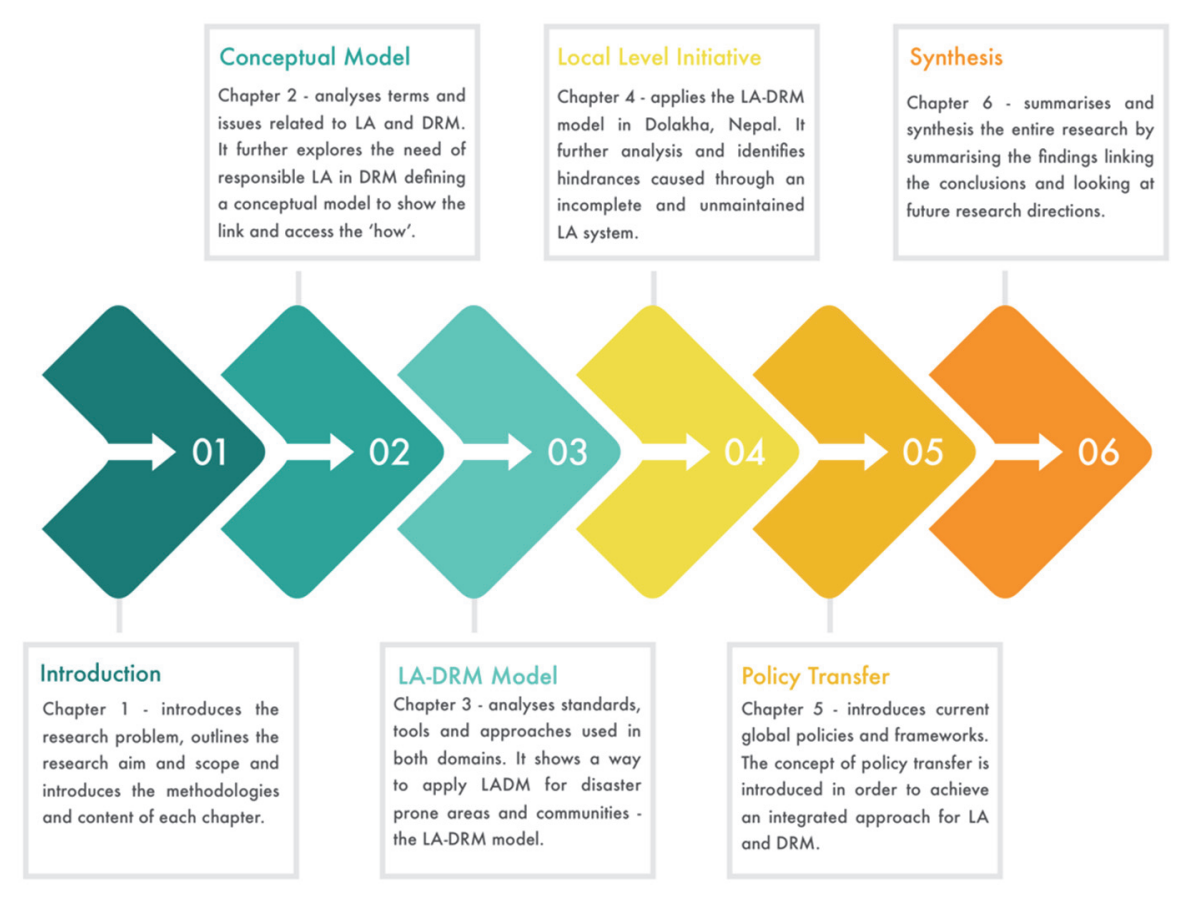

Figure 4: Organisation of chapters

Chapter two - is devoted to the understanding and analysis of the three global change forces (people, land, and disaster) and the three disaster risk drivers (vulnerability, exposure, and hazard). This analysis uncovers the missing relationship between responsible LA and DRM. Thus, this chapter presents the findings from detailed investigations underlined with cases. Overall, this chapter captures the situation of responsible LA in DRM and links those two domains through the development of a conceptual framework. The work of this chapter is published in the journal Survey Review.

Chapter three - investigates supportive data models and standards that could enable the link of the respective domains of LA and DRM. This identifies the gap in literature, tools and models. The chapter results in a conceptual data model linking the two domains and which is applied in Nepal as shown in chapter four. The work of this chapter is published in the journal Land Use Policy.

Chapter four - focuses on the cases from Nepal which show a new practical approach at community level uniting responsible LA and DRM. This new approach explores how FFP LA and interventions can be used in the process of earthquake recovery, to improve the community resilience. The conceptual data model, developed in chapter three, is 
considered as validated through its application in Nepal. The work of this chapter is published as an UN-Habitat GLTN publication.

Chapter five - first provides the contemporary policy developments at global level. It then further focuses on policy transfer as a mechanism to achieve an integrated approach of responsible LA and DRM. The opportunities and limitations in regard to global policies for LA and DRM are investigated and an assessment of which mode (institutional or network) these policies and frameworks are following is shown. The work is currently under review for publication.

Chapter six - synthesizes the entire research by summarizing the key findings of the previous chapters, reflecting on the main results and their implication on knowledge and literature, on the case study areas in Nepal, on other societal challenges and needs, and the overall link to the SDGs. It also recommends avenues for further research.

\subsection{Scope of the thesis}

The scope of this thesis lies within the applied scientific disciplinary areas of LA and DRM. Further, this thesis is primarily set in a developmental context in the global south, although, particularly in terms of tools, some general principles are envisaged. The work of this thesis is bookended between 2012 and 2018. Developments since January 2019 are not included, except for the most relevant and crucial developments for the synthesis, as far as known. Especially in regard to policies and frameworks, which is mainly tackled in chapter five, it can be seen how active the domains of research are. As stated, this thesis was developed with a highly pragmatic grounding, it tackles both local level communities as well as a global policy setting. The thesis focuses on conceptual tools and data technologies but less on theories and tools stemming from the domains of law (e.g. legal frameworks), economics (e.g. business models), social sciences (e.g. perceptions and ideologies), and environmental sciences (e.g. climate change). That said, theories and techniques from these domains are touched upon, with appropriate reference. Throughout the thesis the importance of those domains and the alternate or complementary perspectives, as tackled here, is acknowledged. 


\section{Chapter 2}

On the need of responsible LA in DRM*

* This chapter is based on an ISI journal paper published as;

Unger, E.-M., Zevenbergen, J., \& Bennett, R. (2017). On the need for pro-poor land administration in disaster risk management. Survey Review, 6265, 1-12. 


\section{$2.1 \quad$ Introduction}

Pro-poor $\mathrm{LA}^{1}$ focuses attention on improving the land tenure security of the poor. It is a set of counter approaches that supports recognition of the broader continuum of land rights, not just outright individual private ownership. It can be seen as a subset of 'responsible LA', introduced in (Zevenbergen, et al., 2015) and more broadly related to ideals behind good land governance (FAO, 2012). These approaches emerge because individual land titling, the conventional approach for delivering land tenure security in developed countries at scale, has been shown to be incapable of delivering effective results in less developed contexts (Zevenbergen, et al., 2014a) (Zevenbergen, et al., $2014 b$ ). The reasons for the ineffectiveness are usually a mix of factors relating to inadequately aligned land policies, legislative frameworks, institutional arrangements, technical standards, and a lack of available funding and skilled capacity.

The 'poor' often reside, although not exclusively, in disaster prone areas due to limited land resources, especially in urban areas. For this reason, there is a strong and multifaceted relationship between demands for tenure security, rapid population growth (often in disaster prone areas), and the increasing occurrence and impact of natural disasters. This increase in the number of natural disasters affecting an increasing number of vulnerable and exposed people, who are not addressed through any LA system, has eminent effects on people's resilience. For the field of responsible LA, disaster prone areas therefore represent a special case where tools require development.

Responsible LA has so far received minimal attention in the DRM literature, even though the number of natural disasters and the people affected increased significantly throughout the 2000s. Developing countries are the most affected with regard to the number of natural disasters recorded and the numbers of people impacted. The lack or even non-existence of a functioning LA, specifically missing land information, prevent and delay the DRM processes (Mitchell, 2011). Various works highlight the increasing role of spatial information in DRM (Zevenbergen, et al., 2014a) (Zevenbergen, et al., 2014b). In addition to land tenure information, the relevance of land valuation and land use planning information is also described by (Mitchell, et al., 2015) (Mitchell, et al., 2014) and (Roy \& Ferland, 2014). The research of (Mitchell, et al., 2015) (Mitchell, et al., 2014) and (Griffith-Charles, et al., 2014) illustrate the importance of including the poor in land and DRM approaches. However, there is an apparent gap in the literature: the interrelationship between three fundamental global change forces (people, land and

\footnotetext{
1 Terminology changed from pro-poor LA to responsible LA. The concepts are similar, but, responsible $L A$ is broader and is deemed more appropriate in the context of the thesis.
} 
disaster) and the three disaster risk drivers, defined by (WB and GFDRR, 2012) (vulnerability, exposure and hazard) is conceptually, and therefore practically, rather unexplored. In this regard, more dialogue between the discourses of responsible LA and DRM could be highly profitable to both domains.

This chapter aims to close the cited gap and review the need for responsible approaches in developing countries prone to natural disasters. The review shows the interrelationship, couched in the general study area of LA, between the three identified fundamental global change forces: rapid population growth (people), increasing demands for tenure security (land), and increasing occurrence of natural disasters (disasters) and the three disaster risk drivers: vulnerability, exposure and hazard. Based on a synthesis of these drivers, the need for responsible LA is identified and a conceptual framework is developed. This framework illustrates the need and potential contributions of responsible LA in disaster-affected areas. Further it introduces and describes the link between people-and-vulnerability, land-and-exposure and disasterand-hazard. The utility of the framework is demonstrated by applying it to example cases including the Haiti earthquake in 2011 and the typhoon Hayan in the Philippines in 2013. The examples highlight the need for alternative approaches for LA that better address all people-to-land relationships in order to prevent, mitigate, prepare and respond to natural disasters. This is important for any justification and advancement of responsible LA and its subsequent application in DRM.

The chapter is structured as follows: first, a brief overview of the methodology explains the research method and materials used for the synthesis; subsequently, the research synthesis structured around each global change force - people, land and disaster - is presented. Specific attention is given to clarifying definitions, which are either diverse over different discourses or entirely missing in the literature. The clarification seeks to ensure a common understanding and forms the base for the development of a conceptual framework. The findings of the research synthesis justify the need for responsible LA in DRM specifically to address the poor and vulnerable. This leads to the development of the conceptual framework, which summarises the findings, shows the interrelationship between different concepts, and demonstrates the possible contribution of responsible LA. Finally, a discussion of key issues emerging on the need of responsible approaches, based on the introduced framework is undertaken: this precedes the conclusion encapsulating future research opportunities. 


\subsection{Research method and material}

In order to review the need for responsible LA in areas prone to natural disasters, two processes of conceptual modelling were followed: knowledge acquisition and model abstraction (Figure 5). Justification of the approach is found in a similar work relating to modelling tenure security (Simbizi, et al., 2014).

Regarding knowledge acquisition a research synthesis was applied to enable comparison of research outputs from multiple studies. The approach aims to provide an empirical understanding of the research field through introducing model abstraction processes, explanatory frameworks, enhanced theories, or new conclusions (Cruses \& Dyba', 2011). Through the literature review three global change forces emerged: the increasing world population, summarised through the term 'people'; the limited resource of land, summarised through the term 'land' and the increasing number of natural disasters, summarised through the term 'disaster'. These terms are considered the fundamental global change forces that underline the need for responsible LA in DRM. They provide the foundation reasoning for the subsequently introduced conceptual framework.

The literature review used terms related to the identified global change forces and its three identified disciplines relevant for the research focus: people (social science, development studies), land (geography, LA, urban and regional planning science) and disaster (earth science). It should be noted the disciplinary areas denoted in brackets are indicative disciplinary areas relating to the global change forces, rather than precise divisions of the disciplinary area. It should also be noted that during the review it was revealed that only a relatively small number of studies existed where all three components were addressed concurrently. To conduct the review, inclusion criteria were developed to define boundaries. Four types of documents were considered for the review: (1) peer-reviewed journal articles, (2) dissertations, (3) books and (4) technical reports published by international organisations. For the journal articles, literature was retrieved from scientific indexes including Web of Science, Elsevier, SCOPUS, GEOBASE, Springer Link, JSTOR and libraries to which the researcher was subscribed. For the technical reports, four international organisations were evaluated as the most active in the research fields on responsible LA and DRM: the United Nations' Human Settlement Programme (UN-HABITAT), World Bank Group (WB), Food and Agriculture Organization of the United Nations (FAO) and International Federation of Surveyors (FIG). In addition, resources and grey literature available on the Internet were utilised. Only resources written in English were selected. Since the research area on responsible LA is quite novel, the focus of literature was on recently published material. Therefore, the review period was set from 1995 to 2015, bearing in mind that the literature from 1995 was included because of the definition of land in the cadastral statement of (Henssen, 1995). 
The study area was not limited although the focus, especially for the application of responsible $L A$, was on developing countries. To use the abovementioned scientific indexes, a systematic computer-based search strategy was utilised. The strategy was developed using selected key words and Boolean operations (and, or). This resulted in a number of search queries that could be reused across the repositories. These search queries were extended through reviewing the reference lists of retrieved articles, in detail, to find additional literature. The process resulted in approximately 80 documents being reviewed ( 63 documents are cited in this work). The dominant focus of these 63 documents was on land (geography, LA, urban and regional planning science). The results of the research synthesis, which gave an understanding on the need for responsible LA approaches in DRM, serve as the base for the modelling process.

The second phase of conceptual modelling as described by (Simbizi, et al., 2014) is model abstraction. Steps for model abstraction involve identifying and describing the relationships between the components, graphical modelling, as well as considering the model's limitations. This activity was completed through both graphical and textual representation of the interrelationships, couched in the general study area of LA, between the three identified global change forces of people (rapid population growth), land (increasing demands for tenure security) and disasters (increasing occurrence of natural disasters), and the three disaster risk drivers: exposure, vulnerability and hazard.

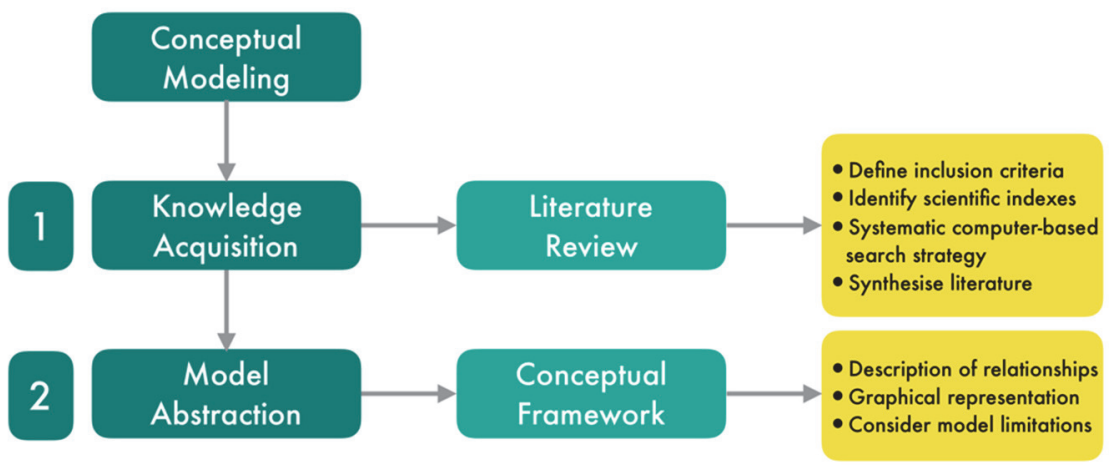

Figure 5: Overview of the research method of chapter 2

\subsection{People}

This section commences the presentation of results from the knowledge acquisition process. Specifically, it focuses on the global change force of people, which is defined in this context as people exposed to natural disasters, is linked to the disaster risk driver, vulnerability. It will be shown how relevant and prominent the interaction and linkages between the two constructs are - particularly with regard to rapid population growth. 
Furthermore, terms used in both disciplines, LA as well as DRM, will be linked to the global change force people.

\section{People and rapid population growth}

Increases in people, or 'population growth', is a key driver behind responsible LA (Alemie, et al., 2015) as well as a key driver behind the increase of human activity, which is suspected to increase the occurrence and impact of natural disasters (Huppert \& Sparks, 2006). The disciplinary areas embodied by the domain of social science, and development studies, tend to concentrate on 'people' - be they individuals or groups, as a scientific unit of analysis, whereas in this context the unit of analysis is people who are exposed to natural disasters and its effects. By definition, any discourse on either land or natural disasters necessarily includes people-related dialogue: it is people who form local understandings of land and natural events, and when impacting negatively upon people these are described as natural disasters. With regards to responsible LA, it is people who form a community with their intangible variety and values, and it is people who rely on sustainable development and responsible approaches, whether in the land tenure security or DRM domain.

Natural disasters are occurring worldwide, although the damage and intensity of the disasters varies within regions: developing countries and their people are more prone to natural disasters and their effects. According to (IEG World Bank, 2006) it is estimated that around $95 \%$ of all casualties occur in developing countries. They also identified China, India, Indonesia, the Philippines and Vietnam among the world's most disasterprone countries, while Small Island Developing States (SIDS) are among the most vulnerable. The population increase as well as the increase of slum dwellers has major consequences on how people access land and increases the people affected and dealing with insecurity of tenure. Further, it influences human activity in a societal context as well as natural resources context, which consequently is suspected to increase the occurrence and impact of natural disasters.

As identified by (Mitchell, 2011) many developing countries are prone to natural disasters and the impact on the country's poor is often greater. Developing countries experience the most excessive population increases as well as being the most likely to have LA systems that are insufficient or non-existent, particularly ones that are not able to respond to or mitigate against natural disasters. This lack of spatial information, which is linked to basic census data, was witnessed in recent disasters. For example, the numbers of people settled in affected areas was unknown during the 2014 Badakhshan mudslides in Afghanistan. Further resettlement strategies failed based of missing landuse strategies, as seen after the Haiti earthquake in 2010. Therefore, responsible LA 
focuses on developing contexts, and on people-to-land relationships, which have not been formally addressed.

The impact of tremendous population increases in developing countries over short periods is crucial as it significantly influences people's livelihoods. Further, land and property issues, especially in relation to natural disasters, become more present in those countries. The urgency of addressing this population increase, in all its manners, is emphasised in the global agenda through the Sustainable Development Goal 11 (SDG). This goal seeks to address people's need to inclusive, safe, resilient and sustainable cities through ensuring access to safe and affordable housing, and upgrading slum settlements (UN, 2015). Therefore, responsible LA is by the researcher seen as a key in building the resilience of the poor to reduce their vulnerability to natural disasters.

\section{People - vulnerability}

The (UNFPA, 2013) as well as (Woodward, 2014) identify specific risks related to rapid population growth, which can be directly linked with one of the disaster risk drivers 'vulnerability'. The specific risks include rising inequalities between developed and developing countries, as well as within those countries, in terms of access to land, housing, food, water and employment. Further, the link between access to land, housing and security of land has been highlighted as a significant issue with regards to urban and rural divides. Those risks increase vulnerability and hinder people's ability to mitigate and respond to natural disasters. Demographic trends, for example, the lack of work and food, are shown in (Desai, 2012) as key for rapid urbanisation. Desai states that people are more likely to move to urban areas, where housing is limited or inaccessible. Especially in Asian and African countries, urbanisation is occurring rapidly (UN-HABITAT, 2010a), (UN-HABITAT, 2010b) and (UN-HABITAT, 2010c). This ongoing rural-urban migration, which also boosts assets in at-risk areas, is resulting in an increase of urban population. Further (Woodward, 2014) and (Shrestha, et al., 2014) identified that these internal migrations are accompanied by so called 'push' and 'pull' factors. Whereas 'push' factors are seen to be directly related to livelihood problems, unemployment, low standards of housing, displacement due to conflicts and natural disasters, 'pull' factors on the other hand are described as economic opportunities, better education and better health facilities in the urban areas. Consequences are high levels of urban poverty and rapid expansion of unplanned urban settlements and slums in areas at risk. These informal settlements and slums are prone to natural disasters and people living there are threatened not just by the potential loss of their informal tenure, but also of lifethreatening situations due to, for example, the lack of building standards. An increase of population increases the scale of informality through an increasing number of informal settlements. The rising inequalities further strengthen the abovementioned 
push and pull factors, which further fosters rural-urban migration. According to (De Filippi, 2009) the most affected by natural disasters are the urban poor who reside in slums located in hazardous areas mainly impaired by insecurity of tenure. The poor implementation of building standards and land use planning regulations has been identified as key factors in worsening disaster impacts. Owing to this high population density, especially in informal settlements in urban areas, and the inequalities rising within those, the scale of vulnerability increases exponentially. Further settlements arise, again with insufficient adherence to building standards, sanitation and education causing more people to be made vulnerable to the impacts of natural disasters.

These 'push' and 'pull' factors, which can be empirically presented in figures and statistical data, are interrelated with the concept of 'social capital'. It is a term identified and used by (Shrestha, et al., 2014), which describes the concept of a strong social network within and outside of informal settlements. Social capital is closely related to resilience, where a community with a strong social capital is more resistant to the effects of natural disasters. Referring to social capital and resilience, in the context of articulating the link between people and vulnerability, it is important to also look at how people organise themselves in different ways in different places as for example, groups, communities, parties or individuals. Nevertheless, the researchers argue that understanding existing levels of social capital and resilience is core in adapting responsible LA solutions that support the DRM domain.

In summary, global populations are on the rise, particularly in developing contexts. When people are not included in an established LA system, an increase of people affected and dealing with insecurity of tenure tends to lead to an increase of the number of informal settlements and slums in at-risk areas, which further increases vulnerability. Vulnerability is related to the push and pull factors of rural-urban migration as well as to levels of societal capital. The push and pull factors are directly linked to the global change forces and can be seen as consequences of them. Therefore, in this section vulnerability is identified as the disaster risk driver most directly linked to people. The global change force of people and its disaster risk driver vulnerability can be addressed and linked with census data gathered via participatory enumeration, for example.

\subsection{Land}

In this section the global change force land, its scarcity as well as the increasing need for tenure security is linked to the disaster risk driver, exposure. It will be shown how LA experts are working on new concepts, addressing the need of tenure security in the developing world, and how those can be linked and used within the DRM domain. 


\section{Land, its limitation and demands for tenure security}

Population increase drives land scarcity and tends to force poorer people onto lands more exposed to disaster. Therefore, land appears regularly in discourses on both responsible development approaches and DRM. The importance of addressing land is also highlighted because it is a limited resource: $29.2 \%$ of the earth surface is land according to (Hoekstra, 2013) - and much less is actually able to be easily inhabited. The meaning of land changes across cultural settings and temporal contexts: land has different meanings for different people, as well as its perceptions differ across disciplines. Viewpoints might be technical, spiritual, physical, social, cultural or economical. The need to organise access to land for people, in one way or another, is apparent especially when natural disasters occur and the ability to respond to this relies on land information. A definition of land by (Henssen, 1995) and (Kaufmann \& Steudler, 1998) focuses on land seen from a cadastral perspective. Another definition could be far more widespread showing the necessity and importance of access to land to meet the basic human needs for shelter and food, especially in connection with natural disasters - or even include spiritual connotations relating to disasters. Therefore, it is essential to include and specifically address the poor in LA approaches for DRM.

LA is a tool, which aims to document the people-to-land relationship. Generally, it can be described as the study of how people organise land including the way people think about land and how it is built and managed by institutions and agencies according to (Williamson, et al., 2010). The term LA has been defined in many different ways, all varying in the focus and the background of the definition. Whereas (Williamson, et al., 2010) see LA as a process which is performed by government, public and/or private sectors related to the four core functions: land tenure, land value, land use and land development. (Ting, 2002) emphasises that the traditional role of LA was to manage the rights and interests that exist over land.

In practical terms, LA is mostly performed through the use of Geographic Information Systems (GIS). Developments in GIS or spatial technologies are now serving a much broader market and are therefore more flexible in its use and application area (Bennett, 2007). (van der Molen, 2006) emphasises that LA systems are more than a mere GIS and manage the social relationship between people concerning land. However, in practice, commonly LA systems are used to only capture legally recognised people-to-land relationships. Nevertheless, especially these social relationships are meaningful in a society and cannot only be captured through attributes used in a GIS. In this regard, all people-to-land relationships, legal or legitimate, are essential to know for improving disaster response and mitigation. They play an important role in all phases of the DRM framework. Lack of this information means a delay and hinders recovery and mitigation. 
Various papers highlight the increasing role of spatial information in DRM (Zevenbergen, et al., 2014a) (Zevenbergen, et al., 2014b) as well as pointing out the relevance of land valuation and land use planning in this context (Mitchell, et al., 2015) (Mitchell, et al., 2014), and (Roy \& Ferland, 2014).

Further, it is estimated that in most developing countries, cadastral coverage is less than 30\% (Lemmen, et al., 2010) (GLTN, 2012) (Antonio, 2011). Various scholars suggest that individual land titling, on its own, cannot cover the need of tenure security to the majority in the developing world according to (Antonio, 2011) (Deininger, 2003) (Jacoby \& Minten, 2007) (Payne, 2002) (Payne, et al., 2009) (Undeland, et al., 2010) (Wehrmann \& Antonio, 2011). According to (Desai, 2012) there is still a lack of tools and strategies to deliver secure land rights for all. This lack of strategies and tools can be explained by the variety and complexity of the range of land rights existing in developing countries, each with a different level of tenure security. Therefore, the global LA community introduced the metaphor of a continuum of land rights (Barry, 2006) in order to address the abovementioned tenure security for all, which is key in disaster risk phases as for example mitigation and response. This continuum of land rights has been widely debated, but largely agreed upon conceptually at the global level.

However, limited cadastral coverage, as well as the urgent need for tenure security for all, and the implication of adopting the continuum of land rights emphasised a broader view of LA. Consequently, this leads to alternative recording and mapping approaches, which are needed in order to address all sets of rights in an affordable and fair way. New tools had to be designed, as the conventional LA and land record systems could not accommodate the range of social tenures as being discussed in (Lemmen, 2012) and (Augustinus \& Lemmen, 2011). In this regard, as already explained, responsible LA emerged as an umbrella phrase to capture these emerging tools. In literature, there are many different terms used for such an approach but they all, in principal, encompass the same: addressing all, rather than only limited numbers of, people-to-land relationships.

Therefore, responsible LA aims to serve the needs of the poor by providing de facto tenure security. (van Asperen \& Zevenbergen, 2007) distinguish between de jure security, which is assessed through laws and regulations and de facto security, which especially matters to informal settlers, and do not need necessarily documents. The general aim is to recognise the people-to-land relationship by either government or local communities or even just by the surrounding neighbours. Tenure security matters especially when natural disasters occur. As identified by (Mitchell, 2011) and (IISD, 2006) land tenure security is an incentive for landholders to invest in adaption measures, as 
for example, building standards. Those investments are also hindered in rural areas by the limitation or even no possibility to access credit, which can be used to finance the construction of a house or to improve the constructions so that the effects of natural disasters can be limited. As stated in (WCDRR, 2015) a life without the safety net of savings and especially property drastically reduces people's ability to cope with a crisis like a natural disaster. Consequently, the lack of security of tenure is directly linked to exposure and reduces the people's ability to mitigate and respond to natural disasters. (Mitchell, et al., 2015) (Mitchell, et al., 2014) and (Griffith-Charles, et al., 2014) both mention the importance on including the poor in land and DRM approaches. This is also emphasised by the researcher and can be realised by the application of responsible LA in the DRM domain.

Further, it is most likely that in areas where land tenure security is not prevalent, disputes over land may delay recovery and reconstruction efforts. After a disaster, tenure problems, such as losing shelter or land, land grabbing, lost records and inheritance issues because of deaths, are likely to arise (Flamm, 2011). As definitions of tenure security vary over literature, it is important, as proposed by the authors of (Simbizi, et al., 2014), to relate the term to a regional context. As stated by (Maxwell \& Wiebe, 1998) researchers must be aware that there is no one-size-fit-all definition of tenure security. (Barry, 2006) further highlights the limitations in providing tenure security and the acceptance of it. Nevertheless, it is the information on all people-toland relationships that is needed with regards to DRM in the context of increasing populations using and occupying land.

\section{Responsible LA and exposure}

Responsible LA tools are available and their effects on LA and its four functions can be directly observed through existing participatory enumeration efforts or indirectly by political statements. Contemporary responsible LA tools implemented and in use are, for example: Social Tenure Domain Model (STDM), Open Title and Solutions for Open Land Administration (SOLA). However, these tools have not necessarily been developed for the use within the DRM domain. Although it needs to be highlighted that these tools have one strategy of data gathering in common: participatory enumeration. Participatory enumeration is an important and vital component for gathering data for both responsible LA systems and DRM applications (Cadag \& Gaillard, 2012). It is a very sensitive process and, based on one definition by (UN-HABITAT, 2010a) (UN-HABITAT, 2010b) (UN-HABITAT, 2010c), the involvement and the acceptance of the community is imperative. The sensitivity can be shown by various papers using this method and is highlighted in (Barry, 2006). Use cases showed for example that the acceptance sometimes relies on only one person, the community chief. Nevertheless, through 
participatory enumeration, land disputes can be for example addressed and prevented. Within DRM, participatory enumeration finds application in CBDRM - particularly within the assessment phases. Participatory enumeration and CBDRM are driven by similar philosophies - namely the active contribution and inclusion of the community.

In summary, exposure is identified as the disaster risk driver directly related to land: when land is not represented through the in situ people-to-land relationship on the ground, it leads to an increase of peoples inability to respond and mitigate towards natural disasters, which further increases exposure. Therefore, exposed communities could benefit from emerging responsible LA, for example those based around participatory enumeration. Indeed, the researchers argue that this communality is the key in the application of responsible LA in DRM. However, thus far application of the responsible LA mind-set has yet to gain significant traction in the DRM agenda.

\subsection{Disasters}

In this section the global change force disaster, specifically the increasing number of natural disasters, is linked to the disaster risk driver, hazard. Countries, like the SIDS, are particularly experiencing increasing numbers of hazards - and this is highlighted. Furthermore, the linkages and common strategies used within both domains highlight the need for cooperation strategies.

Although disasters vary in their effects and causes, they disrupt people and their peopleto-land relationship tremendously. Statistics as well as researchers point to an increase in disasters over the 2000s, which are suspected to be related with population increase and subsequent land related activities.

According to (UNISDR, 2009) a 'disaster' is:

"... a serious disruption of the functioning of a community or a society involving widespread human, material, economic or environmental losses and impacts, which exceeds the ability of the affected community or society to cope using its own resources".

Within (WB and GFDRR, 2012) three variables have been identified which drive disaster risk: exposure, hazard and vulnerability. Comparing other definitions of disaster by (van Westen, 2009) (van Westen \& Montoya, 2011), and (WB and GFDRR, 2012) shows that they differentiate just by the wording and by the focus set within the definition, whereas the focus of the definition can be seen in relation to the institution behind the definition. 
Nevertheless, all of the definitions highlight the social as well as the resource (land) dimension.

This definition and relationship are deepened by the term hazard, which is a dangerous phenomenon, substance, human activity or condition that may cause loss of life, injury or other health impacts, property damage, loss of livelihoods and services, social and economic disruption, or environmental damage (UNISDR, 2009). Within the term hazard, the social dimension and land dimension becomes even more prominent. In literature, as well as in science, this relationship is already well known and published, for example in (Cadag \& Gaillard, 2012), (IISD, 2006), (Mitchell, 2010), (Usamah, et al., 2014) and (Mitchell, 2011).

Reports of disaster recording databases such as Emergency Events Database (EM-DAT) hosted by WHO (CRED, 2015) and the database hosted by (UNISDR, 2013) show that the occurrence of natural disasters resulting of natural processes or phenomena are a severe problem worldwide. Three-hundred and thirty-seven disasters related to natural hazards have occurred in 2014 as stated in (CRED, 2015). Ninety five percent of those natural disasters struck developing countries, which again shows that those countries have to be focused on. The increasing scale and number of natural disasters affect land and the people-to-land relationship tremendously, which is directly linked to hazard. These statistics refer to various kinds of natural disasters for example, drought, flood, earthquake and so on - all affecting the people-to-land relationship.

This variety in disasters also indicates the necessity to focus on different conditions of the three disaster risk drivers and to work on a framework encompassing all of them in relation to people and land. Recording the occurrence and dimension of natural disasters is done using various databases: it is possible to compare data and show trends. According to (FAO, 2013) the SIDS as for example, Fiji and Tonga are among the most vulnerable. The impacts of natural disasters can vary and are always location specific; they can even differ within a region and even within a country. Awareness of the local context addresses social, cultural and economic aspects. Nevertheless, it is present that the most affected countries are developing countries with the highest number of people living in slums and informal settlements. They are suffering from insecurity of tenure, which is directly related to vulnerability.

\section{Disaster and the increase of hazards}

As explained, this chapter is attempting to link understandings of the concepts of people, land and disaster further - in the context of responsible LA - into DRM. As already identified in (Weichselgartner \& Pigeon, 2015) the domains of Disaster Risk 
Reduction (DRR), knowledge management, and social learning are interlinked: understanding these connections can help to improve DRM. Land is one of those links and the missing understandings and information on the people-to-land relationship increases the scale of hazard. The coordination of training, strategies and actions need to accompany land in relation to people and disasters. This risk-informed decisionmaking is dependent on the land information provided by the LA system that has attained the information through the people. Those findings go in line with (Enemark, 2004) and many other land, as well as disaster experts, so that a combination of disaster risk information with relevant information on land tenure, land value, land development and land use - will help identifying and assessing necessary risk prevention and mitigation in relation to legal, economic, physical and social consequences. As already mentioned in section land, the importance of considering land issues in order to respond to natural disasters especially for the poor is a significant issue and on the international development agenda.

In summary, the researchers argue that the potential of responsible LA in DRM is underutilised. The missing existence of spatial information as well as information on the people-to-land relationship increases the scale of hazard. Responsible LA can therefore improve links between people and land. The spatial information created supports improving knowledge about the relationship between those same people, their lands and potential disasters - especially information on hazard risks for assessment, mitigation and prevention. Therefore, hazard is identified as the disaster risk driver directly related to disasters.

\subsection{Consolidating the links between responsible LA and DRM}

This section aims to holistically synthesise the identified links between the global change forces (people, land and disaster) and the disaster risk drivers (vulnerability, exposure and hazard): a conceptual framework that illustrates the need and potential contributions of responsible LA in disaster-affected areas is the intended outcome. From the review, the following links are suggested as already established:

- People-and-vulnerability: population growth causes more people to be affected by insecurity of land tenure and natural disasters. It further increases the scale of informality of people and property in the affected areas, which links to;

- Land-and-exposure: the limited resource land and the lack of security of land tenure is directly linked to exposure. Through natural disasters exposure is further increased through losses of people and property. Consequently, the number of informal settlements, land grabs and land disputes increase; which links to; 
- Disaster-and-hazard: the increasing occurrence and scale of natural disasters increases the number of susceptible people and areas and therefore affect land and the people-to-land relationship.

These relationships are further articulated in a conceptual framework (Figure 6).

The left-hand column in the conceptual framework (Figure 6) represent the three global change forces: increasing world population, summarised through the term people; the limited resource land, summarised through the term land; and the increasing number of natural disasters, summarised through the term disaster. The middle column of the framework represents the three disaster risk drivers, as described in section 'disaster'. The right-hand column represents the key findings and identified needs through the research synthesis, which could likely be addressed by, and contributed to, through responsible LA. The framework has to be read from the left to the right side and then back again. The readers have to bear in mind that the conceptual framework represents a generalised view of the topic: the main aim is to show the interrelationship and relevance, as well as the identification of the need, for responsible LA in DRM. Therefore, it does not claim to address all issues in regard to people, land and disaster. The drivers used influence each other and an increase on one component will in/decrease another one. Each row of the framework is now unpacked in more detail.

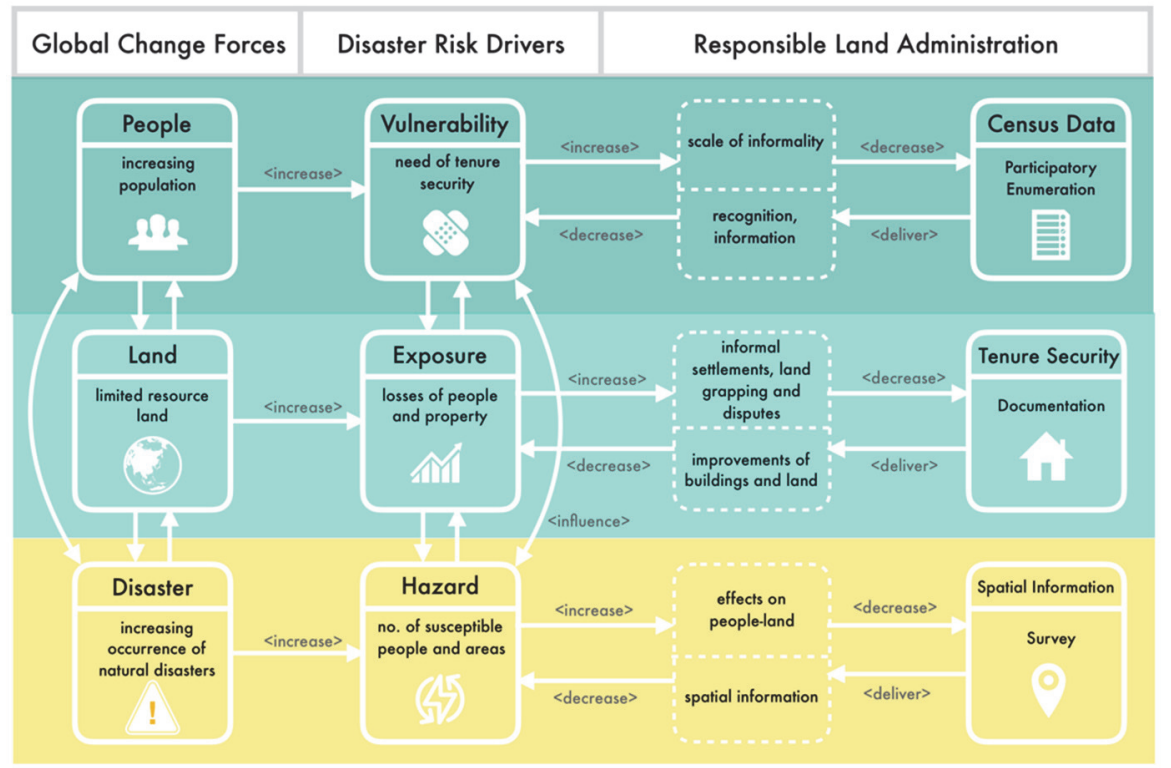

Figure 6: Conceptual framework on the need for responsible LA in DRM 
The global change force 'people' (row 1), illustrated through the increasing world population, is seen to be directly linked to the disaster risk driver vulnerability. Consequently, the need for tenure security increases at the same rate as the increasing scale of informality especially for people who are prone to natural disasters. A key step towards reversing the cycle is to create population data, for example census data, collected using appropriate techniques - for example participatory enumeration, which emphasises the inclusiveness of people.

The global change force 'land' (row 2), which is a finite and limited resource, directly links to the disaster risk driver exposure. People's exposure increases as the loss of people and their land increases through the effects of natural disasters. As seen from examples of current natural disasters, failing land use planning, and therefore failing resettlement strategies, leads to an increase of informal settlements as well as land grabbing and land disputes. Through documenting all people-to-land relationships, people feel more secure of their tenure and invest in improvements of their land and their buildings, which further decreases the scale of exposure.

The global change force 'disaster' (row 3), which increases in size and severity, directly links to the disaster risk driver hazard. Those hazards, which evolve to natural disasters, affect all people-to-land relationships. Especially those people-to-land relationships that have not been addressed in any LA system are considered exceptionally hazardous. Therefore, spatial information derived from spatial analysis and surveying technologies can be used alongside census data and land data in land use planning and DRM assessment, resettlement and mitigation processes.

Based on this conceptual framework the linkages, identified above, can subsequently be further examined and applications of responsible LA articulated. Several such examples are now provided.

\subsection{Potential example applications of the framework}

First, as shown, increasing population growth and resulting rural-urban migration of people leads to an increasing scale of informality and an increase of vulnerability, which is directly linked, with an increasing need for tenure security. Through the introduction of responsible LA in DRM those issues could be addressed through participatory enumeration and identification of priorities for the people living in informal settlements. The census and people-to-land relationship data could further support disaster prevention and early recovery strategies, which can be improved through information provided by responsible LA and influence land use planning especially addressing informal settlements. Through improvements in land use, disaster prevention and early 
recovery strategies can be better addressed as well as people could be more willing to be evacuated and agree to resettlement strategies from disaster prone areas considering concepts like the social capital. Through including informal settlers in those strategies, the scale of informality would decrease as well as the scale of vulnerability.

The case of the Mashimoni slum area in Nairobi, Kenya provides an example of the above: a responsible inclusive approach in land can decrease the scale of informality. Mashimoni is one of the villages in Mathare slum, a populated slum area in Nairobi, Kenya. The impact of responsible LA on the livelihood of a community can be witnessed in various ways. People started to settle in Mashimoni in 1975. One of the reasons for its establishment was the rural-urban migration as well as the linked increase of population and the lack of accessible land in Nairobi. In 2011, Mashimoni leaders piloted the STDM. The members of the settlement gathered information regarding their tenure and community information through participatory enumeration. One of the priorities identified by the people living there was the improvement of sanitation and an establishment of a channel system. Through the application of STDM and followed negotiations with the owners they received tenure rights. Further coordinated land use planning strategies within the community, helps the slum area to deal with minor flooding and improve the livelihood of the poor. The case shows improvements towards disaster mitigation through the application of responsible LA.

Second, as shown, the limited resource land and poor management relating to it leads to an increasing number of informal settlements, land grabbing and disputes over land: especially to those people who are not properly addressed within the given LA system. Poor people tend to settle in areas prone to natural disasters, as they are most likely government land and of less interest, for example for investors. If then a hazard occurs, which is evolving to a natural disaster, the loss of life and livelihoods, property as well as building shelter damages and damages to services increase. Through the use of responsible LA de facto tenure security can be provided which may lead to a stronger relation to the land. Through this stronger relation, it is shown in literature (Mitchell, 2011) that people are more likely to invest in their land and buildings. Also, the potential access to credit is easier feasible through tenure security as well as disputes over land are less likely since all different stakeholders have been involved in the process. Although the limitations stated in (Barry, 2006) have to be considered. Nevertheless, through the introduction of responsible LA, people's exposure would decrease.

An example of where the failure in managing land increased vulnerability and exposure and therefore hindered rebuilding efforts relates to the Haiti earthquake of 2010. The missing spatial information and lack of land-use planning strategies prior to the disaster 
lead to a delay in reconstruction efforts. The unclear property rights led to the failing of 'building back better' efforts, which resulted in transitional shelters turning into permanent shelters. According to (Blake, 2015) rebuilding efforts failed due to the unclear property rights. This was apparent as families were keeping their own land in sub-standard conditions because they feared someone else would occupy it. The Gujarat earthquake of 2001 provides another example. The case highlights the importance of coordination and shows how improvements in land management contribute to rebuilding efforts. Within (Mukerji, 2010) it is shown that homeowners and squatters were able to rebuild and improve their housing through a coordinated strategy of the local government of Bhachau and leading NGOs. Public assistance was critical for housing recovery for both homeowners as well as low-income squatters. Whereas Haiti clearly shows that tenure security can be the key especially in recovery phases, the example of Gujarat shows that the coordination between the government, NGOs and the community itself can be key for the success of rebuilding strategies. Both examples highlight the importance of managing land in an inclusive and integrated way.

Third, the increasing occurrence of natural disasters increases the number of effects on the people-to-land relationships, as well as increasing numbers of susceptible people, societies and areas to the damaging effects of hazards. Through the introduction of responsible LA and providing de facto tenure security, the scale of hazard could decrease: coordination strategies and actions can provide up-to-date spatial information which can provide improved tenure security to susceptible people - and may ultimately discourage people from putting themselves in danger by staying and protecting their land. This spatial information enables various stakeholders to specifically address the poor prior or in the aftermath of a natural disaster. Accessible information about land leads to easier and transparent land dealings since information is provided and structured. Investments and building efforts in order to prepare for natural disasters would be facilitated for people who have been previously not addressed through any LA system. If this information is then linked or enriched with data gathered through participatory enumeration, mitigation and preparedness strategies can focus on the most vulnerable and exposed people. Resettlement strategies could also be more specifically targeted and consider social aspects, as known through participatory enumeration.

Again, the response efforts for the Haiti 2010 earthquake, or lack thereof, are exemplary for the above. Prior to the earthquake, Haiti had neither a sufficient LA system nor a land policy. By 2015, Haiti was still struggling with the aftermath of the earthquake and the lack of secure land rights among the poor and displaced. Indeed, inadequate tenure security is identified as the key factor hampering rebuilding efforts according to (Myers, 
2014). Typhoon Haiyan in the Philippines in 2013 provides a further example. The Haiyan typhoon showed according to (Hanstad \& Prosterman, 2014) the extreme danger people were exposing themselves to hazards because of insecurity of tenure. Families, living in low quality buildings, remained in their homes during a natural disaster fearing the loss of their homes because of the lack of tenure security, which consequently increased the damaging effects of hazards. This arguments are strengthened with examples from Cyclone Odisha from 1999: most of the people killed and affected were the poor who refused to evacuate their informal settlements because they feared eviction. These cases clearly show the importance of some simple form of up-to-date spatial information, an inclusive land-use planning and a LA system addressing the continuum of land rights.

\subsection{Limitations of the conceptual framework}

Having demonstrated the potential of the conceptual framework to support developing more integrated understandings of existing weaknesses and opportunities in LA and disaster management systems, it is also necessary to articulate the limitations of the conceptual framework. One of the most prominent limitations is the visualisation of the framework. Through visualising the framework misinterpretations and misunderstandings are more likely to occur. Especially, as already seen within the discussion of 'the arrow' of the continuum of land rights, the use of arrows can specify but also create exclusion or hierarchy between the attributes used. Also, by labelling the activities between the attributes limitations can arise. Therefore, it is important to emphasise that the main aim of the conceptual framework is to show that there is an interrelationship between the global change forces listed and that this can vary over the variables the users are applying. The three global change forces (people, land and disaster) as well as the focus of the global change force could be extended or adjusted for future applications. For example, the global change force disaster could focus on man-made disaster, whereas the people global change force could then be focused on refugee migration. The conceptual framework is only a starting point for further discussions and more in-depth research. Also, the contribution of responsible LA is much broader than visualised through the framework. Contributions could also be side effects, for example facilitation of communication between informal settlers and government authorities. Consequently, it could be argued that the global change forces and their focus need further subdivision. Owing to the limitations of visualisation and the lack of documented case studies in the research domain, the conceptual framework needs continuous adaption in the future. Yet, the conceptual framework in this chapter is considered accurate and complete in the present moment with the focus set and the literature used for the synthesis. 


\subsection{Conclusions and key lessons}

The global land community has accepted that individual land titling on its own cannot deliver security of tenure to the majority of people in the world in a timely fashion: responsible approaches need to be adopted in some contexts. These approaches also need to be embraced by the global DRM community in order to prevent, mitigate and respond to natural disasters regarding land. This chapter aimed to show the need for the application of responsible LA in developing countries, which are prone to natural disasters.

To do so, it first examined three global change forces (people, land and disaster), the interrelations between them, and the multifaceted relationship with land tenure and the three disaster risk drivers. Results were used to develop a conceptual framework showing and describing this interrelationship and fostering the emergent need of responsible LA in DRM. The conceptual framework consists of the three global change forces: people, land and disaster, the three disaster risk drivers: exposure, vulnerability and hazard as well as the entry points for responsible LA approaches.

The possible contribution of responsible LA to DRM was identified as follows:

- Census data, gathered through for example participatory enumeration could be used to decrease the scale of informality and deliver important information for land use planning and resettlement strategies.

- Tenure security gained through documenting the continuum of land rights could be used to decrease the number of informal settlements and deliver improvements in building standards and land transactions. Spatial information gathered through FFP LA could decrease the effects on people and land.

- Hazard risk assessment and mapping - linked to responsible LA - could bridge the gaps between people-land-disasters and therefore address each global change force.

The possible contributions were emphasised through case studies in Kenya, the Philippines, India and Haiti. Within those, especially participatory approaches were identified as a critical aspect towards an implementable strategy for applying responsible LA technologies in the context of DRM. Participation is crucial in enabling the poor to minimise vulnerabilities and disaster risks through an inclusive land tenure security approach to prevent, mitigate, prepare and respond to natural disasters.

Finally, looking ahead, the conceptual framework can be used for more in-depth research on each of the articulated relationships in specific contexts. Each of the global 
change forces as well as the disaster risk drivers has different aspects to focus on and therefore more research could be done on each of them. Second, LA systems are often using spatial data infrastructures, which are using data models for gathering and storing spatial information. The ISO approved LADM provides such an underlying data model. Currently developed responsible LA tools are using this standard. Future research and application of the conceptual framework could therefore be the development of such a data model based on this conceptual framework. Third, the developed framework could be used as a tool to validate the impact of responsible LA on the identified global change forces and disaster risk drivers. For this validation process indicators and variables would need to be more specifically and clearly defined. Nevertheless, such a validation could be used within any disaster risk phase. For example, evaluating the success of 'building back better' strategies or mitigation strategies could be undertaken.

Further work should focus on refinement of the framework with stakeholder and expert groups; piloting and designing the conceptual framework in different contexts tailoring responsible LA so that it is able to accommodate DRM related information. Importantly, each of the drivers (global change forces and disaster risk drivers) have positive as well as negative effects on each other. Further research on these complex relations was deemed essential. The entry points mentioned in the chapter are more nuanced than presented and there is a variety of options and variables, which need to be thought through within a regional context. Further information, which has already been gathered through participatory enumeration, will be tested on how it can be included and used. Finally, the conceptual framework represents the first step towards the design of a framework, based on field experiences. 


\section{Chapter 3}

Adapting LADM for disaster prone areas and communities*

* This chapter is based on an ISI journal paper published as;

Unger, E.-M., Zevenbergen, J., Bennett, R., \& Lemmen, C. (2019). Application of LADM for disaster prone areas and communities. Land Use Policy, 80, 118-126. 


\subsection{Introduction}

Responsible LA and DRM both focus on empowering vulnerable groups to become resilient communities. When LA is implemented responsibly, it underpins good land governance and ultimately supports sustainable LA by providing strategies and tools to document all people-to-land relationships (Zevenbergen, et al., 2015). DRM and especially community-based disaster risk management (CBDRM) aim to evaluate and manage natural disaster risks at the local level - and highlights the role of communities when it comes to disaster risk reduction (ADPC, 2016).

Contemporary research suggests a relationship between different levels of land tenure security and the negative consequences experienced by groups of people in the context of natural disasters (Mitchell, et al., 2017), (Unger, et al., 2017), (UN-HABITAT, 2010b) and (Rajabifard, et al., 2018). The impact is argued as most severe at the community and household levels, and can be witnessed, for example, through loss of income, loss of shelter and minimal measures for disaster preparedness and mitigation. Moreover, these impacts are greater if land tenure is not secured and if the people-to-land relationships are neither known nor documented (Mitchell, 2011).

On a global level, significant effort remains focused on securing land and property rights for all, seeking to accelerate the proportion of recognized and recorded people-to-land relationships. The 2030 Agenda for Sustainable Development with its defined Sustainable Development Goals (SDGs), together with the Sendai Framework for Disaster Risk Reduction, stimulate innovative and transformative approaches to secure land and property rights for all (UN, 2015). The Sendai Framework (WCDRR, 2015) specifically calls for investments in research and the development of a methodology and models for disaster risk assessment. In (Rajabifard, et al., 2018) a World Bank and FAO funded research project is exploring ways to improve resilience and resilience impact of national land and geospatial information systems.

At a more theoretical level, (Unger, et al., 2017) argues that a relationship between the two disciplines can be understood conceptually via three driving forces - people, land and disaster - and three disaster risk drivers - exposure, vulnerability and hazard. Combined, these elements provide an entry point for developing integrated LA and DRM activities that adequately prepare, prevent, mitigate and respond to natural disasters. Further the need for data modelling is given by the fact that well-designed and documented conceptual and logical models support and allow stakeholders to identify areas for improvements. Consequently, the demand for a shared ontology, which allows all stakeholders to act globally, increases with any software development requiring alignment and standardisation to achieve data compatibility and interoperability (West 
\& Fowler, 1999). Within the LA domain, a globally agreed ISO standard exists, the LADM (ISO, 2012). Within DRM many frameworks already exist that are used to develop practical approaches in DRM. However, none of these models deal directly with the overlap between land and disaster related data.

Potentially complicating the landscape of data management relating to land and disasters, in recent years a new wave of data modelling and data provision techniques emerged. Developments such as predictive modelling, algorithm intelligence, selfdescribing data formats, design adaptive databases (Barry \& Roux, 2012) are likely to impact on future data modelling efforts in the land and disaster domains. Although, as yet most initiatives remain only experimental or at the demonstrator level (Bennett, et al., 2018). Moreover, standardized models such as the LADM (ISO, 2012) can continue to decrease the complexities of achieving efficient data interoperability and storage.

Synthesizing the abovementioned issues, the demand for a data model linking the land and disaster related data appears high. Accordingly, the aim of this research is not to develop yet another data model but build on what is already developed so that standardisation efforts are further met and used conditionally. This integrated LA-DRM model should be capable of capturing the people-to-land relationships in supporting DRM objectives. The model has to encompass attributes describing the nature and scale of vulnerability, exposure and hazard - in order to be used for DRM as well as deliver land tenure security for all. It needs to enable involved stakeholders to communicate over disciplines and institutions. The model further needs to be flexible in order to include bottom up and top down land data governance approaches, in regard to data acquisition, provision and sharing of data (at municipal, regional, national and global level).

Therefore, in this chapter an experimental LA-DRM model that seeks to support land tenure security issues in disaster prone areas is presented in terms of design and applicability. First, the motivation and background of the intended model are provided. Justification and an outline of the selected methodology used to develop the model are presented. Subsequently, the section 'starting points' examines and compares existing models from each domain, available for adaptation. This leads to a description of the outcomes of the data modelling, including a representation of required classes and attributes. The potential application of the model in different contexts and phases of DRM is then explored. Finally, the limitations of the LA-DRM model are drawn, preceding the conclusion and encapsulation of future research opportunities. 


\subsection{Methodology}

In order to develop an experimental LA-DRM model, a methodology called 'design approach', as shown in Figure 7, was followed. Justification of the approach is found in similar research related to tenure security (Lemmen, 2012), (Hay, 2014) and (Lemmen, et al., 2015) and related to DRM (Li, et al., 2007) and (UNISDR, 2015). Throughout this design approach Unified Modeling Language (UML) diagrams, along with textual and graphical descriptions, were used for the representation of all activities, processes, classes, attributes and associations. Especially with regards to the research area of DRM a flexible approach has to be considered: reality is dynamic and with that all the data representing the reality is under constant change, which brings limitations to modelling the real world. The key to address this complexity as well as a constant change in data is to work with standards and conceptual models. The conceptual framework as defined in (Unger, et al., 2017) identified already the associations between different classes at the highest, most abstract level (Figure 6). The conceptual framework, developed through knowledge acquisition, determination of objectives and definition of requirements, and conceptual modelling techniques, was used as the base for the LADRM model.

Following on, the design approach was applied (Figure 7). The first step of the design approach was a review (1) of existing standards, models and tools used in both disciplines. These findings lead to the draft model abstraction (2), followed by an initial definition (3) of classes, attributes and associations. These outputs were used to develop questionnaires and methods to identify tenure security issues in a post disaster context. A preliminary version of the model was then piloted in Nepal within a case study, named 'Support for Land Reform in Nepal and Land Tenure Initiative' (SILTIP) in Dolakha. Dolakha is one of the most affected districts from the earthquakes, which hit Nepal in 2015. Therefore Kadaster, UN-Habitat Global Land Tool Network (GLTN), UN-Habitat Nepal and Human Rights Awareness and Development Centre (HURADEC) implemented a case study in three sites of Bhimeswor Municipality, and one in Bigu rural Municipality in 2017, to address land tenure issues in the post-disaster context. The model's ability to support the process was tested, and data gaps revealed, which were previously not identified, but were seen to be required for an adequate representation of reality. Thereafter, various experts from UN-Habitat, GLTN, University Twente Faculty ITC and Kadaster discussed the developed questionnaires and the underlying data model. The outputs from the resulting expert group discussion were seen as the first validation of the first draft model (4). Findings of the discussion proceeded in a re-definition (5) of classes, attributes and associations. The integrated model was then implemented through the Social Tenure Domain Model (STDM) tool, a plugin for QGIS (an open source GIS). STDM is based on the LADM (GLTN, 2014). At the data level, a separate data 
validation was conducted by the enumerators and communities who and where the model was implemented. The final validation was conducted through the analysis of the generated data using queries (6). Through the analysis, the potential and limitations of such an integrated model was assessed. Combined, the findings from the questionnaire development, the expert group discussion and the physical implementation, using GIS software, as well as the validation at data level are considered the fundamental validation and foundations for the design and development of the final draft of the integrated model, as presented in this chapter.

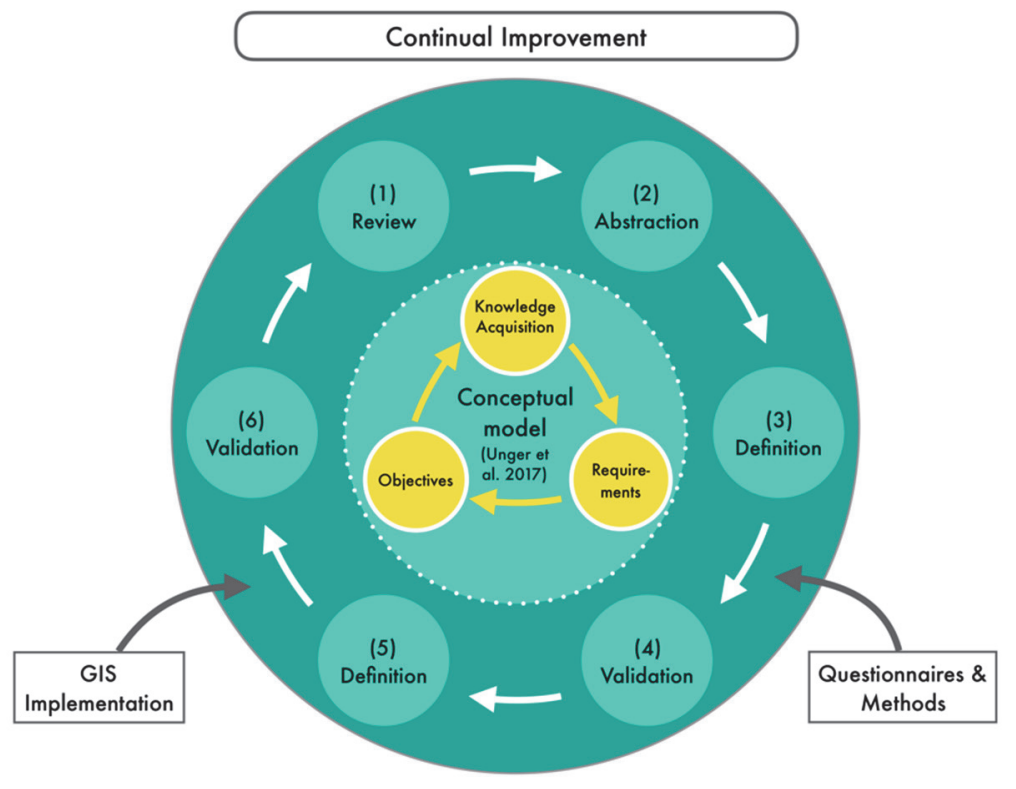

Figure 7: Design approach for chapter three

\subsection{Starting points}

When a structured approach to data modelling is accepted, then standards are needed for such an integrative and interdisciplinary approach. Both domains, LA and DRM work with various data and process models, implemented within GIS tools, to generate land or disaster related data. But as far as the author is aware this research is the first attempt to combine the concept of LA, specifically responsible $L A$, with research on DRM, in order to develop a model using a globally agreed ISO standard.

An audit of existing models and tools, currently utilized within both disciplines, was undertaken and the outputs are summarised in Figure 8. 


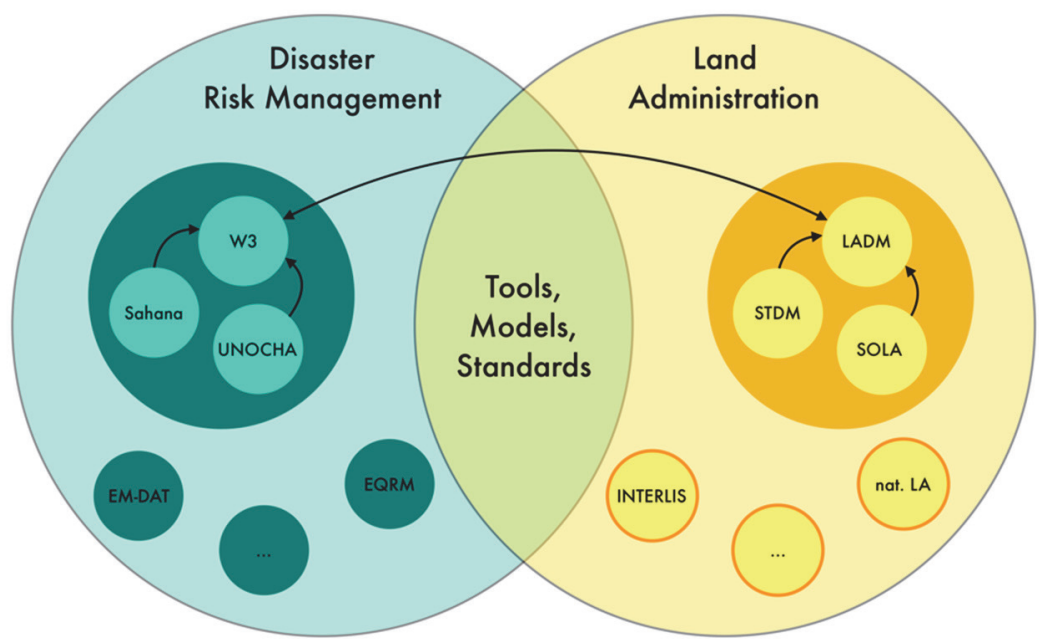

Figure 8: Review of tools, models and standards

Within DRM there is currently no international agreed domain standard. But the global community agreed on the Sendai Framework (WCDRR, 2015), which calls for resources in research and the development of a methodology and models for disaster risk assessment. Further, this framework calls for action regarding inadequate land management and calls for inclusion of informal and non-permanent housing in risk assessments. The tools developed in the DRM domain tend to focus on a specific application or areas (Li, et al., 2007) or a specific kind of disaster (UNISDR, 2015), which is justified through the variety of disasters and its different impacts. At the global level, models such as the Earthquake Risk Model (EQRM) or the Florida Public Hurricane Model, are used to model disasters and to quantify their duration, magnitude, calculate probabilities and so on (UNISDR, 2015). Furthermore, various databases and GIS systems such as Disaster Inventory System (DesInventar), The International Disaster Database (EM-DAT), and Global Disaster Identifier Number (GLIDE), are used to deliver indications about the costs and impact of disasters (UNISDR, 2018). Further investigation of various DRM tools and applications concluded that most address land issues such as tenure security or resettlement only at the parcel level, or not at all. Inspiration for a way forward can be found in the W3C (W3C, 2009), an international community, where member organisations, staff and the public work together to develop web standards. Within the community, two emerging information systems were reviewed, one developed by Sahana Foundation and the other by the United Nations Office for the Coordination of Humanitarian Affairs (UNOCHA). Based on that review a model was built by the W3C, providing a harmonized view of both. The model uses three core classes 'who' (organisations or people) does 'what' (activity) 'where' (location information). 
Within LA various national models and tools for the integration and distribution of LA data are implemented. In Switzerland, for example, INTERLIS a Swiss standard was developed (Bundesamt für Landestopografie swisstopo, 2018). On the other hand, the LADM is intended to be a universal knowledge model for LA, which stimulates the development of software applications and accelerates the implementation of LA systems (Lemmen, et al., 2015). Within literature there are arguments that LADM is already a basic standard when focusing on the mandatory attributes (Lemmen, et al., 2015). The implementation of this International ISO Standard on LA can be seen as a milestone, which supports the development and implementation of the global agenda on land tenure. A specialisation of LADM that presents a generic and inclusive approach for responsible LA was developed by UN-Habitat GLTN, the STDM (GLTN, 2018). In parallel, FAO, likewise influenced through the development of LADM, developed SOLA an open source tool with the aim to provide LA alternatives for land agencies (SOLA, 2016).

The review (Figure 8) showed that the model built by W3C fits well with the basic structure of the ISO standard LADM and STDM (Figure 9), and as such LADM/STDM could be considered as a base for the LA-DRM model. Further the iterative process of defining a standard as the base of the LA-DRM model was supported by experiences learned in the field in Nepal. LADM and STDM provide an inclusive approach to tenure security and also address the 'who', 'what' and 'where' - and are flexible in accommodating various additional attributes and code tables.

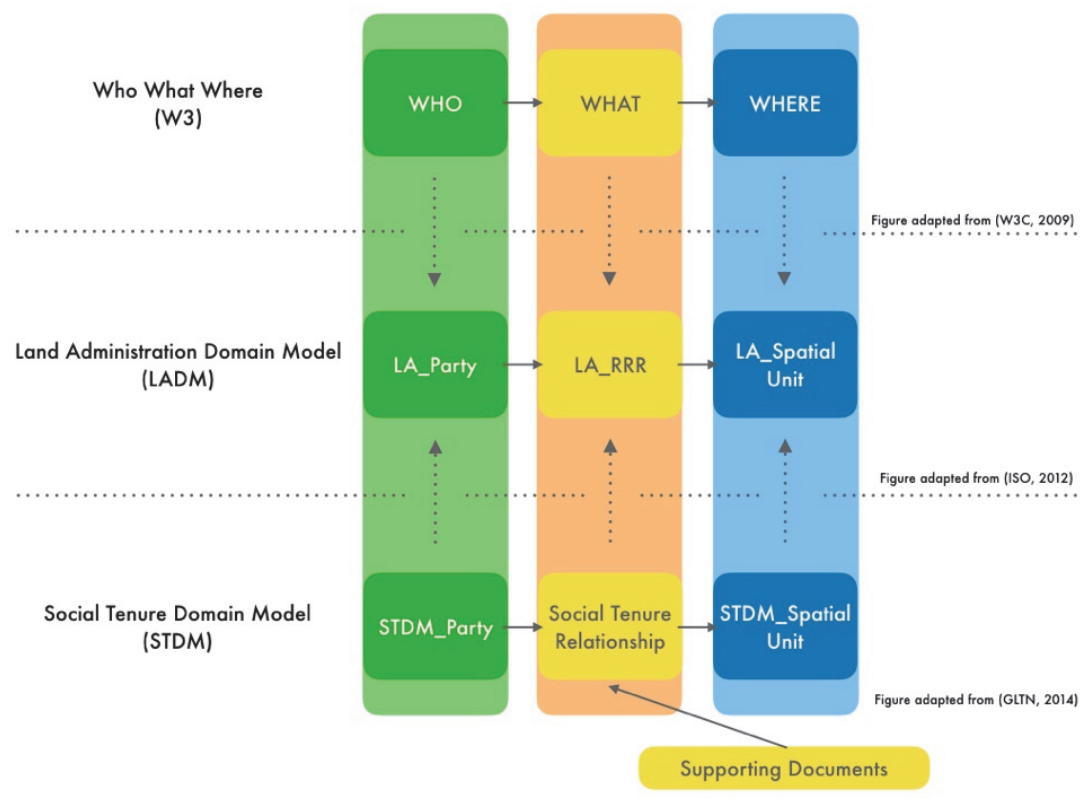

Figure 9: LADM/STDM as a base for the LA-DRM model 
Furthermore, LADM as well as its specialisation, STDM, can be summarised or abstracted to a simplified object-subject relation which, depending on the application and institution can be used for all processes in the real world. In addition, through the very basic and simplified modelling, minimal changes are necessary and also the number of attributes can be minimized, which is essential in such dynamic and agile domains. Finally, the spatial representation in LADM is seen as sufficient to be used for the LADRM model. Following, it was concluded that the base design of the LA-DRM model could be based on the LADM/STDM concept. The already existing W3C and LADM links, coupled with the focus on a participatory and inclusive development approach, and together with the premise to use already existing standards, tools and knowledge, lead to this decision.

\subsection{Elements of an integrated LA-DRM model}

The introduced LA-DRM model is based on the LADM/STDM concept, using the same classes but with additional attributes describing the scale of vulnerability, hazard and exposure. LADM and STDM provide a standard set of terminology, classes and associations. Nevertheless, both models are flexible and can accommodate other attributes, associations, and are extensible to allow inclusion of other situations and disciplines. The core classes of LADM are the spatial unit (LA_SpatialUnit, this can be a parcel), the party (LA_Party, this can be a natural or non-natural person) and the rights, responsibilities and restrictions (LA_RRR), which links the two other classes (ISO, 2012). Those core classes of the LADM can also be found in the STDM, but are named differently as they focus on a different context, SpatialUnit, Party and SocialTenureRelationship (GLTN, 2014). The difference in terminology is based on the fact that the attributes in STDM describe legitimate rights instead of the statutory rights as in LADM (Zevenbergen, et al., 2013). The SocialTenureRelationship is described through the continuum of land rights, as defined by (GLTN, 2014), to describe all peopleto-land relationships. It can also be used to describe secondary use rights, overlapping rights or places where people perceive their rights contradictory.

The development of the LA-DRM is based on literature review, expert group discussions and field experiences from Nepal. Since the LA-DRM is based on the LADM/STDM all the requirements as defined in (Lemmen, et al., 2015) are considered to be valid. Various requirements (Table 1 ) were adapted and some additional ones were added. 
Table 1: LA-DRM requirements

\begin{tabular}{|c|c|c|}
\hline \multicolumn{3}{|c|}{ Requirements based on (Lemmen, et al., 2015) } \\
\hline No. & Requirement & Impact \\
\hline 1 & $\begin{array}{l}\text { A continuum of } \\
\text { land use right } \\
\text { claimants } \\
\text { (subjects or } \\
\text { parties) }\end{array}$ & $\begin{array}{l}\text { The requirement No. } 2 \text { as defined in (Lemmen, et al., 2015) is extended with the } \\
\text { following: the LA-DRM model enables a 'party' to be, for example, a household, } \\
\text { family, or group of families (e.g. } 4 \text { families live in } 1 \text { building) with each person to } \\
\text { be recorded. Especially in regards to DRM, the inclusion of children in any system } \\
\text { is essential and needs to be recorded. Further gender information is currently not } \\
\text { explicitly covered by LADM. In any case women, have to be represented by the } \\
\text { LA-DRM model, and therefore recordation of men and women is necessary. }\end{array}$ \\
\hline 2 & $\begin{array}{l}\text { A continum of } \\
\text { spatial units } \\
\text { (objects) }\end{array}$ & $\begin{array}{l}\text { The requirement No. } 3 \text { as defined in (Lemmen, et al., 2015) is extended with the } \\
\text { following: DRM requires the building or any construction to be recorded and } \\
\text { changed / updated over time. }\end{array}$ \\
\hline 3 & $\begin{array}{l}\text { A range of data } \\
\text { acquisition } \\
\text { methods }\end{array}$ & $\begin{array}{l}\text { The requirement No. } 5 \text { as defined in (Lemmen, et al., 2015) is extended with the } \\
\text { following: data acquisition methods especially in regards to DRM should support } \\
\text { and include community acquired data. Further collaboration and data sharing } \\
\text { with different domains should be facilitated and encouraged e.g. weather radar } \\
\text { stations, ministries of forest and agriculture, geological and geophysical } \\
\text { institutions etc. }\end{array}$ \\
\hline 4 & $\begin{array}{l}\text { A range of } \\
\text { authentic source } \\
\text { documents }\end{array}$ & $\begin{array}{l}\text { The requirement No. } 6 \text { as defined in (Lemmen, et al., 2015) is extended with the } \\
\text { following: in case of a natural disaster all kind of documents can be destroyed and } \\
\text { may not be able to be retrieved from any system. Further witnessing through } \\
\text { neighbours may not be applicable in case they are deceased; therefore any kind } \\
\text { of source document at different stages should be supported. }\end{array}$ \\
\hline 5 & History & $\begin{array}{l}\text { The requirement No. } 8 \text { as defined in (Lemmen, et al., 2015) is extended with the } \\
\text { following: DRM is describing an agile and fast environment whereas LA is defined } \\
\text { through long-term processes and defined rules and regulations with fewer } \\
\text { changes over time. A disaster is in great numbers influencing the life cycle of the } \\
\text { core classes immediately. Normally change in either 'party', 'social tenure } \\
\text { relationship' or 'spatial unit' are long on- going processes but in case of a natural } \\
\text { disaster, this life cycle can be seriously disrupted, ad hoc, or changed into a non- } \\
\text { existing stage. Further historical data give information on the pre-and post- } \\
\text { disaster status. }\end{array}$ \\
\hline \multicolumn{3}{|r|}{ Additional Requirements } \\
\hline No. & Requirement & Impact \\
\hline 16 & Vulnerabilities & $\begin{array}{l}\text { Vulnerabilities at individual, household, family, organisation or business level shall } \\
\text { be described. Those vulnerabilities should also deliver information such as the } \\
\text { level of literacy, education or poverty. }\end{array}$ \\
\hline 17 & Status Info & $\begin{array}{l}\text { Each core class should be supported by a 'Status Info' attribute, as for example } \\
\text { each party/individual can have a different status as e.g. a party can be deceased, } \\
\text { can be handicapped etc., which all influence the social tenure relationship. Also, } \\
\text { the spatial unit itself can have different statuses in the phases of a natural disaster. } \\
\text { Therefore, interoperability and data exchange with other domains will be } \\
\text { supportive in data maintenance and complete coverage based on the principle" } \\
\text { collect once and use multiple times". }\end{array}$ \\
\hline 18 & $\begin{array}{l}\text { Source } \\
\text { Document }\end{array}$ & $\begin{array}{l}\text { Based on the extended requirement No. } 4 \text { this requirement now describes that } \\
\text { various timestamps for the source documents are needed and should be } \\
\text { supported by the system. Those dates could be, for example, the date of } \\
\text { acceptance, or recordation, or reconstruction. This is especially relevant when the } \\
\text { issuance of land documents should be enabled in the aftermath of the disaster. }\end{array}$ \\
\hline 19 & $\begin{array}{l}\text { Model } \\
\text { Boundaries }\end{array}$ & $\begin{array}{l}\text { LADM is organised into several packages, which already cover the needed } \\
\text { packages for the LA-DRM. Nevertheless, this requirement shall describe and } \\
\text { emphasise the importance of linking such a model to other registers such as the } \\
\text { population register, taxation, addresses, land use and land cover and valuation } \\
\text { systems. }\end{array}$ \\
\hline
\end{tabular}


In response to the above requirements, various attributes need to be added and changes made to LADM/STDM in order that the LA-DRM model is able to deliver on those identified needs in (Unger, et al., 2017) and (Lemmen, et al., 2015). Those changes and additional attributes are further explained.

\subsubsection{Individual and community defined vulnerabilities pre- and post-disaster}

The integrated model enables a 'party' to be for example a household, or family - so that also the children are recorded. The scale of vulnerability regarding the 'party' though can then be described and identified at individual but also at household, family, organisation or business level. These vulnerabilities can be identified and can be represented in a code list or as a Boolean value. Vulnerabilities could be, for example, lack of sanitation, educational possibilities/institutions, or lack of electricity, to name a few. Furthermore, at individual 'party' level, information about the level of literacy or education could be recorded, which further indicates the scale of vulnerability. Those identified vulnerabilities enable different stakeholders such as governmental representatives, NGOs or CSOs, to purposefully address them.

\subsubsection{Status info}

The scale of vulnerability in a post disaster context can be described through an attribute 'StatusInfo' in all core classes. For the 'SpatialUnit', the current or previous structure/building can indicate a different status and therefore should be described with a separate attribute under SpatialUnit. This may need a distinction between the parcel and the building/construction. The information shall give an indication whether the rebuilding process at the SpatialUnit has already started, if the construction is under the threat of collapsing, or if measures have been taken for mitigation and prevention, and so on.

For the 'Party', the 'StatusInfo' could give an indication whether or not the 'party' already applied for reconstruction grants. This could be realised through a Boolean value giving an indication whether the party applied or not. Another 'StatusInfo' regarding the 'Party' which can be relevant is, for example, if the party is deceased, is handicapped and so on, all influencing the social tenure relationships and indicating the scale of vulnerability and exposure.

Furthermore, the attribute 'StatusInfo' at 'SocialTenureRelationship' level can describe the level of recognition, whether the 'SocialTenureRelationship' is recognised by the legal framework or socially recognised. Therefore, a code table with various STR_Types could be introduced. Finally, the 'SocialTenureRelationship' can change in case of relocation or resettlement, both measures of DRM. 


\subsubsection{Inclusiveness}

Further, the LA-DRM model needs to be able to accommodate households at 'party' level with a various number of spatial units and subsequently varying 'STR'. This is relevant in case of collecting, for example, agricultural information at household level. This can describe the scale of exposure when it comes to livelihood. In previous versions of the STDM model only one people-to-land relationship could be established (GLTN, 2018). After field-testing STDM in a disaster risk context in Nepal this seemed to be inefficient and not representative for example for the landlord-tenant relationship. This is further relevant when it comes to DRM, which involves for example, modelling resettlement processes as mitigation and prevention measures, where n-numbers of spatial units can be involved.

\subsubsection{Additional considerations}

Further, in the case of a natural disaster procedures, which can take quite some time in a conventional system, may need to be shortened. This means rules and business logic, if incorporated in the model, need to be adjusted and need to be supported by the legal and institutional framework. Additionally, in the model, it needs to be possible to go back in the lifetime of processing a land right. This can be the case, for example, immediately in the response phase when a title or any kind of document is needed to apply for reconstruction grants. Later on, these documents should be made eligible and then included in the national administration system.

Tenure information regarding the structure itself, but also the tenure information of the land the structure is built on, and other land information, for example, agricultural use related to the party, can be gathered and would give additional indication of the level of vulnerability and exposure.

It is important that the integrated model covers all people, for example, from a settlement, community or the area of interest. Also, the people-to-land relationship needs to describe the children being related to the spatial unit. Population growth, migration, urbanization and economic development are all processes increasing the scale of exposure (UNISDR, 2015). All those dynamics need to be linked to the people so that in case of a disaster, nobody and no relevant information is left behind. Therefore, it is important to facilitate a link of the class 'party' to the population and business register.

Furthermore, in a post disaster context, resettlement measures such as previous and current locations, as well as different tenure types for each location need to be enabled. All classes in LADM, except 'source' are a subclass of the so-called class 
'VersionedObject'. This superclass enables LA systems to maintain and manage the history of LA objects. Therefore, it is, in a refined manner, also used in the integrated model to accommodate the agile and fast changing characteristics of natural disasters, but this model includes also the 'source' as a subclass. Therefore, every class inherits from the class VersionedObject. In this way, each class can cover the Tmin and Tmax attributes in the core classes, Party, SocialTenureRelationship and SpatialUnit. The VersionedObject can further manage information of the pre- and post- disaster status regarding the core classes and is indented to provide information when it comes to disaster responses such as, migration or resettlement.

\subsubsection{Integrated LA-DRM model}

All these extensions are important to be accommodated by the integrated model. Nevertheless, those extensions only reveal a small part of what is possible with such an integrated model and can be needed in disaster prone areas. But also, some of those requirements and attributes may also be points of attention and useful for an updated version of the LADM/STDM. The researchers want to emphasise that the main aim of this integrated data model is to establish the link between DRM and LA, and to show that by enabling communities through responsible $L A$, resilience against natural disasters is also enabled. The aim of the proposed LA-DRM model is not to cover the whole range of DRM and LA activities, but to be a model that can be used to give an overview and provide the information needed to enhance the resilience of communities.

The attributes represented in Figure 10 are examples of measures which can be collected when recording the people-to-land relationship in a disaster-prone area, and which can be used to describe the scale of vulnerability, exposure and hazard. This model can be extended and adapted to local situations and is considered able to represent most people-to-land relationships and land issues in regard to DRM.

These additional attributes and requirements lead to the following extension of the LADM UML model (Figure 10): 


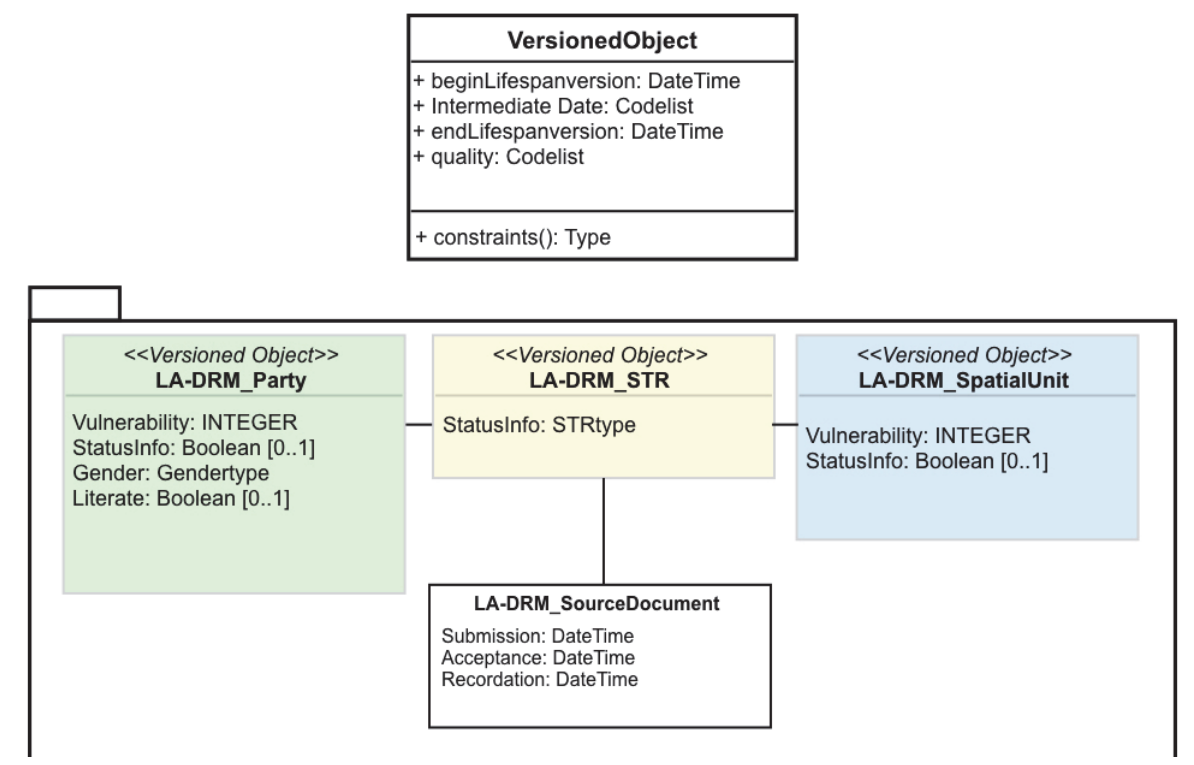

Figure 10: LA-DRM model

\subsection{Potential and limitations of the LA-DRM model}

The integrated model enables stakeholders to identify the most vulnerable groups preand post-disaster to adequately prepare, respond and mitigate. Analysis in Nepal showed that vulnerable or at-risk groups are children, women, elderly, persons with disabilities, the poor and marginalized groups, and especially people affected by tenure insecurity. They differ in their resilience to recover from a disaster. Mapping these vulnerable groups based on their needs, priorities and marginalization can be done during the different stages of DRM.

The researchers have further analysed the potential of the LA-DRM model based on the disaster cycle and its phases as shown in (van Westen, 2009). Nevertheless, it needs to be emphasised that there are different definitions of the DRM phases and stages depending on the institution, organisation and purpose of intervention. In (Mitchell, 2011), for example, a paradigm shift to conceptualize DRM as continuum describes the transition from pre- during and post disaster situation as fluid, in particular for countries, which are regularly exposed to hazards. The analysis (Figure 11) was done using a phased model framework, as used in (W3C, 2009). This presents a structured approach where the disaster phases as separated but related activities are used to show how the integrated model with its classes (Party, Social Tenure Relationship and Spatial Unit) evolve and contribute over time. The phases, the researchers are working with, are Mitigation and Prevention, Preparedness, Prediction and Warning, Response, Recovery, and Risk Assessment - based on the definitions in (UNISDR, 2017) and (van Westen, 
2009). Figure 11 does not cover all potentials and activities but aims to provide a general overview. The identified potential further allows preparing for the changing demands and needs in the different phases. To highlight the relation to the base model, the LADM, the same colour code for the core classes was used.

As shown in Figure 11, the light highlighted activities can make direct use of the integrated model and the data generated, whereas the LA-DRM model could assist with, for example, generated data or findings to the not highlighted activities. As shown in Figure 11, tenure security and therefore the LA-DRM model plays an eminent role in each of the disaster phases and stages. Further, the integrated model could be used when organising and deploying response and recovery strategies, answering the underlying questions 'who', 'what' and 'where'.

The development of the LA-DRM model outlined that focusing on disaster management policies with a long-term perspective may have to be directed towards tenure security, poverty and vulnerability reduction. DRM should integrate structural with nonstructural measures such as increasing tenure security, as a first act towards resilient communities. Especially disaster-prone communities should be engaged in the process of LA and disaster related decision making in order to increase the resilience of these communities.

Having demonstrated the development and potential of the LA-DRM model, which captures both the people-to-land relationship, as well as the link to DRM, from the conceptual perspective, it is also necessary to articulate the limitations.

One of the most prominent limitations was already mentioned in (Unger, et al., 2017), which is the visualisation. Any kind of visualisation can lead to misinterpretation and misunderstandings. Furthermore, it needs to be kept in mind that LA, as well as DRM, are domains, which are dealing with constantly changing data. STDM uses a less specific model to address this dynamism in reality, as represented in the data. Nevertheless, it needs to be taken into account that according to (Hay, 2016), queries therefore become less reliable (or more complex) because there is less certainty regarding the data stored in the system. Further LA systems are country specific systems. Through using standards, this limitation in regards interoperability and cross boundary data exchange, is partly already addressed, but cannot be fully solved. Therefore, introducing such a model at the physical level does mean that there may be adjustments needed in order to use the model in another case or region. 


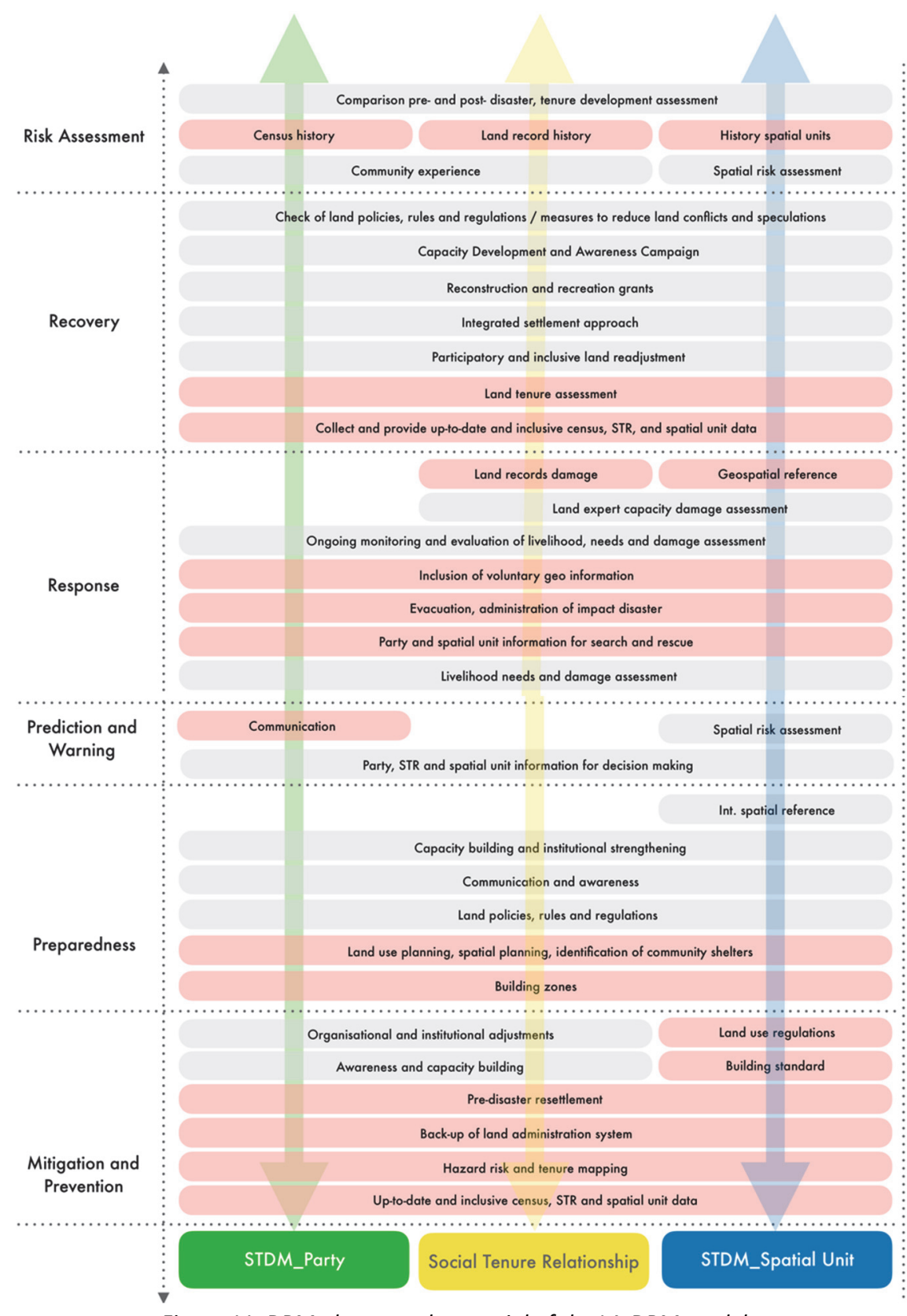

Figure 11: DRM phases and potential of the LA-DRM model

Traditional concerns regarding big data and therefore limitations linked with storage and processing capacity can be addressed by virtualisation and parallel computing, which is a type of computation where processes are carried out simultaneously. 
Yet, the introduced LA-DRM model is considered accurate and complete at the present moment with the focus applied, tools, methods and literature used.

\subsection{Conclusions and key lessons}

The introduced LA-DRM model may, in its implementation, improve the management of land information when it comes to natural disaster contexts. Land issues arising during a disaster may not be sustainably addressed if the current approach of ad-hoc legislative design and separation of disciplines and systems continues. The research shows that it is possible to link LA and DRM, at the data capture level, and that the occurrence of disasters is the most evident reason to include all people-to-land relationships in any LA system. People and or communities who are not recorded or registered are falling through the safety net of any disaster risk measures.

Moreover, there is no need to develop an entirely new model to service the data gap, instead using what is already available is more efficient and also means standardisation efforts are enhanced, rather than being compromised.

When it comes to DRM, the disasters and all its impact need to be mapped, which may be done through cooperation and by information sharing across domains. To administer natural disasters and govern the impact of any disaster, basic questions regarding, What? Where? and How? need to be answered. Therefore, the need to access and share various information, which is facilitated by interoperability and standardisation measures, needs further facilitation.

In summary, this research shows the development, potential, and also limitations of the required LA-DRM model. The research also highlights that participation is crucial in enabling the poor to minimize vulnerabilities and disaster risks through an inclusive land tenure security approach to prevent, mitigate, prepare and respond to natural disasters. 


\section{Chapter 4}

Application of FFP LA tools and approaches in a postdisaster context*

* This chapter is based on a UN-Habitat GLTN publication; Unger, E.-M., Chatkuli, R. (2019). Fit-For-Purpose Land Administration in a post disaster context. Lessons and Applications from Nepal. 04/2019. Nairobi, Kenya 


\subsection{Introduction}

Following two severe earthquakes and subsequent aftershocks in 2015, Nepal still faces reconstruction challenges: shelter needs to be provided for the affected population, infrastructure needs to be rebuilt, and urban and rural livelihoods need to be reestablished. The 2030 Agenda for Sustainable Development (UN, 2015) with its defined goals and the New Urban Agenda (UN, 2017) together with the Sendai Framework for Disaster Risk Reduction (WCDRR, 2015), stimulate innovative and transformative approaches to secure land and property rights for all in regard to DRM. Assessing the impacts of tenure security for the poor is also recommended by (Hendriks, et al., 2019), especially in relation to the SDGs and the New Urban Agenda. Further it can be observed that LA plays a leading role in DRM according to (Mitchell, 2011), (Unger, et al., 2017), (Zevenbergen, et al., 2014a), (Potts, 2012), (Schipper \& Pelling, 2006) and (Rajabifard, et al., 2018). Addressing tenure security in disaster risk prone areas is essential to prevent, mitigate, prepare and respond to natural disasters.

The Government of Nepal recognized the need to prepare a comprehensive reconstruction plan after assessing the damage, loss and recovery needs. This led to the Post Disaster Needs Assessment (PDNA) (NPC, 2015) soon in 2015 and a Post Disaster Recovery Framework (PDRF) (NRA, 2015) in May 2016. The assessments indicated that access to land was a major concern before the earthquakes and is still a major concern after them. Funds have been mobilized by the (inter)national donor community and the government for post-disaster reconstruction. The National Reconstruction Authority (NRA) provides some grants to the victims to support the reconstruction of their houses. Yet, the reconstruction or relocation of houses requires information about people (citizenship certificates), the damaged property (surveys) and information on ownership of land (ownership certificates). The NRA reports that reconstruction and relocation is hampered in most cases because many people do not have a certificate of ownership of their houses or land or any official registration in government records. Currently not all land rights in Nepal are recognized nor recorded in the LA system. Consequently, this causes delays in the post-disaster recovery process and reconstruction processes.

The FFP LA approach can support the Government of Nepal in the recovery from the earthquakes as well as future disaster preparation and mitigation processes by addressing informal, non-formal tenures and encroachment (Unger, et al., 2017). In order to explore and build knowledge related to FFP LA, in which all people-to-land relationships are recognized, a team from the UN-Habitat Nepal Country Office, Kadaster International (the international branch of the Netherlands' Cadastre, Land Registry and Mapping Agency - Kadaster), the Human Rights Awareness and Development Centre (HURADEC) and the Secretariat of the Global Land Tool Network 
(GLTN) as facilitated by UN-Habitat, developed and piloted a FFP LA approach in the post-earthquake context in Nepal. The approach involved trialling and demonstrating the application of relevant land tools specific to tenure security provision and the relocation and reconstruction of settlements in the Dolakha district in Nepal.

The FFP LA approach (Enemark, et al., 2014) supports the data collection and recordation of customary and informal land rights. Further the FFP LA approach includes the continuum of land rights as a guiding principle (Barry \& Augustinus, 2015) and (Antonio, et al., 2017). The Social Tenure Domain Model (STDM) supports the management of the collected data. Further the approach also included capacity building on gathering and maintaining the documented land information in order to get access to grants, and the application of relevant land tools specific for tenure security provision in the Dolakha district in Nepal.

The key finding of the approach confirmed that in the case study areas a third of the earthquake victims could not access the reconstruction grants because the land title was not available. The Nepal Government reacted positively to these findings and worked on a land policy and a related FFP LA strategy which helps to fast-track the access to reconstruction grants (GLTN, 2018). The approach as developed provides the foundation and worked as a catalyst for the FFP LA strategy of Nepal.

This chapter is structured as follows: first a brief overview explains the LA and post disaster land challenges in Nepal; subsequently, the case study areas in Dolakha region are introduced. This leads to an overview of land tools for FFP LA and DRM, followed by a description of the underlying methodology. An overview of the different roles in the FFP LA spatial framework describes the role of grassroot and professional surveyors, which has evolved as a feedback from the case study. Thereafter the key findings and results are presented and confirm the usability of FFP LA in the process of earthquake recovery, to improve the community resilience. Finally, a discussion of challenges and lessons learnt based on the experiences gathered in the field is undertaken which precedes the recommendations and conclusions.

\subsection{Land administration challenges in Nepal}

The Constitution of Nepal advocates ending all forms of discrimination and the creation of an egalitarian society, which is closely linked to equity in citizens' access to land. The land policy from 2018 recognizes citizens' current challenges, especially the challenges of vulnerable groups, regarding access to land and security of tenure through informal occupation, dual ownership, unregistered peasants and tenancies, and outlines ways to 
formalize property rights for these groups. Likewise, the gender strategy to enhance access and ownership of land by women is further boosted.

Land tenure in Nepal (GLTN, 2018) is either statutory or non-statutory. Statutory land tenure can be private (Raikar), state (Government and Public) and trust (Guthi). Nonstatutory tenure on land may further be categorised as non-formal (land on which rights are socially and legally recognised but not registered), informal (land on which rights are socially recognised but neither legally recognised nor registered) and customary (delegalized after the 1961 land reform process, but remnants are still existing in practice) (Figure 12). Further illegal holding over private or public land which is neither socially nor legally recognised are considered encroachments. The current LA of Nepal does not record such non-statutory land holdings and informalities and therefore cannot deal with it (MOALMC, CSRC, UN-HABITAT, 2018). This results in poor land management and thus, increases vulnerability, exposure to and lack of preparedness for natural disasters (Mitchell, 2011).

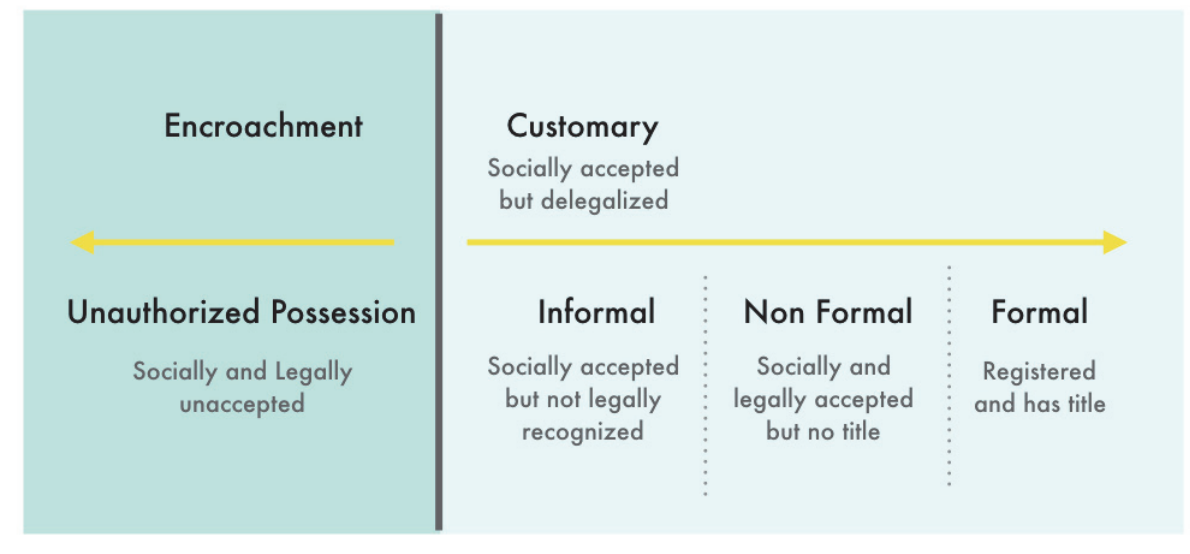

Figure 12: Land tenure in Nepal

The LA system in Nepal only deals with the formal or statutory land tenure and is mostly paper-based. Non-formal or informal land tenure, crudely estimated to be around $25 \%$ of the arable land and settlements, is not dealt with. This is grossly estimated to be around 10 million parcels. Hence, a significant amount of the Nepalese population is living in informality without any documented recognition (GLTN, 2018). The people who do not have formal land records hesitate to rebuild and invest on the land. Without investment, productivity cannot be increased or sustained in case of a natural disaster. Unrecognized land tenure restricts the settlers from getting any government support or compensation following disasters. All these consequences show that land under informal tenure undermines the economy and prosperity of the country. Cadastral 
surveys under the current LA are mostly performed using traditional approaches (plane table) using general boundaries. Map scales vary from 1:500 for urban and dense settlement areas, to 1:2.500 for rural and areas with large parcels. Subdivisions of parcels are generally done according to a verbal description provided by the concerned parties, without field verifications or survey on the ground. Digital transaction processes run parallel to paper-based processes, which causes inconsistency. Paper-based processes have priority because the digital equivalent does not have a full legal recognition. Further, because of limited human resources, the digital data set is not uniformly maintained. This means the digital database is not reliable and cannot provide sufficient information subsequent to natural disasters.

\subsection{Land and post-earthquake challenges in Nepal}

Many land issues after the earthquakes are related to accessibility, resettlement processes, recognition of unrecorded tenure types and disputes (landlord-tenant differences). The growing demand for land and natural resources, and poorly developed land-use planning boosts the number of disputes.

The three most prominent post-disaster land challenges in Nepal are disputes over land holdings, displacement and landlessness ${ }^{2}$, and lack of documentation and records. These challenges can be addressed by introducing a FFP LA approach in a post-disaster context, which aims for complete coverage by documenting all people-to-land relationships.

- $\quad$ Disputes over land holdings

In Nepal, the number of disputes over land is high with almost 47.5 per cent of all civil cases pending in the courts related to land (Chhatkuli, 2013). Earthquakes or any other natural disasters generally increase the number of disputes because of the lack of documentation.

- Displacement and landlessness

Households with informal and non-formal tenure face the greatest impact from natural disasters. This impact may result in displacement, resettlement or even eviction.

- Lack of documentation and records

The loss of documents through a natural disaster can increase vulnerability extensively, especially when the LA system is only paper-based. Further, the lack of

2 landless or near landless is defined as having less than 0.5ha of land by the Ministry of Agricultural Development, 2015 
documentation on inheritance, tenancy or shared ownership can result in the loss of land and / or shelter.

Securing tenure of vulnerable groups, and granting access to land for housing and resettlement, is one of the major aspects in the post-earthquake stage (Mitchell, et al., 2014), (Zevenbergen, et al., 2014b) and (Unger, et al., 2019a). Addressing these issues enables vulnerable groups to respond and mitigate against aftershocks and secondary hazards, such as landslides and avalanches. The lessons presented in this chapter provide the Nepalese land agencies with a summary of the challenges the rural communities face in the aftermath of the disaster. In addition, the results show the link between security of tenure, vulnerability, exposure and hazard of natural disasters, by assessing and analysing the collected information on tenure and basic household economies. The results also inform the development of the national land policy and related changes in the regulatory frameworks (GLTN, 2018).

\subsection{Case study areas in the Dolakha region}

Dolakha district in Nepal is selected as study area. The area is highly vulnerable to natural disasters and also to combined risks such as flood, drought, landslide, skewed ecological, temperature, rainfall etc. (Khezri, et al., 2018). The epi-centre of the second largest 6.8 magnitude earthquake after the largest 7.6 magnitude Gorkha earthquake was located in Sunkhani district. Dolakha district, with a population of approximately 281.000 and approximately 60.000 households, is in the mountains of central east Nepal. Altitudes in this region range from 650 metres to 7.134 metres. The district is covered by high Himalayas ( 35 per cent), high mountains ( 40 per cent) and middle mountains (25 per cent), with the population mostly concentrated in the middle mountains (Khezri, et al., 2018). The 2015 earthquake destroyed 49.992 private houses, 63 health facilities, 1.095 schools and 54 temples as well as numerous other properties and infrastructure. It was estimated that 98 per cent of all buildings collapsed and there were 178 fatalities, 8 people missing and 662 injuries.

The focus of the FFP LA in Nepal is on identifying and documenting legitimate beneficiaries to enable and complete the access to reconstruction grants in the following case study areas in the Dolakha district:

- $\quad$ Phulappa is a settlement located in an area with a difficult accessible terrain and is deprived from basic infrastructure. Many of the households ( $\mathrm{HHs}$ ) are from the indigenous tribe of Thami and Dalits who are considered lower in the social caste system, and are still living in temporary shelters after the earthquake destroyed their houses. Most of the farmers in this community have been engaging in 
subsistence farming based on a feudal tenancy system as unregistered tenants with no written agreements or documentation.

- Jilu consists of two settlements: Dihi and Phasimai. Approximately $220 \mathrm{HHs}$ are affected by the earthquake and most of the population is still living in temporary shelters. Since most of the community members hold land titles, the community plans to develop an integrated settlement plan as part of their post-earthquake recovery.

- Bulunkhani is a village in the Bigu municipality and is left vulnerable due to land ruptures resulting from the aftermath of the earthquakes. The residents are displaced and forced to move to nearby lands, which is mostly owned by the community itself. Therefore, an integrated settlement plan in the resettlement area is proposed.

Additional technical support, awareness raising campaigns through visits and meetings are organised in an additional case study area called Panipokhari. In this area no spatial and administrative data is collected but the community is assisted in the development of an integrated settlement plan.

Figure 13 shows an overview of the three case study areas (four communities) and the households and farms enumerated and recorded during the case study: 485 households enumerated; 421 houses recorded; and 1369 farms georeferenced.

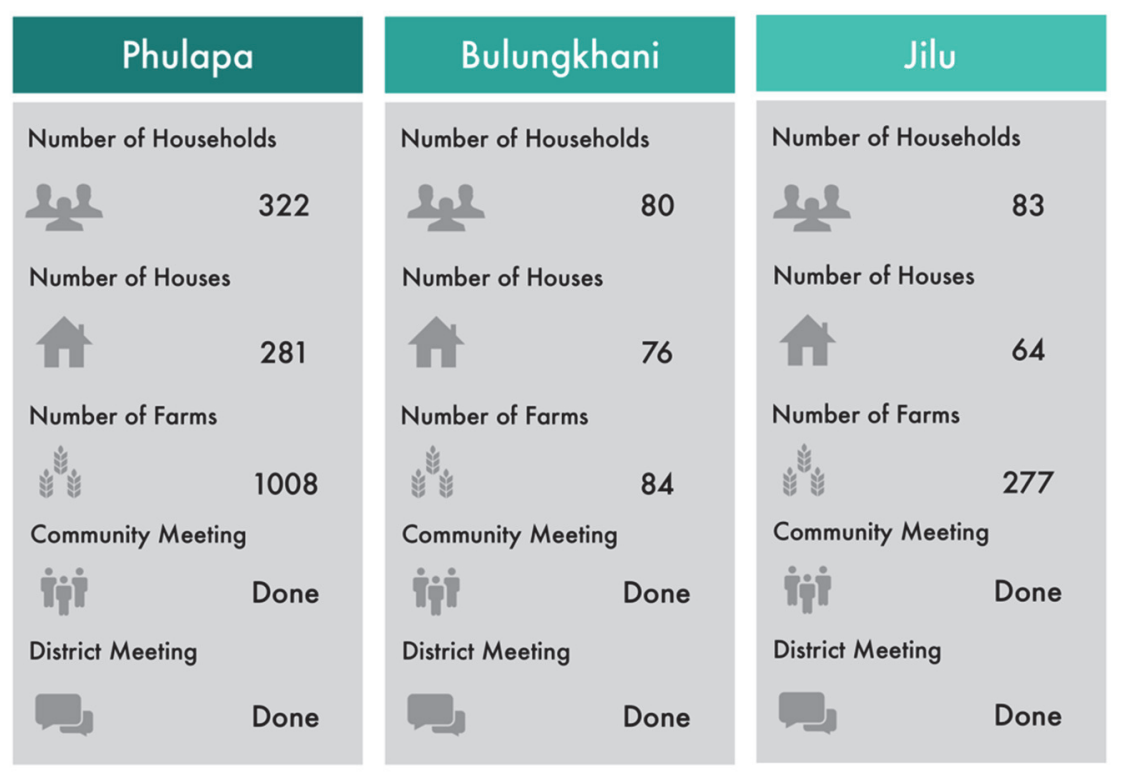

Figure 13: Overview of the case study area 


\subsection{Land tools for FFP LA and DRM}

The GLTN is a coalition of global, regional and national allies contributing to poverty alleviation through land reform, improved land management and security of tenure. GLTN has developed a series of land tools (GLTN, 2012), which can be used to implement the legal, institutional and spatial framework of FFP LA. A land tool is a pragmatic way to address LA issues consisting of a wide range of methods: from checklists to conduct surveys, a set of software and associated protocols to guidelines and approaches. Within this approach the following land tools are used to link LA and DRM:

Continuum of Land Rights, which includes rights that are documented as well as undocumented, formal as well as informal, including individuals and groups, and including pastoralists, slums and settlements, which are legal as well as extra-legal (Barry \& Augustinus, 2015)

Fit-For-Purpose Land Administration (Enemark, et al., 2014) enables appropriate LA systems to be built within a relatively short time, at affordable costs, and with the opportunity to upgrade when required. The FFP LA approach recommends, amongst others, the use of 'visible boundaries' to identify the delineation of land rights and to achieve complete coverage and in a later stage an incremental improvement of quality where needed.

Social Tenure Domain Model (Lemmen, et al., 2010) and (GLTN, 2014) is initiated by the GLTN and is based on the LADM (Lemmen, et al., 2015). The STDM (Antonio, 2011) can be used to support LA of the poor in urban and rural areas, which can later in time also be linked (converted) to the cadastral and land registry system.

Gender Evaluation Criteria, (GLTN, 2016) is a framework, which helps designing genderresponsive land tools and evaluating whether existing land tools are gender sensitive and inclusive. Thus, this framework guides the design of tools and ensures the perspective and requirements for both men and women. Nepal is a patriarchal society, so it is very important to prioritize gender issues. Although the situation is changing slowly, women have historically been excluded and disadvantaged with regard to access, ownership and control over productive resources such as land. In most cases, women usually have secondary and deprived rights to land, and their rights are obtained through their relationship with male family members, such as their father, brother, husband or son.

Participatory Enumeration (UN-HABITAT, 2010a) is applied for data collection in the field using a questionnaire build according to the following skeleton: 
- Enumeration - basic information about the enumeration,

- Respondent - basic information about the person responding to the questionnaire,

- $\mathrm{HH}$ - information about the basic economic unit,

- HH Members - details of all HH Members including the respondent,

- House - details of the house of the $\mathrm{HH}$;

- House Tenure - the tenure information of the land on which the house is built;

- Farm - the farm details; and

- Farm Tenure - the tenure details of the farm land.

Additionally, the questionnaire captures post-earthquake issues such as: pre- and postearthquake land tenure information; grant related information; priority areas - to identify vulnerabilities; and: land tenure issues such as tenancy registry, production share, and issues of land ownership.

Visible Boundaries can be identified on high-resolution imagery in the field using participatory mapping approaches. In most of the cases in Nepal, boundaries between properties are visible on the ground through physical features like hedges, fences, terraces, mud partitions or other forms of natural markers. Administrative data, such as names and personal identities, can be linked on site during the visual boundary identification using preliminary reference identifiers for the spatial units. If boundaries are not visible either in the field or on the image, some simple field surveys may be needed for data completion. It is important in this process that the local community verifies and agrees on the data, preferably immediately after its collection.

\subsection{Methodology}

In this chapter the case study methodology as defined by (Yin, 2014): 'A case study investigates a contemporary phenomenon (the 'case') in its real-world context, especially when the boundaries between phenomenon and context may not be clearly evident' is applied. The case study method is a well-known and often used method for conducting research within the LA discipline according to (Stubkjær \& Cagdas, 2009). (Yin, 2014) recommends four stages for a case study methodology:

- Designing the case study,

- Conducting the case study,

- Analysing the case study evidence, and:

- Writing the case report and research implications.

This chapter is following all those stages. 
The methodology of the field cases starts by agreeing among the community and stakeholders on an approach with a focus on capacity building and the use of the FFP LA tools. During the enumeration, the village residents' current house is mapped with one point using GPS devices. The visible boundary approach is done by the community members. The process includes a meticulous practice of the enumerators checking with the community and guiding them by identifying different landmarks in order to identify the boundaries. Through linking drawn boundaries with the questionnaire, the peopleto-land relationships using the satellite imagery are established. The linking ID is a welldefined ID for HHs and farms, e.g. PHU33 for the HH and F1PHU33 for the correlated farm. In case there is more than one farm related to the $\mathrm{HH}, \mathrm{F} 1$ is changed to $\mathrm{F} 2$ and so on. In order to establish the link, the images are printed on AO paper at a scale of 1:750, which is sufficient to allow the community members to easily understand the images and to identify their farmland, mainly terraces which are approximately 3 meters in width in many cases. HURADEC, its team and the local community perform the data collection in the field. The collected data is then entered based to the data model as introduced by (Unger, et al., 2017). Then the data are analysed and validated using STDM. The methodology is following the steps $1-11$ as visualised in Figure 14.

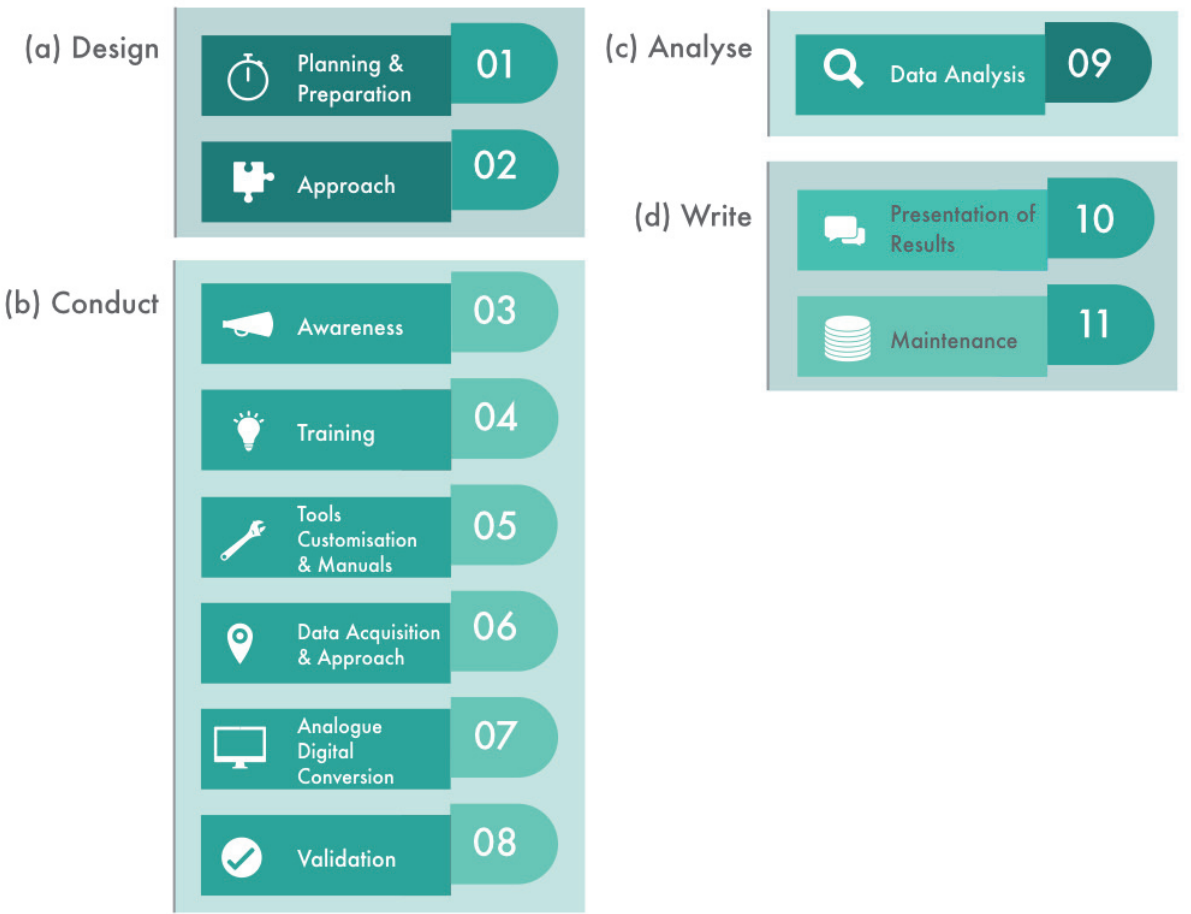

Figure 14: The methodology of the field work

1. Planning and preparation, the availability of base materials, such as satellite imagery, cadastral maps and hardware, from other stakeholders is investigated. Site 
visits are organized to meet the communities and to investigate if the indented approach is feasible. Due to the local circumstances, such as low level of literacy, low internet reception and regular power cuts, a paper-based approach is chosen. The questionnaire and queries are designed. To link the administrative and spatial data, a unique ID system is defined.

2. Approach, a HH-based approach is chosen as the economic unit in the recovery from the earthquake. An inclusive approach is followed, documenting all $\mathrm{HH}$ members, with special attention to women and $\mathrm{HH}$ members working abroad as they often contribute to the $\mathrm{HH}$ income. This is an important factor with regard to the scale of vulnerability and exposure.

3. Awareness raising, is conducted at community, municipality and at national level. Information plates and folders with drawings are used to inform the community on how to access the reconstruction grants. Further meetings and awareness campaigns for community leaders are organised. Local youths (men and women) of Phulappa are organized to establish a 'Concern Committee' who are continuing to work with stakeholders for land management and tenure security.

4. Training, of enumerators and field officers. Training includes participatory enumeration, basic understanding on coordinate systems, on handheld GPS, and on the visible boundary approach. Further the enumerators are sensitized on different language issues and also on how to conduct interviews with and on behalf of women and vulnerable groups. Fourteen local enumerators participate in the process.

5. Tools customisation and manuals, the STDM has to be customised in order to include documentation of the farm tenant relationship, which implies multiple spatial units to one $\mathrm{HH}$, and also to accommodate DRM measures as according to (Unger, et al., 2019a). In order to ensure sustainability within capacity building, various manuals for each exercise are developed.

6. Data acquisition \& approach, various communication approaches and announcements are used. The field officers ensure that all HHs are visited. It takes seven weeks to complete the data collection process in Phulapa area and additional four weeks for the Bululgkhani and Jilu area.

7. Analogue to digital conversion, is done after the data acquisition in the field is finished. The forms are converted to digital data by typing the data into the STDM. 
For the spatial information, the printed satellite images are photographed, georeferenced using a QGIS plugin and then digitized. In the STDM the link between the administrative data and the spatial data, the social tenure relationship, is established.

8. Validation, at four levels is conducted. Those four levels involve the validation by the community during the data acquisition, the validation of selected forms and digitized farms before the data entry by the enumerators, the validation during the data entry by data entry experts, and the validation of data after digitization in each of the communities. In cases of disputes the community leaders are negotiating with the relevant parties and in case no consensus could be achieved the overlapping claim is mapped and documented.

9. Data analysis, with the aim to identify the level of tenure security, the scale of vulnerability, exposure and hazard, their grant status, the basic $\mathrm{HH}$ economy, all related to the people-to-land relationship is completed.

10. Presentation of results, to the community and all relevant stakeholders, including the Deputy Mayor of the local municipality and the Director General of Surveys, has been conducted on November 2018 in Charikot, Nepal.

11. Maintenance, of the data is required until all grants are provided as the status of people may change or they may leave the area. Therefore, within this FFP LA approach special attention is given to enable the employees of local partners to have a good STDM knowledge and so to perform the maintenance to keep the data up to date.

\subsection{Overview of different roles in the FFP LA spatial framework}

The role of so called grassroot surveyors in the FFP LA processes is imminent and creates a lot of potential. This can be utilised by governments to achieve complete coverage in their LA systems to be better prepared for natural disasters. Basically, the data acquisition is done by the people themselves under guidance of a professional surveyor. In the aftermath of a natural disaster housing is a priority, as well as the need for building permits, the need for land documents, and the need for reconstruction grants (Shrestha, et al., 2015).

The following table discusses the different roles of grassroot and professional surveyors in the FFP LA spatial framework, which has evolved as a feedback from the approach. The Table 2 presents a first outline based on a discussion between experts engaged in 
the case study area. Pre-condition to be a grassroot surveyor is literacy and a strong community involvement. Grassroot surveyors can be those who have very short and basic survey trainings, can be engaged in assisting FFP LA projects, and can carry out basic surveying and measurement functions. Depending on the approach and tools used in the field even computer literacy could be required.

Table 2: Different roles in the FFP LA spatial framework

\begin{tabular}{|c|c|c|}
\hline & Grassroot Surveyor & Professional Surveyor \\
\hline Training & $\begin{array}{l}\text { Receive training and build } \\
\text { confidence and routine through } \\
\text { exercising } \\
\text { Able to conduct training after } \\
\text { successful completion of training } \\
\text { from the professional surveyor }\end{array}$ & $\begin{array}{l}\text { - Conduct training on methodology; } \\
\text { identification; image preparation, } \\
\text { interpretation and explanation; } \\
\text { - Create spatial \& cadastral } \\
\text { intelligence within the grassroot } \\
\text { surveyors }\end{array}$ \\
\hline $\begin{array}{l}\text { Planning and } \\
\text { Preparation }\end{array}$ & $\begin{array}{l}\text { - Organize when and where to } \\
\text { conduct communication and data } \\
\text { acquisition with the communities }\end{array}$ & $\begin{array}{l}\text { - Organize local and / or national } \\
\text { support from governmental } \\
\text { agencies (decentralize and central } \\
\text { approach) }\end{array}$ \\
\hline Awareness & $\begin{array}{l}\text { Build trust relation with local } \\
\text { community }\end{array}$ & $\begin{array}{l}\text { - Show support in the field through } \\
\text { governmental representative }\end{array}$ \\
\hline Validation & $\begin{array}{l}\text { - } \quad \text { Conduct validation in the field } \\
\text { with the communities }\end{array}$ & $\begin{array}{l}\text { - Train grassroot surveyors on how to } \\
\text { conduct an inclusive and gender } \\
\text { responsive validation in the field }\end{array}$ \\
\hline $\begin{array}{l}\text { Data } \\
\text { acquisition }\end{array}$ & $\begin{array}{l}\text { - Conduct field work (data } \\
\text { collection by drawing on image or } \\
\text { using GPS or other data } \\
\text { acquisition method), collecting } \\
\text { evidence on existing rights } \\
\text { through photos of documents, } \\
\text { photo of ID and person, } \\
\text { - Introduce (communicate purpose } \\
\text { and procedure) to HH } \\
\text { Check data in detail after } \\
\text { acquisition }\end{array}$ & 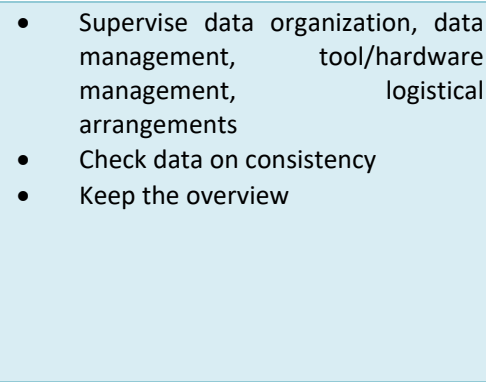 \\
\hline Approach & $\begin{array}{l}\text { Review the approach in regard to } \\
\text { local circumstances }\end{array}$ & Define the approach \\
\hline $\begin{array}{l}\text { Tools } \\
\text { Customization } \\
\text { \& Manuals }\end{array}$ & $\begin{array}{l}\text { - } \quad \text { Review manuals on usability } \\
\text { Use manuals for conducting } \\
\text { sensitization and training }\end{array}$ & $\begin{array}{l}\text { - } \quad \text { Draft and create manuals } \\
\text { Use existing manual for training } \\
\text { purposes for the grassroot } \\
\text { surveyors } \\
\text { - Conduct tool customisation }\end{array}$ \\
\hline A/D Conversion & $\begin{array}{l}\text { - Perform } A / D \text { conversion after } \\
\text { required training }\end{array}$ & - $\quad$ Check quality after A/D conversion \\
\hline Data Analysis & $\begin{array}{l}\text { - Analyse data by using predefined } \\
\text { basic queries } \\
\text { Support the interpretation of } \\
\text { analysis results (both basic and } \\
\text { complex) }\end{array}$ & $\begin{array}{l}\text { - Conduct advanced/complex data } \\
\text { analysis }\end{array}$ \\
\hline $\begin{array}{l}\text { Presentation of } \\
\text { Results }\end{array}$ & $\begin{array}{l}\text { Present and sharing results to } \\
\text { local communities }\end{array}$ & $\begin{array}{l}\text { Support grassroot } r \begin{array}{r}\text { surveyors } \\
\text { bringing institutional knowledge }\end{array} \\
\text { and guidance }\end{array}$ \\
\hline Maintenance & Purpose dependent & Purpose dependent \\
\hline
\end{tabular}




\subsection{Key findings and results}

This case study is the first time that FFP LA concepts and tools are introduced in a postdisaster context. The case study is the first application of the FFP LA approach in Nepal, which facilitated an inclusive, gender sensitive, participatory and transparent approach. The following presents the key findings of the case study in regard to status of land tenure and recovery, relevance of farm tenure for DRM, post-disaster priority assessment and vulnerability of women. Many more detailed conclusions could be derived as per purpose from the data collected and the STDM database created but the main focus of the case study is shown here.

\subsubsection{Status of land tenure and recovery}

A common post-disaster activity in DRM: the assessment of damage and identification of priorities for recovery (van Westen, 2009) is applied in order to determine the priorities and needs of people living in the case study areas. The priorities at $\mathrm{HH}$ level are collected in order to describe the scale of vulnerability. The priorities are defined after an initial community meeting. The priorities at $\mathrm{HH}$ level, are as follows: (1) Housing Improvement, (2) Drinking Water, (3) Education, (4) Electricity, (5) First Aid Kit, or: (6) Toilet.

The result (Figure 15) clearly shows the need for housing improvement. This result is in line with the other results, which show that most of the $\mathrm{HHs}$ are living in temporary houses and do not receive reconstruction grants. It shows that the reconstruction grants, which are based on houses/constructions per HHs, are not sufficient - as the real needs are based on $\mathrm{HH}$ size.

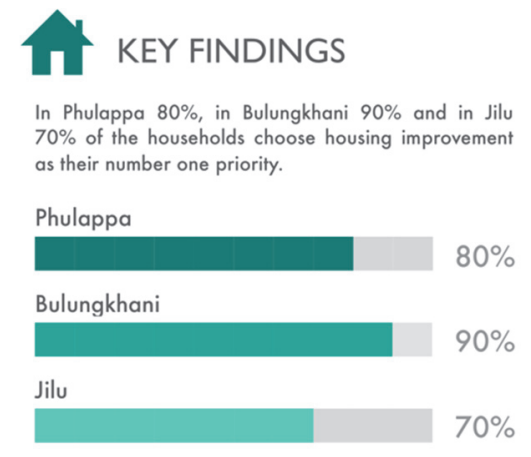

In order to determine if relocation/resettlement

Figure 15: Summary of the key findings - priority has already taken place; what the status of the residents' current houses is; if the grant's allocation for reconstruction is a success; the status of land tenure and recovery is analysed. This analysis describes the level of vulnerability with the link to tenure security of the affected communities. Therefore, the house status is merged with the information of the existing land documents. To underline this result, the grant status is also analysed. 


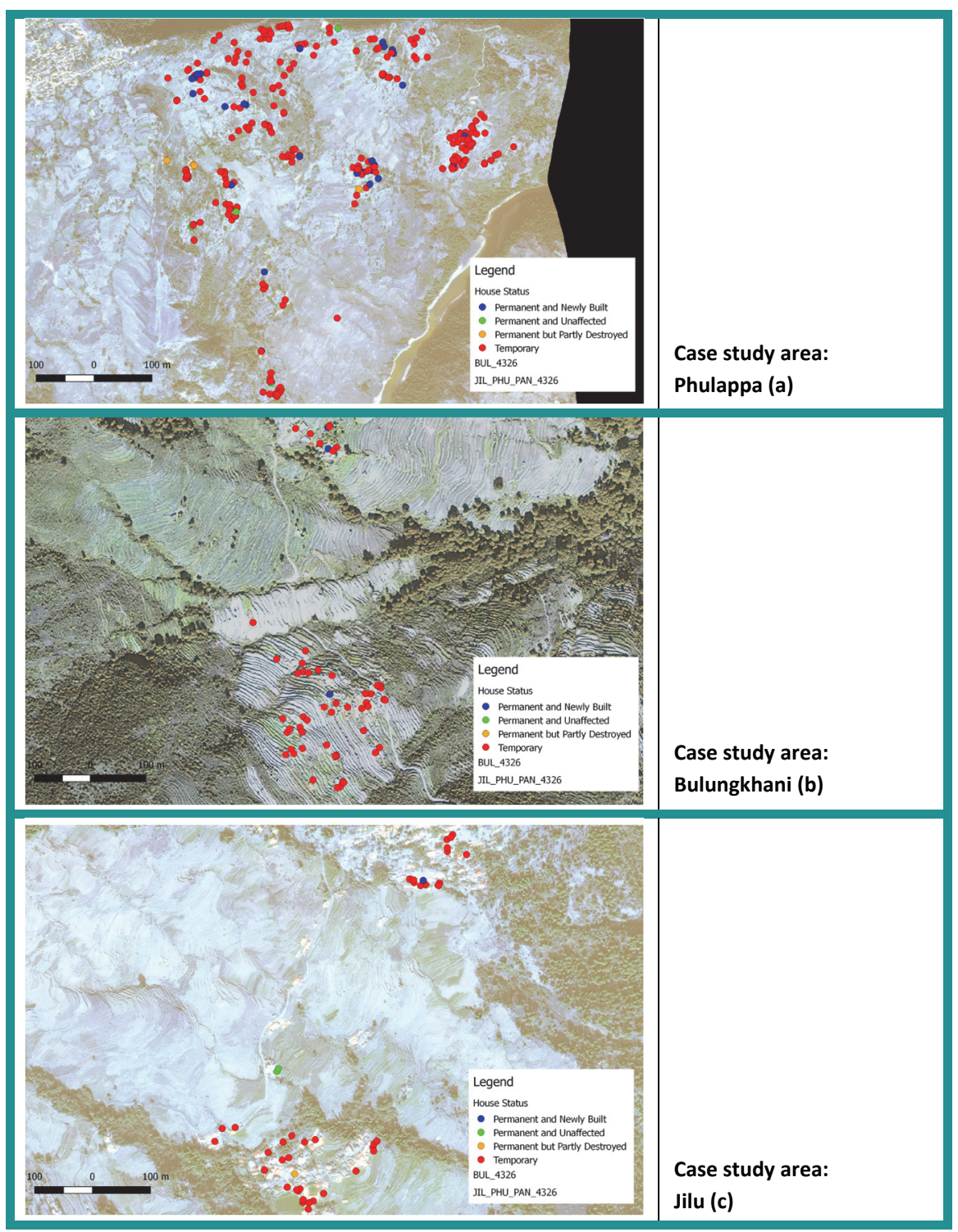

Figure 16: House status in case study areas

The maps in Figure 16 show the HHs, georeferenced through a point collected on site with a handheld GPS device. For each case study area, maps are generated with the STDM. Especially in regard to DRM one point per house, farm or spatial unit (parcel) is in the first stages of recovery more useful, easier and quicker to generate.

The first result focus on the house status, which can be: (1) Permanent and newly built, (2) Permanent and unaffected, (3) Permanent but partly destroyed, or: (4) Temporary. 
As shown in the maps above of the different case study areas, most of the houses are temporary (a), (b) and (c) (Figure 16). Living in these temporary houses increases vulnerability and exposure. $\mathrm{HHs}$ are waiting to receive reconstruction grants but are either not aware of the procedures on how to obtain those or are lacking the required documents. Both are issues, which can be visualised through the location and which can be addressed through a link between LA and DRM. The lack of documents is stressed by the result of the analysis which shows that approximately $1 / 3 \mathrm{HHs}$ has no land documents. To underline the above results the status of the reconstruction grant in relation to the land document is analysed. Because of the lack of documents, 1/3 of the $\mathrm{HHs}$ in the three case study areas cannot access the reconstruction grants. Hence, 133 out of 421 houses in the case study areas are not eligible for the reconstruction grants.

\subsubsection{Relevance of farm tenure for DRM}

In order to determine the number of people who cannot prove their farm tenure and to determine the number of people living under crop-share tenancy relationships - which are both seen as measures for the scale of vulnerability and also exposure - the farm tenure is analysed. The farm tenure can be: (1) Registered Tenancy; (2) Unregistered Tenancy; (3) Single Ownership; (4) Joint Ownership with Others; (5) Inheritance Ownership; (6) Contract; or: (7) Communal Ownership. Farm tenure gives an indication in relation to production losses, changes in trade flows and agriculture sector growth, all important to boost food security and productivity and curb the harmful effect of climate change according to (FAO, 2015). Farm tenure, which is unregistered is under constant threat of either eviction or unequitable share of crops. In many cases landlords do not provide any evidence on crop-sharing relations with their tenants.

People whose tenure or tenancy is not secured are the most vulnerable as those HHs can hardly be addressed since they are officially non-existing. Further the result shows that the visible boundary approach is practicable and that these huge areas can be covered with spatial data without walking through and surveying the boundaries in the field.

The maps in Figure 17 show that there is a clear difference between the case study areas with a lot of unregistered tenancy in Phulappa (a) and mainly single ownership farmers in Bulungkhani (b). 


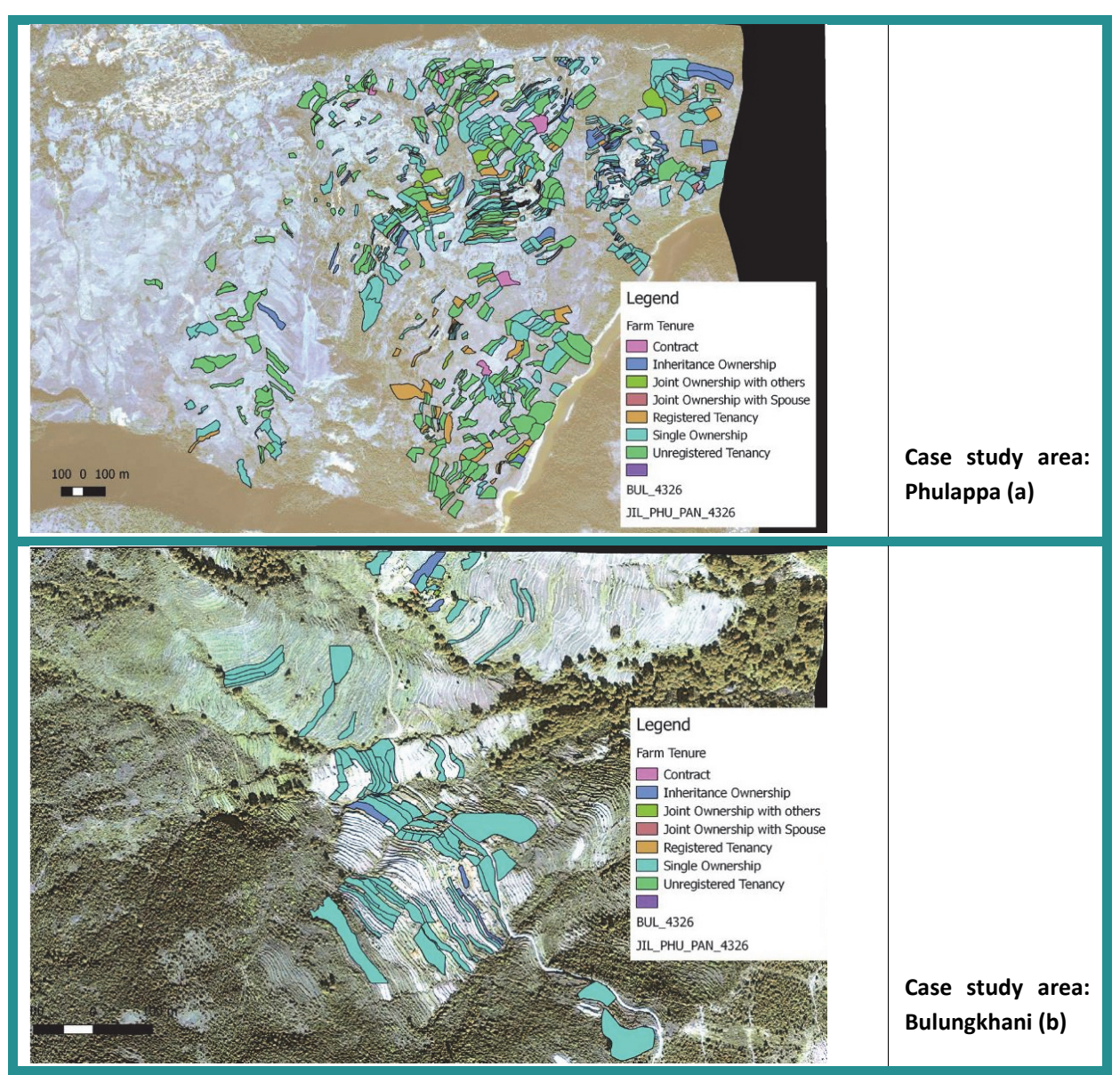

Figure 17: Farm tenure status in case study areas

Land is one of the most significant assets in the Nepalese rural-agrarian economy. Further it is the prime source of livelihood for many rural HHs. More than 83 per cent of Nepalese live in the rural area (CBS, 2014) and nearly 75 per cent depend on agriculture for livelihood (CBS, 2006). Phulappa (a) is the case study area with the highest number of non-statutory tenure relationships and therefore it is suspected to have the highest number of landless or near landless HHs. The result shows that $62 \mathrm{HHs}$ out of $442 \mathrm{HHs}$ in Phulappa are completely landless and without any ownership of land or near landless without official documents of tenancy. Landlessness influences economic development, social stability, food security, housing, access to drinking water, health and work and therefore increases the vulnerability of individuals. 


\subsubsection{Vulnerability of women ${ }^{3}$}

In 2011 the government of Nepal introduces 'joint ownership' among spouses with the aim to empower women and set a clear step towards gender equality. Still men predominantly own most productive land resources. Studies (GLTN, 2018) show that only approximately 20 per cent of women have ownership of land. In order to determine the vulnerability of women which is indicated by the number of joint ownerships, the number of joint ownership certificates is collected and analysed. This result focuses on the number of joint ownerships within the case study areas. Therefore, within the participatory enumeration the community members are asked about their tenure status, which can be: (1) Registered Tenancy, (2) Unregistered Tenancy, (3) Single Ownership, (4) Joint Ownership with Spouse, (5) Inheritance Ownership, (6) Contract, or: (7) Communal Ownership.

\section{KEY FINDINGS}

Only $16 \%$ of land ownership in Phulappa, Bulungkhani and Jilu is joint.
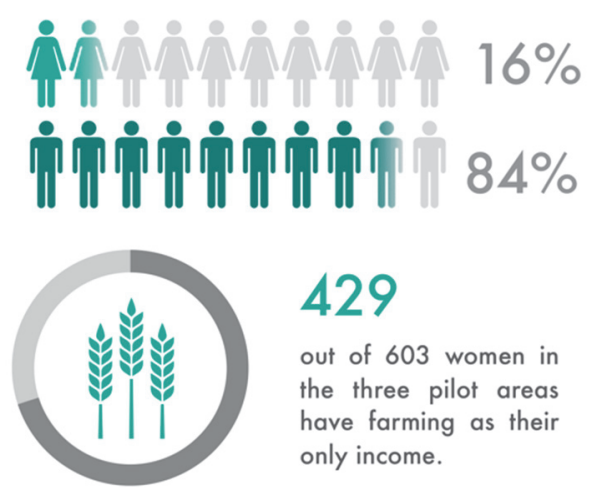

\section{9}

out of 603 women in the three pilot areas have farming as their only income.

Figure 18: Summary of the key findings - gender

The results show (Figure 18) that there is a clear need for promotion of joint ownership in accordance to the policy. A lot of people are not aware of this policy and especially the awareness and knowledge among the women of the communities need to increase. Interestingly most of the men do show agreement to a joint ownership but again a lack of knowledge hinders them to apply for it.

Realizing the importance of joint ownership to secure the access to and control over land and housing of both spouses, government has also brought the mandatory provision on this in a government led initiative. A joint ownership certificate is mandatory for the beneficiaries who will receive land purchase grants from the government or receive government land for relocation (NRA, 2015).

\footnotetext{
${ }^{3}$ There are several gender responsive provisions in the Financial Act 2072 BS (2015/16 AD) according to which women receive tax break from 25 - $50 \%$ depending on the geographical region, $35 \%$ in case of single woman, $25 \%$ in case of senior citizens above 70 year, and $50 \%$ while transferring land to daughters or grand-daughters within three generations. Joint land registration (husband and wives) can be done by paying NPR. 100 (Approx USD 1).
} 
Women are found to be more vulnerable than men before and in the post-earthquake context. Due to lack of their access to land, they are made more vulnerable in receiving the grant as earthquake victims. The findings confirm the importance of tenure security especially for women who are farming to sustain their livelihoods but also for children, elderly, persons with disabilities, the poor and marginalized groups.

In order to determine whether or not policy changes are needed, to support tenure security and increase the resilience of communities and individuals, the results of the case study areas are shared at all levels: community, regional nat. and int. level. The Nepalese government reacted responsibly to these findings, and developed a FFP LA strategy and also made changes on the requirements to access the reconstruction grants. Through advocacy and awareness, a change of regulation of NRA allowed nonholders of titles or ownership of land to receive land grants of USD 2.000 per HH. Further the NRA and land authorities are sensitised to provide support to identified landless and $\mathrm{HHs}$ without land documents. Applications for land grants or land documents from 62 landless HHs of Phulappa are under process with these authorities.

\subsection{Challenges and lessons learnt}

Different local dialects within the different case study areas are a challenge. The Nepalese enumerators who are trained have struggles to communicate with especially elderly people from the communities. This challenge is addressed through local field officers who supported the enumerators in the field and make sure that in all the $\mathrm{HHs}$ somebody is present who can participate in the enumeration. Though interestingly, the language barrier is not an issue for the visible boundary approach, as all the community members can immediately understand the task to identify their farmland. This language barrier could also be witnessed in other countries where FFP LA was applied. Therefore, the involvement of community leaders is essential.

After various expert group discussions, the decision for a paper-based approach is made due to commonly appearing power short cuts and due to limited computer literacy of community members. This decision has several consequences as e.g. the printing of the satellite image and digitalisation afterwards. This is a step, which could be avoided through a digital approach, but the local partners are well trained so that post georeferencing did not lead to a decrease in geometric accuracy.

Capacity needs should be addressed according to the situation therefore procedures and processes are tested many times before going in the field. This created confidence in the enumerators. Further it is important to give feedback and to create the opportunity for the enumerators to show that they are able to apply the knowledge 
gained in the field. All FFP LA applications imply capacity development based on the needs. In Nepal community members do the FFP LA recordation whereas in other FFP LA applications the recordation may involve governmental employees.

Having a strong local partner is crucial. The local partner HURADEC shows that they are capable of executing FFP LA and that the approach can be applied in other fields, like the STDM can be used in different contexts (public administration, health, schooling etc.). Further the involvement and participation of the community is based on the engagement and dedication of the local partner. Working with a strong local partner, governmental officials and also young people and women is key to the success of any FFP LA application.

\subsection{Conclusions and Recommendations}

Many land issues after the earthquakes are related to grant accessibility, resettlement processes, recognition of unrecorded tenure types, and disputes (landlord-tenant disputes). The growing demand for land and natural resources, and poorly developed land use planning, boosts the number of disputes. Hence, there is an urgent need to understand, as well as to discuss, an effective and efficient way to address land tenure issues in Nepal. This understanding and discussion is also relevant to the formulation and implementation of a National Land Policy.

Inclusive, participatory and transparent LA plays a leading role in DRM. The case study shows that vulnerable or at-risk groups are: children, elderly, persons with disabilities, women, the poor and marginalized groups and especially people affected by tenure security. Mapping these vulnerable groups based on their needs, priorities and marginalization vs. integration to implement interventions can be done during preparedness, planning, response and relief processes.

DRM policies have to be redirected towards tenure security, poverty and vulnerability reduction instead of merely compensation, resettlement and relief responses. Disaster management should integrate structural with non-structural measures such as increasing tenure security as a first act towards resilient communities. Especially disaster-prone communities should be engaged in the process of LA and disaster related decision making in order to increase the resilience of these communities. The case study proofs the importance of documenting all people-to-land relationships in order to prepare, mitigate and respond to natural disasters. Through the documentation of all people-to-land relationships efficient and effective land use planning can further mitigate disaster risks. Further a backup of all documents related to tenure needs to be 
stored safe so that the return to land, which is safe, is ensured and those documents can be used for an inclusive, participatory and transparent resettlement process.

The role of grassroot surveyors is imminent and can create a lot of potential, which can be utilised by governments to achieve complete coverage in their LA systems and so to be better prepared for natural disasters. In the aftermath of a natural disaster housing is a priority, as well as the need for building permits, the need for land documents, and the need for grants for all. By having a complete LA coverage creates opportunities to mitigate and prepare for disasters. This chapter proves that the approach works and that the link between LA and DRM is there - and addressing both benefits all people.

Finally, the application of a FFP LA approach for tenure security is well recognised in Nepal which is reflected by the initiation of STDM projects in Ratnanagar and Belaka Municipalities in 2019. The Ministry of Land Management, Cooperatives and Poverty Alleviation has expressed its interests to expand this approach further to other municipalities. Further the new land policy is dedicated to empower land-poor women and men, enabling them to claim and exercise their basic rights including the right to land resources, and contributing to eradicate poverty and injustice. Stakeholders at national, provincial and local level contributed to the new policy. The FFP LA approach is the foundation and catalyst in those developments. The majority of the land professionals within the government embraced the FFP LA approach. Together with land experts from government, academic sector and civil society a strategy document on FFP LA is drafted and launched in June 2018 (GLTN, 2018).

Interventions also led to the final integrated settlement plans (ISP) of Panipokhari and Jilu, and a preliminary plan of Bulungkhani. As a result of the interventions, additional to housing grants, governments investments for physical infrastructures in the two communities Jilu and Panipokhari are leveraged. 


\section{Chapter 5}

Global policy transfer for LA and DRM*

* This chapter is based on a draft ISI journal paper which is under review as;

Unger, E.-M., Bennett, R., Lemmen, C., de Zeeuw, C., Teo., C., \& Zevenbergen, J., (2019). Global

Policy Transfer for Land Administration and Disaster Risk Management. 


\subsection{Introduction}

According to (Dolowitz \& Marsh, 1996), the construct 'policy transfer' is:

"...the process by which actors borrow policies developed in one setting to develop programs and policies within another."

The concept gains importance at the global level, where politically and institutionally speaking, broad agreement exists in policies, goals, and indicators with regard to the achievement of global sustainability (UN, 2015). Methods for transferring the agenda to national level are a logical next step in the implementation of the 2030 Agenda for Sustainable Development and its seventeen Sustainable Development Goals (SDGs). The United Nations Committee of Experts on Global Geospatial Information Management (UN-GGIM) (UN-GGIM, 2019), was established by a resolution of the Economic and Social Council of the United Nations (ECOSOC), E/RES/2011/24, in July 2011 and comprised all Member States of the United Nations. ECOSOC adopted another resolution in 2016 entitled "Strengthening institutional arrangements on geospatial information management" (E/RES/2016/27) broadening and strengthening the mandate of the Committee of Experts as the relevant body on geospatial information consisting of government experts, and to report to ECOSOC on all matters relating to geography, geospatial information and related topics. UN-GGIM is the apex intergovernmental mechanism for making joint decisions and setting directions with regard to the production, availability and application of geospatial information within national and global policy frameworks. Led by Member States, UN-GGIM aims to address global challenges regarding the use of geospatial information, including in the development agendas and the wellbeing of people, planet, peace and prosperity, and to serve as a body for global policymaking in the field of geospatial information management. Within its programme of work is LA and management and DRM, which offers policy diffusion opportunities between DRM and LA, amongst others.

In 2016, plans for the Framework for Effective Land Administration (FELA) (UN-GGIM, 2018) and the Strategic Framework for Geospatial Information Services for Disasters (SFGISD) (WG GISD, 2017) were instigated. Both frameworks are driven by the SDGs (UN, 2015) and are developed through global consultation and agreement among Member States within the UN. The SFGISD builds from the Sendai Framework for Disaster Risk Reduction (2015-2030) (WCDRR, 2015) and aims to support the prevention of the human, socio-economic and environmental risks and impacts of disaster. Through the use of geospatial information and services, the FELA uses globally accepted concepts and approaches with a view to effectively and efficiently link people-to-land recognizing, documenting and recording people-to-land relationships in all their forms - and, in this 
way, securing land and property rights for all. A key benefit of the two frameworks is that they constitute important steps in creating shared understanding and knowledge in the creation and use of geospatial information for LA and DRM. The transfer of the policies could support better collaboration between institutions with increased interaction at global policy level as well as local level harmonization, and ultimately help to achieve the SDG ambitions.

This chapter seeks to assess the approaches being taken to transfer and diffuse the two frameworks established by UN-GGIM, specifically considering the policy creation processes, harmonization, and integration of local feedback loops. The key question focuses on whether the policy transfer is following the institutional or the network mode. First, the SFGISD and FELA frameworks are introduced in more detail. This is followed by an outline of the methodology explaining the action research approach adopted. Subsequently, adapted policy transfer assessment parameters, as described in the background, are applied to the two frameworks. The findings and the result of the assessment are shown in a table where an ample system indicates which mode is currently used for each parameter. Stemming from the results, the discussion section articulates potential strategies for enhancing and scaling up the policy transfer processes in regard to LA and DRM, preceding the conclusion and recommendations.

\subsection{Background}

\subsubsection{Overview of the frameworks}

Both the FELA and the SFGISD frameworks were developed based on an emerging need to address global issues supported by international consensus between Member States on the significance of geospatial information for sustainable development.

The UN-GGIM Expert Group on Land Administration and Management (EG-LAM) seeks to tackle the challenge that an estimated seventy percent of humanity do not enjoy recognized and secured land and property rights. There is a need to accelerate efforts by developing the FELA (UN-GGIM, 2018). The FELA promotes the documentation, recordation, and recognition of people-to-land relationships in all forms. The FELA further includes references to existing concepts, approaches and mechanisms, such as the Voluntary Guidelines on the Responsible Governance of Tenure of Land, Fisheries and Forests (VGGTs) in the Context of National Food Security (FAO, 2012), the continuum of land rights (UN-Habitat, 2008) and (Barry \& Augustinus, 2015), and the Land Governance Assessment Framework (Deininger, et al., 2012). The framework also considers standardization developments by international bodies such as the Land Administration Domain Model (LADM) (ISO, 2012) and defines a reference for the 
development, improvement and modernization of national and regional LA and land management systems.

On the other hand, the UN-GGIM Working Group on Geospatial Information and Services for Disasters (WG-GISD) developed the SFGISD (WG GISD, 2017) bringing together stakeholders and partners involved in Disaster Risk Reduction and/or Emergency Management that deal with geospatial information. It is based on the principles included in the Sendai Framework for Disaster Risk Reduction (2015-2030) (WCDRR, 2015) with a focus on geospatial information. The SFGISD aims for geospatial information and services to be available, at an appropriate level of quality, and accessible in a coordinated way, in support of decision making and operations prior, during and post-disaster, in order to formulate policies on and manage risks and impacts of disasters.

\subsubsection{The policy transfer challenge}

Two apparent challenges for global policy frameworks emerge:

1) awareness, feedback and minimization of fragmentation between institutions themselves at global, national, regional, as well as at the local levels; and

2) policy harmonization, alignment, and coordination across functional areas ${ }^{4}$.

On the first challenge, at local level (national, regional and community), within country contexts, targeted initiatives and tool applications seek to respond to local challenges and these may or may not be driven by, ( $n$ )or be linked to, global level policies and monitoring. Whilst (Antonio, et al., 2017) show that local initiatives in Kenya and Uganda can impact the policy level, the lessons of other local interventions often do not necessarily feedback into the policy development loop. Indeed, (Evans \& Yen, 2006) emphasize the importance of awareness raising and community feedback when it comes to the implementation of national policies. Hence, there lies the potential for local initiatives to benefit from globally developed policies, standards and tools - but, also for the global level to utilize the outputs, lessons, and data emanating from local projects for aggregation into national and global monitoring mechanisms.

On the second challenge, even within a thematic area, for example 'climate change', there exists the potential risk of different but related policies, from different functional areas, to overlap and or lack harmonization. For example, (Schipper \& Pelling, 2006) identify a redundant and sometimes conflicting policy response to climate change due

\footnotetext{
${ }^{4}$ Functional areas are considered disciplines, study areas, or domains constituted of practitioners, champions, standards, accrediting bodies, academic discourse, curricular, amongst other elements
} 
to non-developed coordination and to institutional overlap. This potential incongruence can confound decision making and intervention planned at global, national and local level.

One way to address both challenges can be through the consideration of 'policy transfer' theory, tools and initiatives (Dolowitz \& Marsh, 1996). Regarding the two investigated frameworks, FELA and SFGISD, policy transfer can be witnessed in various ways (Figure 19). (Stone, 2004) suggests the process of policy transfer is considered to include the transformation of frameworks into regional and national policies, which can occur horizontally or vertically. Whereas horizontal transfers occur between states or between functional areas within states, vertical transfers occur between states and international organizations. It is possible to learn from more than one jurisdiction at a time, and to take away a multiplicity of lessons, which leads to adaptive innovation to make policy development better fit to local conditions and communities. These horizontal and vertical policy transfer processes can also be witnessed in the assessment in this chapter and are graphically shown in Figure 19 indicated through arrows. Within this chapter the focus is primarily on the policy transfer of (a) FELA and SFGISD to national and regional laws and policies, and (b) the policy harmonization between FELA and SFGISD. The other transfers, indicated by the arrows, are also variously considered where they are seen to add to the discussion.

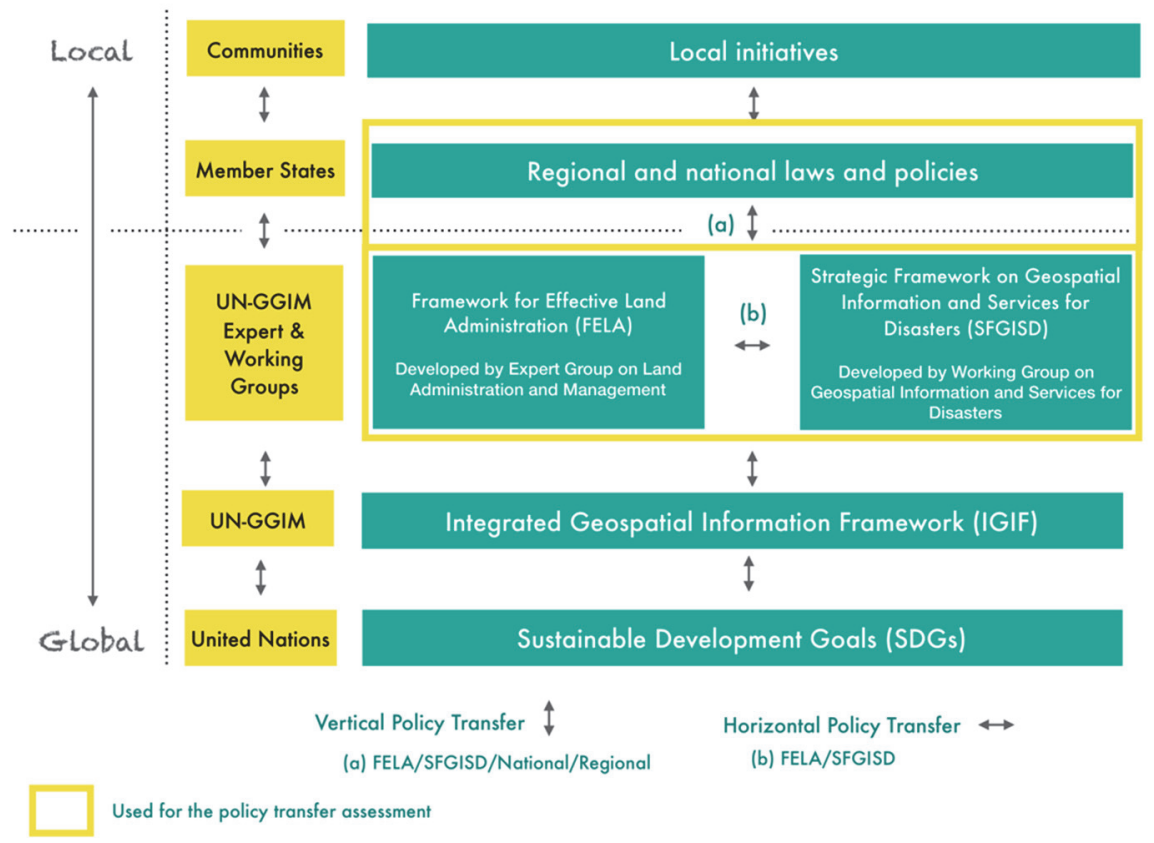

Figure 19: Policy transfer - local (national, regional and community) to global level 


\subsubsection{Background on policy transfer theories}

The above-mentioned challenges find scholarly roots in the concept of 'policy transfer'. The concept is defined by (Stone, 2004) and (Knill, 2005) as the transformation of policy frameworks into regional and national policies. The study area also examines how policies can be further implemented in the field, and how implementation lessons may feed back into the original policies.

The concept is part of a broader 'public policy' and 'public administration' study area and is also seen to incorporate concepts related to policy harmonization and policy diffusion. According to (Stone, 2004) policy diffusion describes a trend of successive or sequential adoption of a practice, policy or program or dispersion of models or practices from a common source or point of origin. Further diffusion patterns can emerge from, national networks, geographical proximity of neighbouring states, 'pioneer' states that lead the adoption of a policy, or national government exerting top-down influence according to (Berry \& Berry, 1999) as cited in (Stone, 2012).

Both 'policy diffusion' and 'policy transfer' share the assumption that governments do not learn about policy practices randomly, but rather through common affiliations, negotiations and institutional membership (Knill, 2005) and (Elkins \& Simmons, 2005). Those processes can be global, international and transnational sources of policy exchange informing state-to-state relations, as for example done by the UN.

When describing policy transfer terms such as 'harmonization', 'convergence' and 'divergence' are used. Whereas harmonization may be defined as making the regulatory requirements or governmental policies of different jurisdictions identical or at least more similar according to (Majone, 2014). Convergence places particular emphasis on effects, and not on processes as in policy transfer according to (Knill, 2005). According to (Stone, 2012), divergence can be drawn from negative lessons elsewhere, and those experiences contribute to active pursuit for counter or alternate policies.

(Ladi, 2011) differentiates 'hard' and 'soft' transfer. Officials are more involved in 'hard' transfer of policy practices and instruments involving formal decision-making, legislation and regulation. Whereas the 'soft' transfer of ideas and information via networks can be personal, professional or electronic and is proposed to be rapid and frequent, see also (Stone, 2012).

Going beyond broad definitions and generalizations, (Stone, 2004) identified three modes of policy transfer: 
1) ideational, which can be described as the transfer of ideas and ideologies. Those are difficult to map but can be distinguished, as they tend to be more input oriented for policy development, rather than for output;

2) institutional, which is the most familiar understanding of policy transfer and involves the creation of similar structures, or constitutional apparatus, and is led by organizations and institutions through processes of institutional isomorphism; and

3) networks, which includes transnational actors and structures such as global networks, international task forces and or commissions.

Policy transfer can occur in all three modes. Additional to the modes as introduced by Stone in 2004 and in a later article in 2012, the originally three modes, ideational, institution and networks changed into five modes (Stone, 2012). However, the original modes were considered detailed and robust enough to apply to the case at hand. The development's in Stone's models suggest that policy transfer is a dynamic study area, particularly driven by societal changes such as mass media, increasing political awareness and participation, and accessibility to information. Nevertheless, for the assessment in this chapter the two modes, institutional and network modes are used, as those are the most appropriate and applicable to assess policy transfer and diffusion of the two frameworks and the integration of local feedback loops.

Typically, the institutional mode finds footing with international organizations such as the UN, e.g. with its Committees of Experts. In this vein, UN-GGIM at a first look appears to be following the institutional mode, making use of consultation and dissemination among the UN Member States. The policy transfer assessment parameters as defined by Stone (2004) are, in an adapted version used to assess the policy transfer processes in this chapter.

\subsubsection{Putting it together}

The theoretical basis for the work at hand, is drawn around three overlapping study concepts, see Figure 20, indicated through numbers (1-7) in that figure and related explanations. The above-mentioned challenges and policy transfer solutions manifest themselves in the related knowledge domains of LA (1) and DRM (2). Contemporary research shows the interrelated effects of natural disaster on $L A$, and how the obstacles inherent to an ineffective LA have impact on DRM, before, during and after the specific event (Unger, et al., 2019a), (Mitchell, 2011) and flow, for example, into patterns of migration (Mitchell, et al., 2018). In response, (Mitchell, 2011) assesses and identifies ways to respond to land tenure issues in DRM. Likewise, other approaches investigate a conceptual link between LA and DRM, with a view to enhancing practice (Khezri, et al., 2018), (Potts, 2012) and (Rajabifard, et al., 2018). 
Going further, (Unger, et al., 2017) developed a conceptual framework (Figure 6), using constructs and terminology common to both domains, creating a shared viewpoint and language for analysing approaches that might better address the needs of the poor and vulnerable people living in disaster prone areas. The development of the conceptual framework reveals the importance of the availability of reliable data relating to natural disasters and land, and how integrated datasets, available to local communities and higher levels, could enhance both LA functions and also DRM processes. Within (Unger, et al., 2019a) the conversion of the conceptual framework into a data model, the $L A$ DRM model (3) (Figure 10) is shown. This model is aligned to an internationally agreed standard, the Land Administration Domain Model (LADM). A resultant application in Dolakha, Nepal reveals the benefits of applying tools and models to generate data to identify levels of tenure insecurity, gender related land issues, and vulnerability levels (Unger, et al., 2019b). The data and information gathered in Dolakha could be shared at community, regional level and be aggregated to national and global level. However, whilst (Unger, et al., 2019b) demonstrated the benefits of tool linkage within LA and DRM for a specific case, the broader introduced challenges in regard to policy transfer had until recently remained to be tackled.

Recent Global Policy (4) development and the establishment of the two frameworks FELA (5) and SFGISD (6), created an opportunity to assess the Policy Transfer (7) processes at various levels.

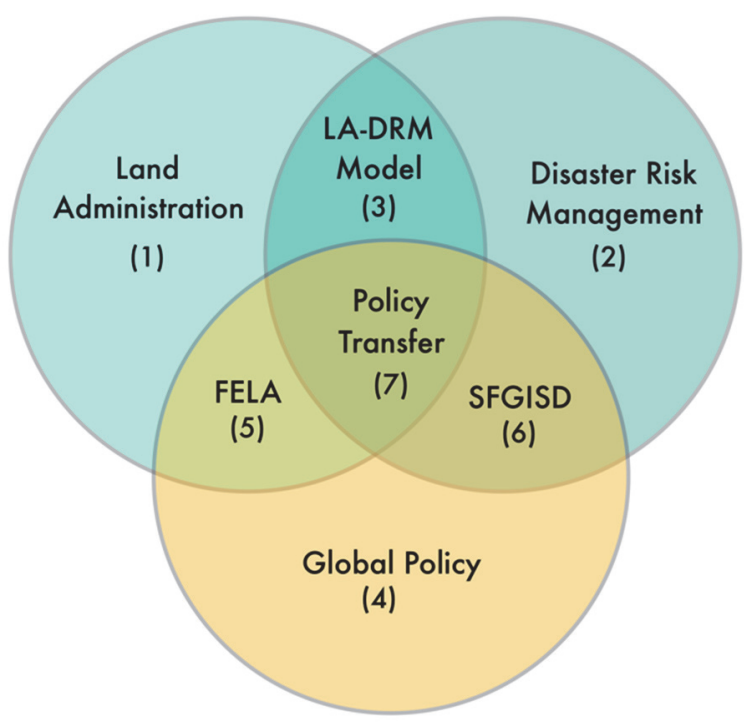

Figure 20: Research setting: LA - DRM - Global Policy 
Applying the experiences that five ${ }^{5}$ of the researchers gained first hand while participating in the development of the frameworks, supports the assessment of policy transfer at the global level and experiences from the application in the field supports the assessment of policy transfer at local level.

\subsection{Methodology}

In order to determine 'whether' policy transfer occurs, as per (Stone, 2004), several policy transfer assessment parameters were concentrated upon: i) 'who' are the transfer agents; ii) 'what' policy is transferred; iii) 'how' is the policy transferred; iv) 'where and when' does transfer occur, v) 'why' and 'why not' is the policy transferred. This led to an assessment of 'which' mode of transfer - institutional or network - was being adopted, with regards to the transfers described as being (a) between governance layers and (b) between functional areas (Figure 19).

To provide data to support the application of Stone's (2004) assessment parameters, an 'action research' inspired approach was adopted, whereby the concept of 'reflexivity' was considered central. According to (Reason \& Bradbury, 2008), action research is: "... a participatory process concerned with developing practical knowing in the pursuit of worthwhile human purposes. It seeks to bring together action and reflection, theory and practice, in participation with others, in the pursuit of practical solutions to issues of pressing concern to people, and more generally the flourishing of individual persons and their communities". Within (Reason \& Bradbury, 2008) 'reflexivity' in action research is about reflecting on the researcher's power to perceive, interpret and communicate about their research participants. As shown in (Stringer, 2008), who undertook action research relating to policy development in East Timor, the methodology was central at each stage of the policy development. Several consultations with various stakeholders were conducted and fed into the action plans that emerged to the developmental process, based on the reflexivity principle.

For this chapter, the concept is relevant as five of the researchers were both observers and subjects in the work undertaken, during the development of the two policy frameworks. The action research approach was used because the researchers of this chapter and the authors of the researched frameworks share their knowledge as equals, which is a basic principle according to (Swantz, 2008). Both frameworks were developed under various consultation processes since 2016, which then feed back into the frameworks. The researchers are actively involved in the development of the frameworks and are also undertaking this and related research. The researchers and

\footnotetext{
${ }^{5}$ Unger, Bennett, Lemmen, de Zeeuw and Teo
} 
their associated institutions are participating in the Expert/Working Group meetings, workshops and seminars during those the frameworks are developed.

Specifically, the development of the FELA and SFGISD framework can be assessed in terms of policy transfer and diffusion between them and the integration of feedback loops from local levels. Therefore, this research assesses which mode the policy transfer on various levels is following and subsequently discussing the implications in regard of the two issues.

(Stone, 2004), introduces three different modes - however, only the institutional and network mode were considered in this work: the ideational approach was considered outside the scope of the work due to what was already known about the policy development process prior to undertaking the analytical work. Overall, the policy transfer assessment parameters plot how policy transfer mechanisms can differ between different modes. The assessment parameters utilize a core set of questions and broad answers under each transfer mode, aimed at enabling readers to better understand the form of that particular mode as shown in Figure 21.

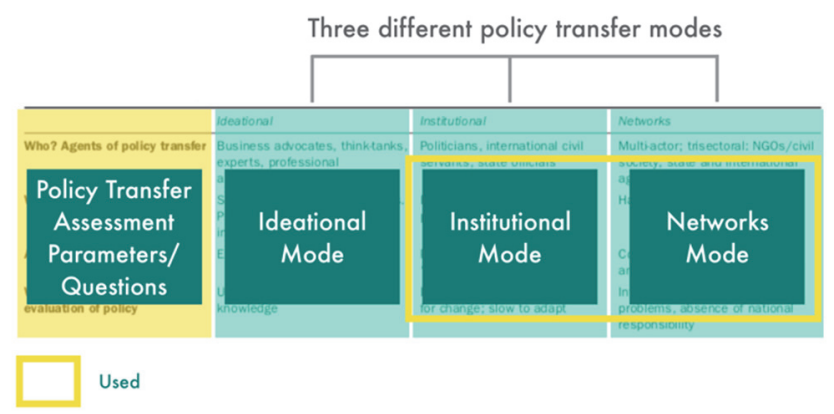

Figure 21: Assessment parameters and modes adapted from (Stone, 2004)

The proposed assessment parameters were considered the most appropriate for analysing the policy transfer mode because they represent consistency between the assessment objectives and the chosen methodology. Further the number of policy assessment frameworks with clear structured assessment parameters is limited and others as, for example, in (Dabrowski, et al., 2018) seemed less correspondent to the research objectives. The use of the policy transfer assessment parameters as a means to assess specific case applications in the LA and spatial domain is justified through similar research related to policy development. Within the domain of $L A$, the usage of the policy transfer assessment parameters developed by (Stone, 2004) is new, but, similar approaches can be found in literature for example in various Spatial Data Infrastructure (SDI) literature such as (Rajabifard, 2002) where diffusion of regional SDI is discussed but also in others as for example (Cho \& Crompvoets, 2018). In more recent 
research according to (Crompvoets, et al., 2009) SDI-assessment will become a performance focus for public management and policy. (Bennett, et al., 2012) investigate how global drivers, in addition to others, can drive the development and upgrade national LA infrastructures, specifically the creation of data and services relating to land tenure, use, value, and development.

The assessment uses a table representation to underline the result (Table 3).

Table 3: Policy transfer assessment questions and modes adapted from (Stone,2004)

\begin{tabular}{|c|c|c|c|}
\hline \multirow[t]{2}{*}{ Parameters } & \multirow[t]{2}{*}{ Assessment Questions } & \multicolumn{2}{|c|}{ Mode } \\
\hline & & Institutional & Network \\
\hline \multirow{2}{*}{$\begin{array}{l}\text { Transfer } \\
\text { Agents } \\
\text { (Who?) }\end{array}$} & $\begin{array}{l}\text { Who are the agents of } \\
\text { policy transfer? }\end{array}$ & $\begin{array}{l}\text { politicians, international civil } \\
\text { servants, state officials }\end{array}$ & $\begin{array}{l}\text { Multi-actor, NGOs/civil society, } \\
\text { state and international agencies, } \\
\text { business }\end{array}$ \\
\hline & $\begin{array}{l}\text { What is their authority } \\
\text { basis? }\end{array}$ & Political/bureaucratic, 'de jure' & $\begin{array}{l}\text { Collective: pooled responsibility } \\
\text { among 'stakeholders', 'de facto' }\end{array}$ \\
\hline \multirow{3}{*}{$\begin{array}{l}\text { Transfer } \\
\text { Content } \\
\text { (What?) }\end{array}$} & What is transferred? & $\begin{array}{l}\text { Hard: instruments, legislation, } \\
\text { policy approaches }\end{array}$ & Hard and soft \\
\hline & $\begin{array}{l}\text { Where are the lessons } \\
\text { taken from? }\end{array}$ & $\begin{array}{l}\text { Dominant institutions, } \\
\text { psychologically proximate } \\
\text { jurisdictions }\end{array}$ & $\begin{array}{l}\text { Experience of network } \\
\text { members, i.e. network bounded } \\
\text { rationality }\end{array}$ \\
\hline & $\begin{array}{l}\text { Which languages were } \\
\text { used where? }\end{array}$ & $\begin{array}{l}\text { Diffusion, mimetic } \\
\text { isomorphism }\end{array}$ & Collective action, multilateralism \\
\hline \multirow{3}{*}{$\begin{array}{l}\text { Transfer } \\
\text { Process } \\
\text { (How?) }\end{array}$} & $\begin{array}{l}\text { How is change } \\
\text { imposed? }\end{array}$ & Structural power & Network power \\
\hline & $\begin{array}{l}\text { How is the policy } \\
\text { searched for } \\
\text { (character)? }\end{array}$ & Path dependent, incremental & $\begin{array}{l}\text { Problem-solving, organic } \\
\text { (initially) as goals are unclear }\end{array}$ \\
\hline & $\begin{array}{l}\text { Which mechanisms } \\
\text { were used? }\end{array}$ & $\begin{array}{l}\text { Legislation, regulation, } \\
\text { standards setting, aid } \\
\text { conditionality }\end{array}$ & $\begin{array}{l}\text { Partnerships, alliances for } \\
\text { implementation }\end{array}$ \\
\hline \multirow{3}{*}{$\begin{array}{c}\text { Transfer } \\
\text { Outputs } \\
\text { (Where and } \\
\text { When?) }\end{array}$} & $\begin{array}{l}\text { Where are the policy } \\
\text { lessons realized? }\end{array}$ & $\begin{array}{l}\text { Decision-making, resource } \\
\text { allocation, implementation }\end{array}$ & $\begin{array}{l}\text { Implementation, service delivery } \\
\text { and monitoring }\end{array}$ \\
\hline & $\begin{array}{l}\text { How is change enacted } \\
\text { by users? (voluntarily) }\end{array}$ & Rules and regulations & $\begin{array}{l}\text { Organized anarchy, trial and } \\
\text { error }\end{array}$ \\
\hline & $\begin{array}{l}\text { Where are the lessons } \\
\text { applied/implemented? }\end{array}$ & $\begin{array}{l}\text { In nation-states, multilateral } \\
\text { venues }\end{array}$ & $\begin{array}{l}\text { Between and above states, } \\
\text { transnationally via networks }\end{array}$ \\
\hline \multirow{3}{*}{$\begin{array}{l}\text { Transfer } \\
\text { Outcomes } \\
\text { (Why?) }\end{array}$} & $\begin{array}{l}\text { What factors prompt } \\
\text { the re-evaluation of } \\
\text { policy? }\end{array}$ & $\begin{array}{l}\text { Institutions refract pressures } \\
\text { for change, slow to adapt }\end{array}$ & $\begin{array}{l}\text { Intractable cross-border policy } \\
\text { problems, absence of national } \\
\text { responsibility }\end{array}$ \\
\hline & $\begin{array}{l}\text { Which outcomes are } \\
\text { aimed to be achieved? }\end{array}$ & $\begin{array}{l}\text { Harmonization, convergence } \\
\text { and divergence }\end{array}$ & $\begin{array}{l}\text { Shared identity and common } \\
\text { preference through action }\end{array}$ \\
\hline & $\begin{array}{l}\text { Which outcomes were } \\
\text { imposed? }\end{array}$ & $\begin{array}{l}\text { Penetration and resistance, } \\
\text { divergent outcomes }\end{array}$ & $\begin{array}{l}\text { Lack of recognition of network } \\
\text { authority }\end{array}$ \\
\hline \multirow{3}{*}{$\begin{array}{l}\text { Transfer } \\
\text { Limitations } \\
\text { (Why Not?) }\end{array}$} & $\begin{array}{l}\text { What might prevent } \\
\text { policy transfer? }\end{array}$ & Lack of institutional 'fit' & $\begin{array}{l}\text { Lack of shared vision, network } \\
\text { disunion }\end{array}$ \\
\hline & $\begin{array}{l}\text { What might undermine } \\
\text { nation-state } \\
\text { convergence? }\end{array}$ & $\begin{array}{l}\text { Exogenous pressures on the } \\
\text { political economy }\end{array}$ & $\begin{array}{l}\text { Networks shape the search } \\
\text { process and constrain } \\
\text { implementation cross-nationally }\end{array}$ \\
\hline & $\begin{array}{l}\text { What might be reasons } \\
\text { for divergence? }\end{array}$ & $\begin{array}{l}\text { Internal determinants, e.g. } \\
\text { bureaucratic resistance }\end{array}$ & $\begin{array}{l}\text { Absence of coordinating and } \\
\text { consensus-making in networks }\end{array}$ \\
\hline
\end{tabular}


Limitations of the applied method including data utilized need to be outlined. First, Stone's (2004) assessment parameters require adaptation in order to ensure phrases and questions were complete enough to apply to the case at hand. This involved adjustment, rephrasing and reshuffling of the assessment parameters according to the researchers' expertise, which necessarily introduces a level of bias to the assessment parameters. Other limitations include incompleteness of FELA as still being under development, limited data sources as country implementations of the SFGISD is ongoing, lack of recorded information on the development process as a lot of consultation are happening during meetings and workshops in discussions which are not documented and only partly reflected in the summary reports.

\subsection{Assessment}

The determination of the six assessment parameters used in the policy transfer: 'who' Transfer Agents, 'what' - Content, 'how' - Process, 'where and when' - Outputs, 'why' Outcomes and 'Why Not' - Limitations, are presented in Table 3. Each of the assessment parameters are first explained, related questions are outlined and then applied for the two frameworks with respect to the policy transfer occurring at (a) between governance layers and or (b) between functional areas as shown in Figure 19.

\subsubsection{Transfer agents}

Transfer agents refers to ' $w h o$ ' and is about the individuals, networks and organizations involved in the policy transfer. According to (Stone, 2004) key actors are historically international organizations and non-state actors such as non-governmental organizations (NGOs) but also increasingly less 'traditional' actors such as think-tanks, consultant firms and other cooperate businesses. (Keck \& Sikkink, 1998) as cited in (Stone, 2004) further highlight the considerable agenda-setting influence of these nonstate actors in some contexts. Meanwhile, the subordinate concept 'authority basis' referring to 'what' is the so called 'steering capacity' (Kern et al., 2001) of the transfer agents. It differentiates whether the rules and regulations are set in a political/bureaucratic environment or in a more networked environment, where responsibility is pooled amongst stakeholders. The authority basis is dependent on whether the policy is driven by national rules and regulations. If this is the case, then it can be clearly categorized into the institutional mode. If the policy is driven by a social movement or more economically driven, resulting in conversion of practice and field work approaches into guidelines, instead of rules and regulations, then the transferred policies can be categorized into the network mode.

With regards to the policy transfer (a) and (b), for FELA and SFGISD, the definable transfer agents are the members of the WG-GISD and the EG-LAM. These groups focus 
on progressing the work items as defined in the Workplans of the Expert/Working groups and following up decisions adopted the annual UN-GGIM session (UN-GGIM, 2019). The Expert/Working group composed of experts from Member States, international organizations, international geospatial societies, academia, private sector and United Nations system. The memberships are dominated by expert representatives representing Member States with due consideration for broad geographical representation and development context. Within the EG-LAM, some limited networks are also represented including the Global Land Tool Network (GLTN) (facilitated by UNHabitat), international geospatial societies including the International Federation of Surveyors (FIG), and corporate members, for example Esri, are represented. The members of the Expert/Working group are in this sense the transfer agents. Under UNGGIM Rules of Procedures ${ }^{6}$, the decisions of its annual session are made by a majority of the representatives present and voting when adopting or endorsing developed polices. Though it has been observed that decisions have all been unanimous: policy transfer at (a) is then realized through the member states participating in UN-GGIM. The annual session takes place in the UN Headquarters in New York and so far, UN-GGIM held eight sessions. In terms of the authority basis, referring to policy transfer (a), this appears in a more conventional nation-state transfer, utilizing political/bureaucratic structures, that can be described as 'de jure' in the institutional mode. That said, the consultation involves some characteristics of the network mode, where policy transfer is driven in a collective and multilateralism approach. This is particularly the case for policy transfer (b). Within the EG-LAM, the GLTN, participates in the consultation, but still the policy transfer and endorsement for the FELA occurs primarily through governmental institutions at national level (a). Also, within the SFGISD it is recommended to include the role of geospatial information and services in DRM in national laws on SDI. Overall, for both frameworks the policy transfer is considered to be institutional rather than networked: participation outside of the UN-GGIM members is limited.

\subsubsection{Transfer content}

Transfer content refers to 'what' is transferred, which can be considered the distinction between so-called 'soft' or 'hard' policy transfer. Another part of the transfer content is 'where' are the lessons taken from, which describes if the lessons are taken from field experiences which is an indicator that the transfer content is related to the network mode. On the other hand, if the lessons are taken from jurisdictions that would describe a typical institutional mode. Another element of transfer content is 'which' languages were used and where. The institutional mode, for example, promotes a mimetic

${ }^{6}$ http://ggim.un.org/meetings/GGIM-committee/8th-Session/documents/E_C.20_2018_3Rules_of_procedure.pdf 
isomorphism which appears through common ontology (Knill, 2005). Further, the institutional mode promotes the existence of longstanding, often historical based legacies that are embedded economically, socially and culturally (Stone, 2004) - whereas the network mode relates more to a collective action.

Within both policy frameworks, hard policy transfer is proposed but since other stakeholders, for example, corporate members, networks and academia also participate in the Working/Expert group, instruments from the network mode are also applied. Members of the EG-LAM are involved in the development of the LADM standard (ISO, 2012). Within FELA, standards are mentioned as a recommendation to address interoperability, but are not described as a necessity or as being mandatory. The two frameworks investigated are, in their core, strongly institutional. However, within the consultation of, for example FELA, lessons learnt from the field and presented in workshops and seminars in September 2018 in Deqing, China - assisted the transfer at both (a) and (b): through global consultation, inclusion of cooperate members and network activities, field experiences gained traction in the policies. In regard to the language used, for both investigated frameworks, a formal language common to UN institutions and documents is used. The frameworks are built on already approved, existing and validated guidelines and principles. This again suggests the institutional modality is applied for both FELA and SFGISD. Overall, for transfer content, it can be concluded that the two investigated frameworks, and the two policy transfers (a) and (b), lie in between the institutional and the network modes.

\subsubsection{Transfer process}

Transfer process refers to 'how' the policy transfer imposes change. According to (Stone, 2004), that can be either through structural power for the institutional mode, or through network power for the network mode. Further, it is about 'how' the policy was identified or searched for. If the policy was established in an incremental and path dependent way this suggests the institutional mode is at play. Whereas, the network mode would describe an organic (initial) approach, where the goals would be unknown up front, and the process would be more problem-solving oriented. Finally, transfer process also refers to 'which' mechanism is used for the policy transfer. The institutional mode promotes a legislative and standard setting approach, whereas the network mode promotes alliances for implementations. According to (Stone, 2012), 'think tanks' are a typical mechanism for the network mode.

Since both the FELA and SFGISD frameworks are strongly orientated in the institutional mode, it can be expected that the change is imposed through structural power (a). The endorsement of global frameworks such as the FELA and the SFGISD, which were 
developed through the United Nations inter-governmental mechanism, is neither rigid nor imperative, but can be relevant and useful as a basis or a reference for country-level policy formulation, program design and implementation. For both frameworks, the character of search is path dependent as both policies are based on the IGIF, itself driven by clear goals, closely linked to the SDGs, suggesting both FELA and SFGISD policy development and later transfer are associated towards the institutional mode. The mechanism they are promoting appears to be focused on legislation, regulation, policies, and standards for (a) and (b). But through the participation of related domains, corporate members and networks, there is a tendency towards the network mode. Regarding the transfer process it can be concluded that the two investigated frameworks are in between the institutional and the network mode.

\subsubsection{Transfer outputs}

Transfer outputs refer to 'where' are the policy lessons realized, which for the institutional mode, may be either nation-states or at multilateral venues, or for the network mode between and above states, or transnationally. It also refers to ' $h o w$ ' the change is enacted by the users which can be either through rules and regulations for the institutional mode, or through trial and error, which would be an indicator for the network mode. Further transfer outputs referring to 'where' are the lessons applied and implemented. This can either be through decision-making and resource allocation for the institutional mode, or as described in (Hall, 1993), through the development of new institutions. Further, 'implementation' through service delivery systems and monitoring mechanisms are indicators that the network mode is applied. As for example, the Kyoto protocol (UNFCCC, 2008) represents a full institutional mode in regard to policy transfer output, whilst the VGGTs (FAO, 2012) appear to be more of a network mode.

In terms of FELA and SFGISD policy transfer and the relationship with local levels (a), the outputs of a case study conducted in Dolakha, Nepal, and how they interacted with FELA is worth examination. The case study conducted in 2017/2018 recorded around 1800 spatial units and aimed to support the Nepalese government in their draft of a National Land Policy, by conducting a FFP LA in an earthquake affected region (Unger, et al., 2019c). The case study tackled both LA and DRM measures. The lessons learnt provided the Nepalese land agencies with a summary of the challenges rural communities faced in the aftermath of the disaster. In addition, the results showed the link between security of tenure, vulnerability, exposure and hazard of natural disasters, by assessing and analysing the collected information on tenure and basic household economy. The result also informed the current development of the National Land Policy and also fed into global policy discourse via UN-Habitat (GLTN, 2018). Subsequently, these findings fed into the discourse and development of FELA and SFGISD during their development 
phases in 2018/19. This implementation can be seen as a good example where policy transfer was happening between global to national to community levels (a).

Overall, in terms of transfer outputs, the two policy framework transfers investigated tend towards the institutional mode. Despite practical demonstrators and trials, the aims of FELA and SFGISD are not to build software and/or provide service delivery and monitoring mechanisms. The frameworks are seen to be guiding principles which can be followed by member states (a) in the development of national policies and regulations. Change through the application/implementation of the policy frameworks will be enacted voluntarily, as Member States sign up or endorse the frameworks. In contrast, with regard to the enacting 'power', the two frameworks tend towards the network mode, since they are not promoting rigid rules and regulations, but promote flexible approaches. Though UN-GGIM is an inter-governmental mechanism, within its construct are four networks, namely academic, geospatial societies, private sector and UN system, thus affording a multi-stakeholder setting in its workings. Nevertheless, the implementation of both frameworks will be seen in or via nation-states and multilateral venues, instead of transnational via networks.

\subsubsection{Transfer outcomes}

Transfer outcomes refer to 'what' factors prompted the initial re-evaluation of policies (i.e. what societal outcomes were the transfer agents looking to change), and accordingly whether those are achieved. Factors that can prompt a re-evaluation from the network mode are cross-border policy problems or the absence of a national responsibility according to (Stone, 2004). Further, transfer outcomes refer to 'which' outcomes are aimed for. For the institutional mode, these could be either harmonization, convergence or divergence of policies. Regarding the network mode, these could be a shared identity through shared actions during policy implementation. Finally, transfer outcomes also refer to 'which' outcomes are imposed and 'why'. Within the network mode outcomes are imposed when there is, for example, a lack of recognition of the network authority, or for the institutional mode, for example when there is institutional resistance and divergent outcomes.

In terms of (a) and (b) policy transfer outcomes in relation to 'what' factors prompted the initial re-evaluation of policies, the development of the two policy frameworks were driven by emerging global issues as described in (Unger, et al., 2017), both with a significant geospatial component, and both of which partly address cross-border issues such as natural disasters or tenure security when it comes to migration. Cross-border policy problems, manifest in (a), are described as typical network mode drivers, but the national responsibility for the issues which are addressed by the two frameworks, 
natural disasters or tenure security, are governed by national bodies and agencies (i.e. the institutional mode). Though through the participation of corporate members and network institutions in the UN-GGIM Expert/Working group, it can be argued that both frameworks cannot be clearly categorized into either the institutional or network mode in terms of policy outcomes, but the policy transfer approach does appear to lean more to institutional. The aimed outcomes of both frameworks are very similar: both have typical institutional aims (a) such as alignment of policies amongst government bodies and supportive agencies. Alignment efforts in regard to FELA and SFGISD (b) can further be justified through cross boundary effects of both the impacts and economic loss of natural disasters and an inefficient LA system. 'Which' imposed outcomes could be for (a) national laws, rules and regulations, but in this case the imposed outcomes cannot be named directly for both frameworks. But what could be shown through the development of both frameworks is that the negotiation process is key when it comes to the endorsement of such policies. Regarding the transfer outcome it can be concluded that the two investigated frameworks are in between the institutional and the network mode.

\subsubsection{Transfer limitations}

Transfer limitations refer to 'what' might prevent the policy transfer. For the institutional mode, this could be a lack of institutional 'fit'. For the network mode, this might be a lack of shared vision amongst stakeholders. According to (Stone, 2004), further it refers to 'what' might undermine nation-state convergence which can either be an exogenous pressure on the political economy for the institutional mode. Also, it refers to 'what' might be reasons for divergence which can be for the institutional mode, internal determinants as for example, bureaucratic resistance. Regarding the network mode it could be an absence of coordinating and consensus-making in networks.

Regarding the FELA, limitations which can prevent the policy transfer and undermine nation-state convergence (a) appears inherent in the institutions governing and delivering LA. As seen in the FFP LA approach, bureaucratic resistance was formed not because of a lack of a shared vision, but because of internal determinants and vested interests. Comparative analysis on the thematic themes reveals that the transfer limitations cannot be put down to differences between the two investigated frameworks (b) i.e. a lack of alignment. 


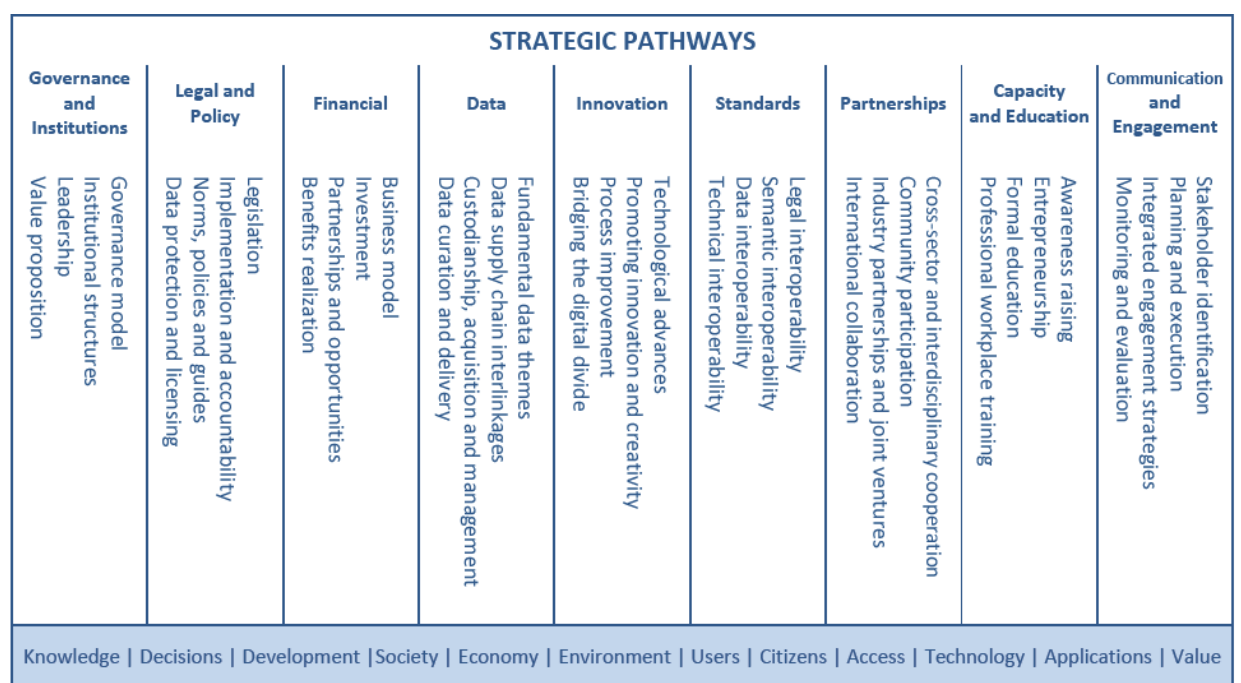

Figure 22: The nine strategic pathways of the IGIF source (UN-GGIM, 2018)

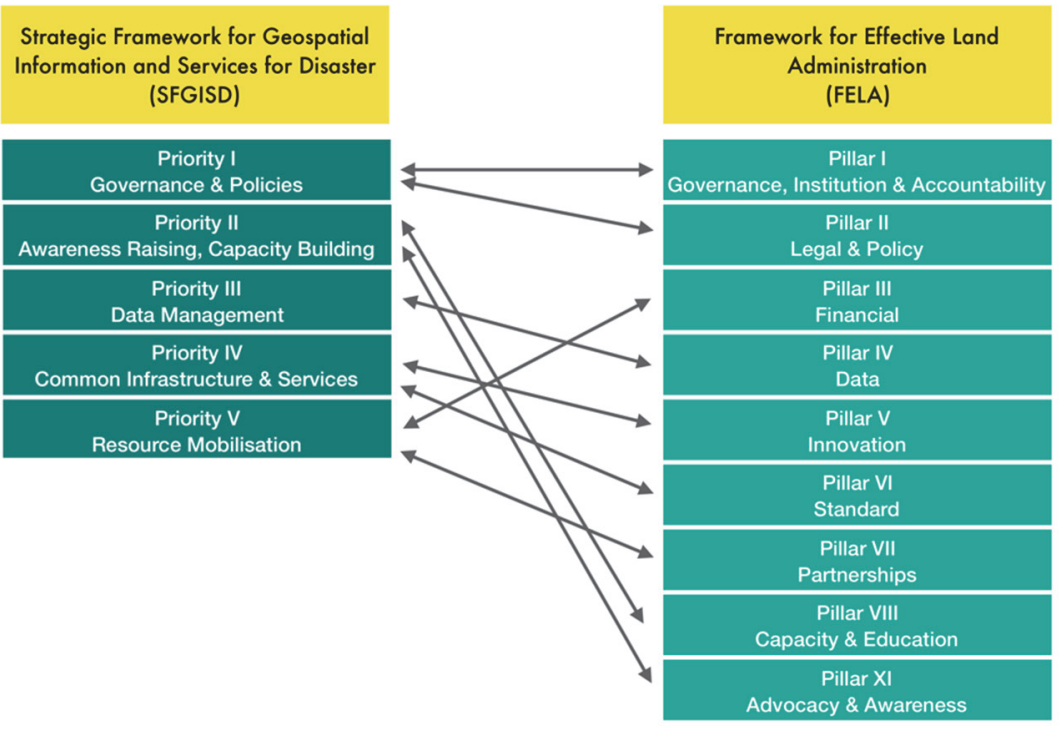

Figure 23: Alignment between SFGISD and FELA

Both frameworks are clearly and necessarily based on the United Nations Integrated Geospatial Information Framework (IGIF) (UN-GGIM, 2018) (Figure 22), and when merging/aligning those as shown in Figure 23, it is clear that the priorities as defined in the SFGSID align with the pillars ${ }^{7}$ as defined in the FELA. Further exogenous pressure, as

7 renamed to strategic pathways in the latest version of FELA (June 2019) 
for example the achievement of the SDGs, is stated as an indicator for the institutional mode. Another exogenous pressure caused through natural disasters is the economic loss experienced by countries. Current investigation shows that both frameworks are more leaned towards the institutional mode which could bring the above-mentioned limitations.

The findings and the result of the assessment is viewed in Table 4 where an ample system indicates which mode is currently used for each parameter. This assessment is relevant to discuss the transfer and diffusion of the two frameworks and its integration of local feedback loops.

Table 4: Policy transfer assessment parameters adapted from (Stone, 2004)

\begin{tabular}{|c|c|c|c|}
\hline \multirow[t]{2}{*}{$\begin{array}{l}\text { Assessment } \\
\text { Parameters }\end{array}$} & \multirow[t]{2}{*}{ Assessment Questions } & \multicolumn{2}{|c|}{$\begin{array}{l}\text { Mode (i.e. institutional vs } \\
\text { network) }\end{array}$} \\
\hline & & FELA & SFGISD \\
\hline $\begin{array}{l}\text { Transfer Agents } \\
\text { (Who?) }\end{array}$ & $\begin{array}{l}\text { Who are the agents of policy transfer? } \\
\text { What is their authority basis? }\end{array}$ & Inst & Inst \\
\hline $\begin{array}{l}\text { Transfer } \\
\text { Content } \\
\text { (What?) }\end{array}$ & $\begin{array}{l}\text { What is transferred? } \\
\text { Where are the lessons taken from? } \\
\text { Which languages were used where? }\end{array}$ & $\begin{array}{l}\text { Inst/ } \\
\text { Network }\end{array}$ & $\begin{array}{l}\text { Inst/ } \\
\text { Network }\end{array}$ \\
\hline $\begin{array}{l}\text { Transfer } \\
\text { Process } \\
\text { (How?) }\end{array}$ & $\begin{array}{l}\text { How is change imposed? } \\
\text { How is the policy searched for (character)? } \\
\text { Which mechanisms were used? }\end{array}$ & $\begin{array}{l}\text { Inst/ } \\
\text { Network }\end{array}$ & $\begin{array}{l}\text { Inst/ } \\
\text { Network }\end{array}$ \\
\hline $\begin{array}{c}\text { Transfer } \\
\text { Outputs } \\
\text { (Where and } \\
\text { When?) }\end{array}$ & $\begin{array}{l}\text { Where are the policy lessons realized? } \\
\text { How is change enacted by users? (voluntarily) } \\
\text { Where are the lessons applied/implemented? }\end{array}$ & Inst & Inst \\
\hline $\begin{array}{l}\text { Transfer } \\
\text { Outcomes } \\
\text { (Why?) }\end{array}$ & $\begin{array}{l}\text { What factors prompt the re-evaluation of policy? } \\
\text { Which outcomes are aimed to be achieved? } \\
\text { Which outcomes were imposed? }\end{array}$ & $\begin{array}{l}\text { Inst/ } \\
\text { Network }\end{array}$ & $\begin{array}{l}\text { Inst/ } \\
\text { Network }\end{array}$ \\
\hline $\begin{array}{l}\text { Transfer } \\
\text { Limitations } \\
\text { (Why Not?) }\end{array}$ & $\begin{array}{l}\text { What might prevent policy transfer? } \\
\text { What might undermine nation-state convergence? } \\
\text { What might be reasons for divergence? }\end{array}$ & Inst & Inst \\
\hline
\end{tabular}

\subsection{Discussion}

This section is built around the results in terms of

1) the initial issues as identified at the beginning of the chapter, namely policy transfer and diffusion between the two policies, FELA and SFGISD, (b) and the integration of feedback loops from local levels (a);

2) confirming the extent of usage for the two modes identified (institutional or network);

3) considering the relative strengths, limitations and obstacles of those approaches in the context of LA and DRM; and 
4) strengthening the relevance of policy transfer assessment generally in the LA and DRM domains.

\section{1) Referring to the two initial issues:}

i. awareness, minimization of fragmentation, and feedback between institutions themselves as well as to the local levels (a); and

ii. policy harmonization, alignment, and coordination across functional areas (b) several points can be made.

- First, UN-GGIM through the inclusion of both DRM and LA functions assists in policy harmonization: transfer agents and experts from the different functions are part of the same setting. Through a combined and coordinated policy transfer, by transfer agents, FELA and SFGISD implementation at national level can be harmonized, with less chance of conflicting and overlapping policies and institutions. Transfer agents, as represented by the Working/Expert group members, both at global and national levels, are imperative for scaling up efforts.

- Second, through the utilization of standards, a common language and harmonized ideas and approaches between institutions, shared in the transfer content, can minimize fragmentation and ensure the feedback loop in policy development. Further harmonized transfer content can support nation-nation cooperation and in case of a natural disaster support response and relief efforts.

- Third, through the inclusion of local initiatives, which are realizing the FELA and SFGISD at local level, in global policy development and monitoring processes the transfer process and outputs enable a mutual understanding between institutions and local levels. This can be especially relevant for the realization and monitoring processes for the SDGs. Transfer outputs and lessons learnt from local projects can be imperative when developing policies.

- Fourth, through sharing the transfer outcome with and between institutions, but also at local levels, awareness and an understanding of global issues can be raised. This further support scaling up efforts in promoting the importance of tenure security as mitigation measure to increase the resilience towards the impacts of natural disasters.

- Finally, transfer limitations can occur through rigid rules and regulations and in silo institutional settings. Across functional areas these can be addressed through harmonization and alignment at an early stage in policy/framework development. 


\section{2) Confirming the extent of usage for the two modes identified (institutional or network)}

Using Stone's (2004) assessment parameters, it is apparent that a more conventional 'institutional' approach to policy transfer is being applied - for both the development of the global policies (i.e. FELA and SFGISD), and the dissemination of those to national and local levels. Albeit, some evidence for a network approach is evident. A caveat here is that the policies are still being developed (in the case of FELA) or at early stage of implementation (in the case of SFGISD), and in particular, outputs and outcomes of those transfers may reveal more evidence that a networked approach is being sought.

\section{3) Considering the relative strengths, limitations and obstacles of those approaches in the context of LA and DRM}

In terms of justifications for the institutional approach, the two frameworks are developed and intended for technical domains, those typically comfortable to the development of an adherence to technical standards, regulation, and even legislation. On the other hand, more recently successful policy transfers, at least in terms of policy development, the SDGs for example, were heavily driven by network modalities - albeit with obvious alignment to some of the institutional elements. The negotiations around the development of the SDGs were multidisciplinary and inclusive, that has at least led to widespread awareness and consideration in Western contexts. Indeed, in general, policy transfer research points to put more of an emphasis on the network approach driven by technological and social developments. It is the authors view that policy transfer is more likely to be achieved through policy transfer following the network mode, at least in the contemporary era. In general, this would suggest there is opportunity for UN-GGIM, with better participation from its networks, to move towards more of a network approach.

Depending on the mode different obstacles for the success of policy transfer need to be taken into account. One obstacle could be, the institutional memory, which is described according to (Marsh \& Evans, 2012) as the process where jurisdictions do, or do not, learn from their own past, which can influence the policy transfer. This obstacle can occur especially in countries with a long history of LA processes and in countries where DRM is well established. This can be addressed through policy harmonization including all stakeholders. Further as described in (Drezner, 2005) it is believed that regulatory harmonization at global level will be increasingly difficult over time with the ongoing growth of for example, India and China. This is justified through a globalizing economy, whereas governments who are possessing large internal markets are seen as important 
factors contributing to regulatory convergence. Further through the development and dissemination of guidelines and best practices policy coherence can be achieved which is described in (OECD, 2016) to support policies for sustainable development. Nevertheless, these kinds of policies, FELA and SFGISD, are best to be developed within the UN systems where Member States are invited for discussion and negotiations. The research by (Dussauge-Laguna, 2012) argues for a more systematic consideration of temporal factors to broaden the understanding of how cross-national policy transfers develop. This argument is well founded and with the SDGs as a base and as a driver for the developed policy frameworks serves as the best temporal setting.

\section{4) Strengthening the relevance of policy transfer assessment generally in the LA and DRM domains}

It is for the first-time policies focused on geospatial information management are developed at the United Nations. This development is driven in part by the need to scale up efforts in regard to tenure security for all, and the increasing frequency and economic loss of natural disasters. Policy transfer assessment is not a common approach in both domains, it appears increasingly important in domains that are interrelated or whose implied effects cross national borders. With the development of the SDGs it is clear that no disciplinary domain works in a silo, and that it is likely that in the future, applications of such policy transfer assessments will increase. Indeed, both disciplines are integrated and intrinsic to other study areas such as poverty reduction, food security, gender equality etc. Overall, the assessment of the policy transfer of the two frameworks established by UN-GGIM and their feasibility to integrate local feedback loops serves scaling up efforts which are needed for both domains, LA and DRM. Policy transfer, tools and initiatives are a powerful tool to understand, assess, and potentially redesign the policy transfer process. The impact of global frameworks such as FELA and SFGISD can be enhanced with greater awareness of policy transfer and methods.

\subsection{Conclusions and recommendations}

Contemporary global policy development is increasingly shaped through the 2030 Agenda for Sustainable Development. UN-GGIM plays a leading role in the development and diffusion of policy frameworks with regard to geospatial information. Two frameworks, FELA and SFGISD, are developed to tackle global issues in regard to tenure security and natural disasters.

This chapter sought to assess 'whether' and 'how' this policy transfer occurs at different levels and across functions, and which mode, institutional or network, these two policy frameworks follow. As far as the researchers are aware such an assessment has not been 
completed previously in both domains, and therefore this work acts as a starting point to specify future policy transfer processes for LA and DRM, but also for others which are relevant for the SDGs. In this regard, especially with increasingly multi-disciplinary approaches in the domains, LA and DRM, policy transfer processes may need to be assessed on a regular basis. This is further stressed through an increasing speed of emerging technological but also socio-economic developments. Further work should focus on the refinement of policy transfer assessment parameters tailored for current trends and communication patterns. Further policy coherence as a mean to achieve sustainable development in policy development needs further investigation.

With the focus on policy transfer and the two policy frameworks also previous research of the researcher could be integrated and combined, which draw a holistic picture on the policy transfer from global to local level, which were fed back to the global development. When it comes to policy transfer, all different levels of the transfer need to be assessed and incorporated in future negotiation processes. Nevertheless, results reveal that the approach used for policy transfer is taking conventional institutional means for both LA and DRM domains. That said, UN-GGIM incorporated, through its networks, the knowledge and experiences from the field in the development of the frameworks: characteristics of a more networked approach are therefore apparent. There appears the opportunity to utilize a networked approach for more robust and farreaching uptake and diffusion of the policies. On this, there also lies the opportunity to provide better mechanisms for feeding results from local level initiatives and successes into the global monitoring mechanism.

In summary, the research introduced the two policy frameworks, the policy transfer assessment parameters, its application, and also its limitations and obstacles. The research also highlighted that a global approach for policies, especially for the two domains, is relevant and should be strengthen through field experiences at the national and community level. The developed frameworks were assessed specifically considering the policy creation processes (i.e. from where the policies are derived), harmonization (i.e. the alignment between the two policies), and integration of local feedback loops. 


\section{Chapter 6}

Towards responsible LA in DRM: summary and conclusion* $^{*}$

* Parts of this chapter are published as conference paper; Unger, E.-M., Bennett, R., Lemmen, C., Zevenbergen, J., Dijkstra., P., \& de Zeeuw, C., (2019). LADM based models for Sustainable Development. $8^{\text {th }}$ Land Administration Domain Model Workshop, 1-3 October 2019. Kuala Lumpur, Malaysia. 


\subsection{Introduction}

The integration of LA and DRM is gaining momentum amongst both theorist and practitioner communities with regards to policy creation, tool development and applications. The lack of LA processes that are responsive to DRM needs, challenges the realisation of sustainable development in disaster prone areas. This driver underpinned the research problem, research objectives, and subsequent research undertakings.

Chapter two established the links between the two domains through the identification of the global change forces (people, land, disaster) and the disaster risk drivers (vulnerability, exposure and hazard) and harmonized those concepts into a unified conceptual framework. The framework can reveal the extent and complexity of peopleto-land relationships, and how those are intrinsically related to the occurrence of natural disasters.

Chapter three was devoted to an analysis uncovering the specific data standards and tools used and developed in both LA and DRM domains. The knowledge was converted into a conceptual data model, linking elements of responsible LA and DRM, with the international LADM standard used as a basis. Further, an analysis of the potential of the LA-DRM model based on the disaster cycle and its phases was shown.

Chapter four tested the application of the developed conceptual data model from chapter three and represented the findings of the case study conducted in one of the most severely affected regions of the 2015 earthquakes in Dolakha, Nepal. The methodology and land tools used for the FFP LA application in a post-earthquake context were shown. Further analysis on the effects and hindrances of an incomplete LA system in a post-disaster context were presented.

Finally, chapter five focused on policy transfer and investigated two policy frameworks each relating to one of the specific domains, and both developed by UN-GGIM, on their levels of integration, approach to transfer, and prospects for converged governance of LA and DRM. An assessment framework from the policy transfer discipline was adapted and used for this investigation.

This chapter synthesises the findings from chapter two to chapter five based on the four research objectives proposed in the introduction. 
These objectives were:

1) To illustrate the theoretical linkages within responsible LA in DRM, by developing a conceptual framework explaining the interactions between global change forces, disaster risk drivers, and foundational LA constructs.

2) To develop a conceptual data model linking the domains of LA and DRM to support resilience to natural disasters.

3) To assess responsible land tools applied in DRM in a post-earthquake context.

4) To assess the opportunities and limitations of policy transfer within LA and DRM.

Section 6.2 summarises the main findings of each specific research objective. Section 6.3 discusses the implications of these results for knowledge and literature, and the benefits to the specific case study country Nepal, and how the research outputs and methodologies developed can support other contemporary societal challenges. Section 6.4 provides future research prospects.

\subsection{Main findings}

This section summarises the main findings for each research objective.

\section{1) To illustrate the theoretical linkages within responsible LA in DRM, by developing a conceptual framework explaining the interactions between global change forces, disaster risk drivers, and foundational LA constructs.}

The global land community has accepted that individual land titling on its own cannot deliver security of tenure to the majority of people in the world in a timely fashion. Responsible approaches need to be adopted, and more importantly need to be integrated, with other domains such as DRM to address emerging global challenges. The aim of this research was to close the gap of the missing linkages between LA and DRM, identified by various researchers in both domains. This gap was closed through the development of a conceptual framework which showed the need for the application of responsible LA in developing countries, which are prone to natural disasters. Therefore, the three global change forces (people, land and disaster), the interrelations between them, and the multifaceted relationship with land tenure and the three disaster risk drivers (vulnerability, exposure and hazard) was examined. The results were used to develop the conceptual framework showing, through a graphical representation, and describing this interrelationship and hence, fostering the emergent need of responsible LA in DRM. The components of the conceptual framework were the three global change forces: people, land and disaster, the three disaster risk drivers: exposure, vulnerability and hazard as well as the entry points for responsible LA approaches. The possible contribution of responsible LA to DRM was identified and classified in three categories: 
census data provision, gathered through, for example, participatory enumeration; tenure security gained through applying the continuum of land rights; and hazard risk assessment and mapping - linked to responsible LA. The possible contributions were underlaid through cases studied in literature from Kenya, the Philippines, India and Haiti. Within those, especially participatory approaches were identified as a critical aspect towards an implementable strategy for applying responsible LA technologies in the context of DRM. Participation and inclusion are crucial enabling factors for the poor to minimise vulnerabilities and disaster risks.

\section{2) To develop a conceptual data model linking the domains of LA and DRM to support resilience to natural disasters.}

The literature review of chapter two showed that land issues arising during a disaster are often addressed with ad-hoc legislative design, and tool development in separated approaches for different disciplines or domains. This led to the need to create a conceptual framework establishing a link between responsible LA and DRM. However, in order to administer natural disasters and govern the impact of any disaster, basic questions concerning, 'What?' 'Where?' and 'How?' need to be answered with regards to impacted individuals and communities, and also at an aggregated national level. Therefore, the need to access and share various information by interoperability and standardisation measures, needed further facilitation. In order to realise this link, established at conceptual level in chapter two, a literature review studying various tools and standards used in LA and DRM was conducted. Within this literature study, no standard nor tool could be found which could be applied in both fields, therefore the aim was to develop a conceptual data model. The developed and introduced LA-DRM model aims to improve the management of land information when it comes to natural disaster contexts and to find its application at national, local and community level. The work shows it is possible to link LA and DRM, at the level of data capture, and that the occurrence of disasters is the most evident reason to include all people-to-land relationships in any LA system. Further the potential of the LA-DRM model in each of the DRM phases was described and graphically illustrated to emphasise this linkage. This chapter has shown the development, potential, and also limitations of the LA-DRM model.

\section{3) To assess responsible land tools applied in DRM in a post-earthquake context.}

The conceptual data model development of chapter three delivered a tool applicable in the field for assessing impact on tenure security and recording disaster risk elements, such as vulnerability and exposure. The tool was tested in the post-earthquake setting of Nepal. The case study identified that vulnerable or at-risk groups are children, elderly, persons with disabilities, women, the poor and marginalized and especially people 
affected by tenure insecurity. The LA-DRM, as developed in chapter three, was used to map these vulnerable groups based on their needs, priorities and marginalization. The results and analysis were then further used to integrate and implement interventions for planning, response and relief processes. The research highlighted that DRM policies have to be redirected towards tenure security, poverty and vulnerability reduction, instead of only short-term compensation, resettlement and relief responses. The research proved the importance of documenting all people-to-land relationships in order to prepare, mitigate and respond to natural disasters. The research also highlighted the role of grassroot surveyors as a potential way to achieve complete coverage in any LA system, and especially in regard to being better prepared for natural disasters. Further results showed that through the documentation of all people-to-land relationships, efficient and effective land use planning can further mitigate disaster risks: backups of all documents, stored safe, can be used for an inclusive, participatory and transparent resettlement process. Through the application of the LA-DRM model it is expected that a complete LA system creates opportunities to mitigate and prepare for disasters. This case study further validated the results of chapter two and three, illustrating the practicability of those concepts and further confirmed the presence of a strong link between LA and DRM and the benefits of an integrated information system approach.

\section{4) To assess the opportunities and limitations of policy transfer within LA and DRM.}

Having established the link between LA and DRM at theoretical, methodological, and technical levels, the need to understand, assess, and enhance the transferability of the research results, at various policies levels became evident. For this, the study of policy transfer was necessarily focused upon. Here, the 2030 Agenda for Sustainable Development, with its 17 goals and 169 targets, was used as a starting point. In terms of geospatial information and its relationship to the 2030 Agenda, UN-GGIM plays a leading role in the development and diffusion of policy frameworks relating to all geospatial technical aspects and applications. Two UN-GGIM frameworks, FELA and SFGISD, are under development seeking to tackle global issues in regard to tenure security and natural disasters. This chapter assessed whether and how policy transfer occurs at different levels and across functions in the specific domains of LA and DRM. Further, the assessment focused on the identification of which mode, institutional or network, these two policy frameworks appear to be following. As far as the researcher is aware such an assessment is new for both domains and therefore this research acts as a starting point to specify future policy transfer processes and options, for LA and DRM, but also potentially for others relevant for the 2030 Agenda. Results of the research revealed that the approach used for policy transfer in the LA and DRM domain is taking conventional institutional means for both LA and DRM. Though UN-GGIM incorporates, 
through its networks and members, the knowledge and experiences gained from the field for the development of the frameworks, which are clear characteristics of a networked approach.

\section{Putting all the findings together}

Whilst the results above articulate the responses to each of the specific research objectives, they are clearly related: they represent a sequence of activities and knowledge creation, each question building on the results of the previous (Figure 24). This synthesis was already partly explained in chapter five (Figure 20), however, here, the synthesis results, stemming from the combined results of the four research objectives are further presented.

This research demonstrates a holistic approach for the integration of LA in DRM - from theories to tools, and from local to global levels. The impact of such a holistic approach was witnessed at the community level through the case study implementation in Nepal, which informed the national level in the development of an inclusive land policy, and at the global level through a conceptual framework, conceptual data model, and a policy transfer assessment. Stemming from a theoretical/conceptual, to methodological, to application, and back to conceptual perspective - each research output used participative and integrative means - driven by the same objective - the 2030 Sustainable Development Agenda. Additionally, this integration is shown through the consideration and application of tools, data models and concepts from both domains, LA and DRM, but also from outside domains (policy transfer). Further each research output can be applied on its own for other related domains. 


\begin{tabular}{|c|c|c|c|c|}
\hline Level & As is situation & $\begin{array}{l}\text { Research } \\
\text { Objective }\end{array}$ & Methodology & Main Findings \\
\hline $\begin{array}{l}\text { Theoretical and } \\
\text { Conceptual } \\
\text { (Why? and What?) }\end{array}$ & $\begin{array}{l}\text { Limited linkages } \\
\text { between LA and DRM } \\
\text { Limited literature on } \\
\text { integrated approaches } \\
\text { SDGs and Global } \\
\text { Agenda boost }\end{array}$ & $\begin{array}{l}\text { Chapter } 2 \text {. } \\
\text { theoretical linkage } \\
\text { at conceptual } \\
\text { level }\end{array}$ & $\begin{array}{l}\text { Conceptual Modelling: } \\
\text { - Knowledge } \\
\text { Acquisition } \\
\text { - Model Abstraction } \\
\end{array}$ & $\begin{array}{l}\text { Linking of disaster risk drivers } \\
\text { and global change forces } \\
\text { Development of conceptual } \\
\text { framework } \\
\text { Identification of responsible } \\
\text { LA contribution to DRM }\end{array}$ \\
\hline $\begin{array}{c}\text { Methodological : } \\
\text { (What?) }\end{array}$ & $\begin{array}{l}\text { Link at conceptual } \\
\text { level established but } \\
\text { no dedicated standard } \\
\text { or tool to represent } \\
\text { linkage }\end{array}$ & $\begin{array}{c}\text { Chapter } 3 \text { - } \\
\text { development of } \\
\text { conceptual data } \\
\text { model }\end{array}$ & $\begin{array}{l}\text { Design approach } \\
\text { Review, 1st Draft, } \\
2 \text { nd Draft, Validation, } \\
\text { Re-Definition, Final } \\
\text { Validation }\end{array}$ & $\begin{array}{l}\text { Establish link of LA and } \\
\text { DRM at data capture level- } \\
\text { Conceptual Data Model } \\
\text { (LA-DRM) } \\
\text { Potential of LA-DRM in DRM } \\
\text { phases }\end{array}$ \\
\hline $\begin{array}{l}\text { Tools and } \\
\text { Techniques } \\
\text { (How?) }\end{array}$ & $\begin{array}{l}\text { Conceptual data } \\
\text { model developed but } \\
\text { no integrated } \\
\text { application }\end{array}$ & $\begin{array}{l}\text { Chapter } 4 \text { - } \\
\text { assess conceptual } \\
\text { data model and } \\
\text { land tools in DRM }\end{array}$ & $\begin{array}{l}\text { Case Study/Application } \\
\text { «<lead to〉> }\end{array}$ & $\begin{array}{l}\text { Application of LA-DRM } \\
\text { model } \\
\text { Assessment of land tools in } \\
\text { DRM context }\end{array}$ \\
\hline $\begin{array}{l}\text { Methodological } \\
\text { and Conceptual } \\
\text { (How? And What?) }\end{array}$ & $\begin{array}{l}\text { Policy development } \\
\text { boosted by SDGs but } \\
\text { policies created in } \\
\text { silos whereas SDGs } \\
\text { clearly call for } \\
\text { integration }\end{array}$ & $\begin{array}{l}\text { Chapter } 5 \text { - } \\
\text { opportunities and } \\
\text { limitations of policy } \\
\text { transfer }\end{array}$ & Action Research & $\begin{array}{l}\text { Updated Assessment } \\
\text { Framework for policy } \\
\text { transfer for LA and DRM } \\
\text { Identification of policy } \\
\text { transfer mode }\end{array}$ \\
\hline
\end{tabular}

Figure 24: Synthesis overview

\subsection{Implications of results}

\subsubsection{To knowledge and literature}

As shown in the different chapters, responsible LA can be directly linked and even integrated in DRM processes. However, at the commencement of the research activities there was very little literature on this integration. This integration issue now gains more attention following the 2015 agreement on the SDGs and the recognition of many goals being cross-domain challenges.

Regarding an integrated approach for LA and DRM, this research investigated different levels of integration: conceptual/theoretical, conceptual data models, applications, and policy development and diffusion. The work showed the opportunities and limitations at each level. Especially now, the interrelationship of LA with various disciplines reflected in the SDGs becomes visible. In regard to responsible LA and DRM, both disciplines are integrated and intrinsic to other fields of study including poverty reduction, food security, gender equality etc. The Venn Diagram as introduced in chapter five (Figure 20) can be adapted for various LA related disciplines/domains or SDGs, and through the nature of a standardised underlying data model, such as the LADM, an integrated data capturing mechanism can be realised (Figure 25). Such 
standardised data models can support interoperability and the overall idea of 'collect once - use multiple times' but can also identify coordination problems and support their solution. Further, the research from chapter four is referenced and contributing to the update and development of the LADM2 ${ }^{8}$ (Lemmen, et al., 2019).

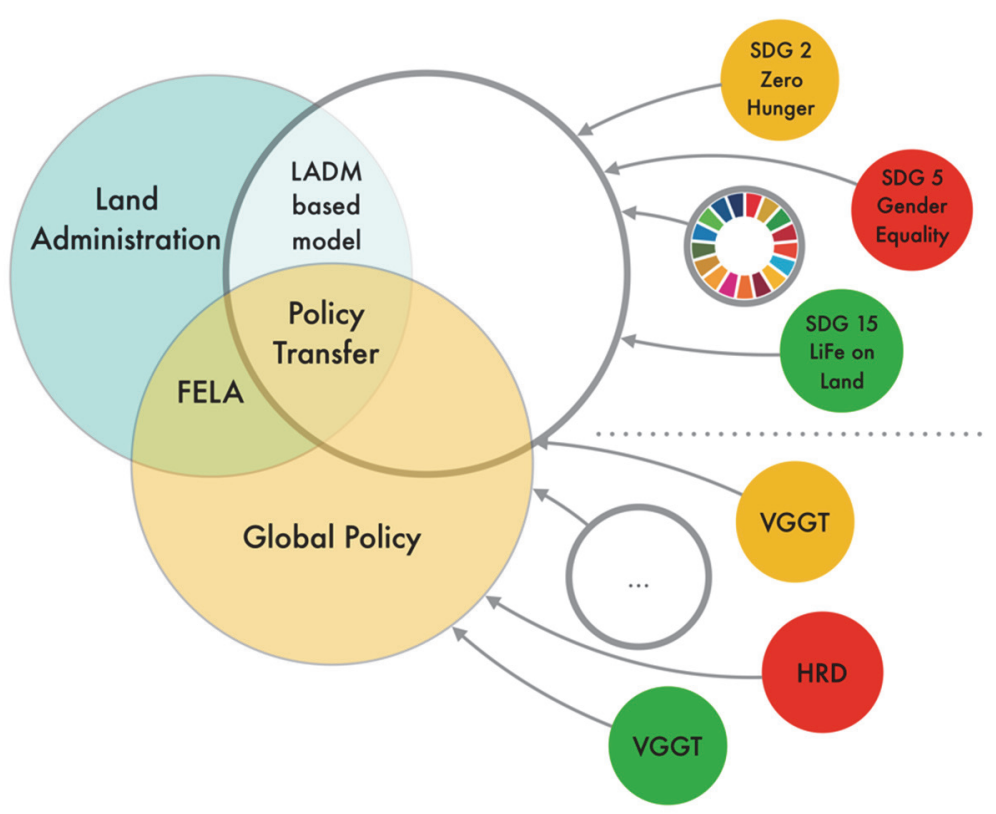

Figure 25: Integration with other SDGs

\subsubsection{To case study areas in Nepal}

In the aftermath of the earthquakes the Nepalese government issued an official procedure for the distribution of reconstruction grants and the required documents. Soon the Nepalese government realised that the request of a land ownership certificate can just be fulfilled by around $68 \%$ of the population in the case study areas. Therefore, the government changed the approach and the required documents for the reconstruction grant to also enable people without a land ownership certificate to access reconstruction grants. This window of opportunity was used for the case study areas and an alternative approach for recording the people-to-land relationship, FFP LA could be introduced in Nepal. The case study resulted in an UN-Habitat GLTN publication with the title 'Fit-For-Purpose Land Administration in a post disaster context'. The application lead to a wide acceptance within both the surveying community as well as

8 June '19 OGC TC/PC Meetings - Leuven, Belgium, https://www.opengeospatial.org/events/1906tc 
the Nepalese people and government. This led to the achievement of a significant milestone in March 2019 - the National Land Policy - recognising informal tenure, and equitable access to land for the landless, small holders and informal settlers in Nepal. This land policy supports the national but also the global agenda for sustainable development. Further this land policy follows the underpinning principle of inclusivity that covers, for example, land rights of women and vulnerable groups, rehabilitation of the landless, squatters and informal tenure-holders for improved housing etc. It also considers key environmental challenges related to food security, infrastructure development and the application of FFP LA (GLTN, 2018). Further the outlook to new technology, such as Automated Feature Extraction and the possibility for an integrated approach, for example the use of UAVs, in order to achieve a maintained and up to date LA system for Nepal, further boosts the sustainable development agenda for Nepal.

\subsubsection{To meeting other societal challenges and needs}

Considering that the majority of people do not enjoy secure land tenure, but also an increasing number of people are affected by natural disasters, efforts to document, record and recognize all people-to-land relationships is becoming more urgent. A holistic approach, as developed and shown in this research, strengthens the demand for, and also the possibilities of, interlinkages with the 2030 Agenda for Sustainable Development and its 5Ps (People, Planet, Prosperity, Peace and Partnership) (UN, 2015) and the domain of LA. FELA is being developed to address these interlinkages and further strengthen partnerships among disciplines and domains. This development has direct resonance with the term effective $L A$ and management. Whereas, effective LA is based on the approach of responsible LA but focuses on the integration with other disciplines to be effective and efficient. Therefore, it facilitates the integration and usage of geospatial information gathered through other disciplines. Effective LA is realized through integrating this information, for land tenure, land value, land use, and land development, as visualised in Figure 26.
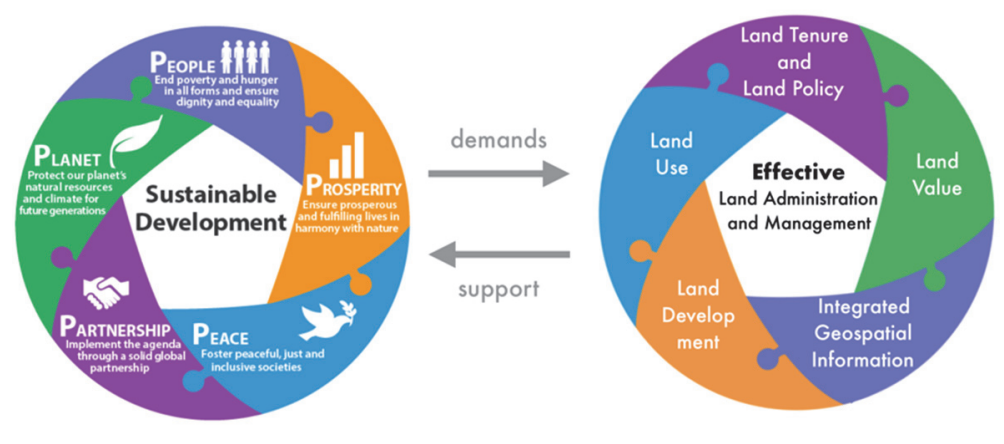

Figure 26: Effective land administration 


\subsection{Future research prospects}

This thesis showed the potential and added value of an integrated approach of responsible LA and DRM. Future research should focus on applying a similar holistic approach on other domains/global challenges to enhance an understanding of effective LA.

In addition, future works should focus on applying, testing and hence further developing the conceptual framework as well as the conceptual data model. For example, each of the global change forces as well as the disaster risk drivers, as introduced in chapter two, have different aspects to focus on and therefore more research could be undertaken to refine and tailor the concepts and tools towards these focuses.

Standardisation, as introduced in chapter three through the conceptual data model, which is based on an internationally agreed standard, LADM, creates opportunities but can also create dangers, especially in case of a natural disaster. As reported in media, the Federal Emergency Management Agency (FEMA) in the US shared the data of 2.3 million disaster (hurricane and wildfire) survivors with a federal contractor (Georgiadou, 2019). Standards support interoperability and hence can be used by machine learning mechanism. Therefore, future research could address these dangers, where personal data collected may be manipulated and linked to other data, and hence used for less benevolent purposes than the immediate disaster response.

Further, the approach used in Dolakha, Nepal, was used for a specific context but may not be fully replicable in other regions. Also, especially in regard to natural disasters, scaling up mechanisms need to be further investigated. This scaling up can be achieved through integration of other domains and disciplines but may also be achieved through technologies, which are outside the 'normal' FFP LA or DRM toolboxes.

In regard to policy transfer, future research should focus on opportunities created by working on more integrated approaches already at the policy development level. Further, when applying those international and globally agreed policies for development of, for example, a national legal framework or development of land tools, this integration should be at the core (Figure 27). Therefore, trends and communication patterns could be investigated to create awareness and hence increase the impact - for all people. 


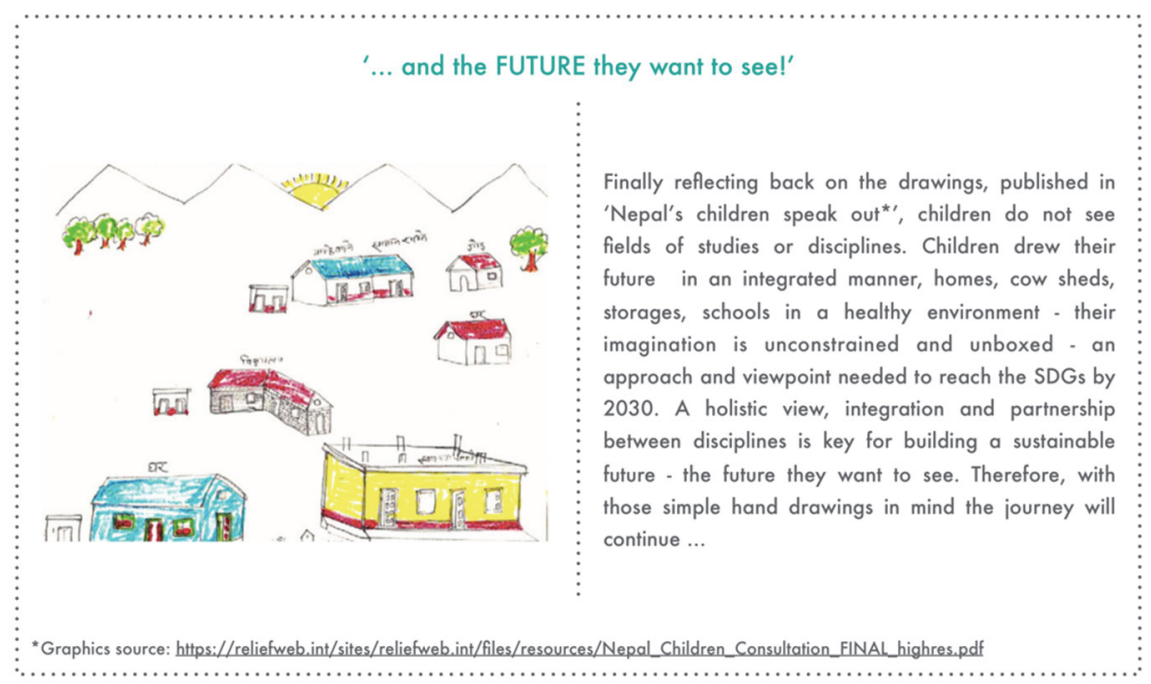

Figure 27: The future they want 


\section{Bibliography}

ADPC, 2016. CBDRR-25 Community-Based Disaster Risk Reduction in a Changing Climate, Bangkok, Thailand: Asian Disaster Preparedness Center.

Alemie, B., Bennett, R. \& Zevenbergen, J., 2015. Evolving urban cadastres in Ethiopia: the impacts on urban land governance. Land Use Policy, Issue 42, pp. 695-705.

Anaafo, D., 2013. Systems approach to pro-poor land reforms: a concept paper. Land Use Policy, Issue 35, pp. 421-426.

Antonio, D., 2011. Social tenure domain model: Towards addressing the information requirements of informal settlements. FIG Working Week 2011, 'Bridging the Gap Between Cultures', Marrakech, Morocco, 18-22 May 2011.

Antonio, D., Marongwe, N., Nyamweru, H. \& Okello, J., 2017. Securing Land Rights within the Continuum of Land Rights Approach: Evidence from Tenure Security Innovations in Kenya and Uganda. World Bank's Land and Poverty Conference 2017: Responsible Land Governance-Towards an Evidence-Based Approach, Washington DC, US, 20-24 March 2017.

Asiama, K., 2019. Responsible Consolidation of Customary Lands. Enschede: University Twente.

Augustinus, C. \& Lemmen, C., 2011. What is required to bring the social element into land administration? Moving from the Land Administration Domain Model to the Social Tenure Domain Model. Paper presented at the Annual World Bank Conference on Land and Poverty, Washington DC, 18-20 April 2011.

Barry, M., 2006. Formalising informal land rights: the case of Marconi Beam to Joe Slovo Park. Habitat International, Volume 30, pp. 628-644.

Barry, M. \& Augustinus, C., 2015. Property metaphors, property theory and communicating the continuum of land rights. Washington, US.

Barry, M. \& Roux, L., 2012. A change based framework for theory building in land tenure information systems. Survey Review, Volume 44, pp. 301-314.

Bennett, R., 2007. Property rights, restrictions and responsibilities: their nature, design and management. Melbourne: University of Melbourne.

Bennett, R., Pickering, M. \& Sargent, J., 2018. Innovations in land data governance: unstructured data, nosql, blockchain, and big data analytics unpacked. Annual World Bank Conference on Land and Poverty.

Bennett, R., Rajabifard, A., Williamson, I. \& Wallace, J., 2012. On the need for national land administration infrastructures. Land Use Policy, Volume 29, pp. 208-219. 
Berry, F. S. \& Berry, W., 1999. Innovation and Diffusion Models in Policy Research. In: P. Sabatier, ed. Theories of the policy process. Boulder CO.: Westview Press, pp. 169-200.

Blake, E., 2015. Addressing key land issues in Haiti program. Annual World Bank Conference on Land and Poverty, Washington DC, 23-27 March 2015.

Bundesamt für Landestopografie swisstopo, 2018. INTERLIS. [Online]

Available at: http://www.interlis.ch

[Accessed 12 March 2018].

Cadag, J. \& Gaillard, J., 2012. Integrating knowledge and actions in disaster risk reduction: the contribution of participatory mapping. Area, Volume 44, pp. 100-109.

CBS, 2006. Agriculture Monograph Preface and Contents. [Online]

Available at:

http://cbs.gov.np/sectoral statistics/agriculture/agriculture monograph preface and contents

CBS, 2014. Population Monograph of Nepal Volume II (Social Demography). [Online] Available at: http://cbs.gov.np/image/data/Population/Population Monograph of Nepal 2014/Population Monograph V02.pdf

Chhatkuli, R. R., 2013. National Consultant Land Expert Report, Kathmandu, Nepal (Unpublished): UNDP/ CPP.

Cho, G. \& Crompvoets, J., 2018. The INSPIRE directive: some observations on the legal framework and implementation. Survey Review, pp. 1-8.

CRED, 2015. Centre for Research on the Epidemiology of Disaster-EM-DAT-The International Disaster Database. [Online]

Available at: $\underline{\text { http://www.emdat.be }}$

[Accessed 18 June 2015].

Crompvoets, J., Rajabifard, A., Loenen, B. v. \& Delgado Fernandez, T., 2009. Future directions for SDI-assessment. GSDI 11 World Conference Spatial Data Infrastructure Convergence: Building SDI Bridges to address Global Challenges, Rotterdam, The Netherlands, 15-19 June 2009.

Cruses, D. \& Dybå, T., 2011. Research synthesis in software engineering: a tertiary study. Information and Software Technology, Volume 53, pp. 440-455.

Dabrowski, M., Musialkowska, I. \& Polverari, L., 2018. EU-China and EU-Brazil policy transfer in regional policy. Regional Studies, 52/9: International policy-transfer initiatives in regional development and planning, pp. 1169-1180.

De Filippi, F., 2009. Slum[e]scape: A challenge for sustainable development, Firenze: Alinea Editrice.

Deininger, K., 2003. Land policies for growth and poverty reduction. Oxford University Press. 
Deininger, K., Selod, H. \& Burns, A., 2012. The Land Governance Assessment Framework. Washington, D.C.: The World Bank.

Desai, V., 2012. Urbanisation and housing the poor: overview. The International Encyclopaedia of Housing and Home.

Dolowitz, D. \& Marsh, D., 1996. Who Learns What from Whom: A Review of the Policy Transfer Literature. 44(2), pp. 343-357.

Drezner, D. W., 2005. Globalization, harmonziation, and competition: the different pathways to policy convergence. European Public Policy, 12(5), pp. 841-859.

Dussauge-Laguna, M. I., 2012. The neglected dimension: bringing time back into cross-national policy transfer studies. Policy Studies, 33(6), pp. 567-585.

Elkins, Z. \& Simmons, B., 2005. On Waves, Clusters, and Diffusion: A Conceptual Framework. The ANNALS of the American Academy of Political and Social Science, 598(1), pp. 33-51.

Enemark, S., 2004. Building land information policies. Aguscalientes, Mexico, Paper presented at UN, FIG, PC IDEA Inter-regional Special Forum on The Building of Land Information Policies in the Americas, 26-27 October 2004.

Enemark, S., Bell, K. C., Lemmen, C. \& McLaren, R., 2014. Fit-For-Purpose Land Administration FIG Publication. Copenhagen, Denmark: International Federation of Surveyors (FIG).

Evans, D. \& Yen, D. C., 2006. E-Government: Evolving relationship of citizens and government, domestic, and international development. Government Information Quarterly, pp. 207235.

Evans, M., 2009. Policy transfer in critical perspective. Policy Studies, 30(3), pp. 243-268.

FAO, 2012. Voluntary Guidelines on the responsible Governance of tenure of land, fisheries and forests in the Context of national food security. Rome, Italy: Food and Agriculture Organization of the United Nations.

FAO, 2013. Food and Agriculture Organisation of the Nations [Online]. Available. [Online] Available at: http://www.fao.org/doCrEP/005/y4307E/y4307e04. htm [Accessed 1 December 2013].

FAO, 2015. The Impact of disasters on agriculture and food security 2015. [Online] Available at: https://reliefweb.int/report/world/impact-disasters-agriculture-and-foodsecurity-2015

[Accessed 2211 2018].

Flamm, M., 2011. Shelter Report 2012 - Build Hope: Housing cities after a disaster. Habitat for Humanity. Atlanta, US. 
Georgiadou, Y., 2019. Opportunities and risks arising from digital and emerging technologies three recommendations. Nairobi, Kenya, United Nations Fourth Expert Group Meeting on Science, Technology and Innovation (STI) Roadmaps for the SDGs Agenda.

GLTN, 2012. Handling Land: Innovative Tools for Land Governance and Secure Tenure. Nairobi: UN-HABITAT.

GLTN, 2014. Social Tenure Domain Model. [Online] Available at: http://www.stdm.gltn.net [Accessed 1711 2014].

GLTN, 2016. Gender Evaluation Criteria. [Online] Available at: https://gltn.net/2016/11/09/gender-evaluation-criteria-for-large-scaleland-tools/

[Accessed 2010 2018]

GLTN, 2018. Fit-For-Purpose Land Administration - a Country Level Implementation Strategy for Nepal, Kathmandu, Nepal: UN-HABITAT.

Griffith-Charles, C. et al., 2014. Land tenure and natural disaster management in the Caribbean. Land Tenure Journal, Food and Agriculture Organization of the United Nations, Volume 1, pp. 137-161.

Hall, P., 1993. Policy paradigms, social learning and the state: the case of economic policymaking in Britain. Comparative politics, Volume 25, pp. 275-296.

Hanstad, T. \& Prosterman, R., 2014. How the Poor Get Washed Away. [Online] Available at: http://www.nytimes.com/2014/01/15/opinion/how-the-poor-getwashed-away.html?src=twrhp\& $r=0$ [Accessed 11 November 2015].

Hay, G. C., 2014. Architecture for Instrument-centred Land Administration Applications, Otago, New Zealand: University of Otago.

Hay, G. C., 2016. Supporting Dynamic, Evolving and Emerging Land Information. Christchurch, New Zealand, FIG Working Week.

Hendriks, B., Zevenbergen, J., Bennett, R. \& Antonio, D., 2019. Pro-poor land administration: Towards practical, coordinated, and scalable recording systems for all. Land Use Policy, Volume 81, pp. 21-38.

Henssen, J., 1995. Basic principles of the main cadastral systems in the world. Delft, the Netherlands, Modern Cadastres and Cadastral Innovations, Proceedings of the One Day Seminar, pp. 5-12.

Hoekstra, A., 2013. The water footprint of modern consumer society. London: Routledge. 
Huppert, H. \& Sparks, S., 2006. Extreme natural hazards: population growth, globalization and environmental change. Philosophical Transactions of the Royal Society, Volume 364, pp. $1875-1888$.

IEG World Bank, 2006. World Bank Independent Evaluation Group. [Online] Available at: http://www.worldbank.org/ieg/recent/ [Accessed 1 November 2013].

IISD, 2006. Addressing Land Ownership after Natural Disasters. [Online] Available at: https://www.iisd.org/pdf/2006/es addressing land.pdf [Accessed 7 July 2015].

ISO, 2012. ISO 19152:2012 Geographic Information - Land Administration Domain Model (LADM), Edition 1. 118p. Geneva, Switzerland. [Online] Available at: https://www.iso.org/standard/51206.html [Accessed 20 February 2018].

Kern, K., Jörgens, H., Jänicke, M., 2001. The diffusion of environmental policy innovations: A contribution to the globalisation of environmental policy. Berlin, Germany. Discussion Papers FS II 01 - 302, Wissenschaftszentrum Berlin für Sozialforschung.

Jacoby, H. \& Minten, B., 2007. Is land titling in Sub-Saharan Africa cost-effective? Evidence from Madagascar, World Bank Economic Review.

Johnson, B. \& Gray, R., 2010. A History of Philosophical and Theoretical Issues for Mixed Methods Research. In: SAGE Handbook of Mixed Methods in Social \& Behavioural Research. California: SAGE, pp. 69-94.

Kaufmann, J. \& Steudler, D., 1998. Cadastre 2014. [Online] Available at: http://www.fig.net/cadastre2014/translation/c2014-english. pdf [Accessed 1 October 2014].

Keck, M. E. \& Sikkink, K., 1998. Activists beyond Borders. First Edition ed. Ithaca, United States: Cornell University Press.

Khezri, A., Bennett, R. \& Zevenbergen, J., 2018. Evaluating a Fit-For-Purpose Integrated ServiceOriented Land and Climate Change Information System for Mountain Community Adaptation. ISPRS International Journal of Geo-Information, 7(9).

Knill, C., 2005. Introduction: Cross-national policy convergence: concepts, approaches and explanatory factors. Journal of European Public Policy, Volume 12:5, pp. 764-774.

Ladi, S., 2005. Globalisation, policy transfer and policy research institutes. Cheltenham, UK: Edward Elgar.

Ladi, S., 2011. Policy Change and Soft Europeanization: the Transfer of the Ombudsman Institution to Greece, Cyprus and Malta. Public Administration, 89(4), pp. 1643-1663. 
Lemmen, C., Augustinus, C., Haile, S. \& van Oosterom, P., 2010. The Social Tenure Domain Model - A Pro-Poor Land Tool, FIG Publication. Copenhagen, Denmark: International Federation of Surveyors (FIG).

Lemmen, C., 2012. A domain model for land administration. Delft, the Netherlands: Technische Universiteit Delft.

Lemmen, C., Oosterom, P. v. \& Bennett, R., 2015. The Land Administration Domain Model. Land Use Policy, Volume 49, pp. 535-545.

Lemmen, C., Oosterom, P. v., Kalantari, M., Unger, E-M., de Zeeuw, C., 2019. OGC White Paper on Land Administration. [Online]

Available at: https://docs.opengeospatial.org/wp/18-008r1/18-008r1.html

Li, J., Zlatanova, S. \& Fabbri, A., 2007. Geomatics Solutions for Disaster Management. Berlin, Germany: Springer-Verlag.

Majone, G., 2014. Policy Harmonization: Limits and Alternatives. Journal of Comparative Policy Analysis, 16(1), pp. 4-21.

Marsh, D. \& Evans, M., 2012. Policy transfer: into the future, learning form the past. Policy Studies, 33(6), pp. 587-591.

Maxwell, D. \& Wiebe, K., 1998. Land tenure and food security: A review of concept, evidence and methods. Land Tenure Research Center-Research Paper, Volume 129.

McCann, E. \& Ward, K., 2012. Policy Assemblages, Mobilities and Mutations: Toward a Multidisciplinary Conversation. Political Studies Review, 10(3), pp. 325-332.

McDougall, K., Rajabifard, A. \& Williamson, I., 2009. Local Government and SDI - Understanding their Capacity to Share Data. In: SDI convergence: research, emerging trends, and critical assessment. Delft, Netherlands: Netherlands Geodetic Commission, pp. 205218.

Mitchell, D., 2010. Reducing vulnerability to natural disasters in the Asia Pacific through improved land administration and management. 24th FIG International Congress 2010, Facing the challenges - building the capacity, Sydney, Australia, 11-15 April, 2010, pp. 1-10.

Mitchell, D., 2011. Land Tenure Manuals: Assessing and Responding to Land Tenure Issues in Disaster Risk Management. Rome, Italy: FAO.

Mitchell, D., Myers, M. \& Grant, D., 2014. Land Valuation: a key tool for disaster risk management. In: Land Tenure Journal. Food and Agriculture Organisation of the United Nations.

Mitchell, D., Jacob des Combes, H., Myers, M. \& Mcevoy, D., 2015. Addressing land issues in disaster risk management in the Pacific Island Countries. Land Tenure Journal, 1. pp. 101-135. ISSN 2079-7168 
Mitchell, D. et al., 2017. An evaluation framework for earthquake-responsive land administration. Land Use Policy, Volume 67, pp. 239-252.

Mitchell, D., McEvoy, D. \& Antonio, D., 2018. A Global Review of Land Tenure, Climate Vulnerability and Adaptive Capacity. Washington, 2018 World Bank Conference on Land and Poverty.

Mitchell, D. \& McEvoy, D., 2019. Land Tenure and Climate Vulnerability. Nairobi, Kenya: GLTN.

MOALMC, CSRC, UN-HABITAT, 2018. Locally Present Land Tenure Typology in Nepal: A Study Report, Kathmandu, Nepal.

Morgan, D., 2014. Pragmatism as a Paradigm for Social Research. Qualitative Inquiry, Volume 20, Issue 8, pp. 1045-1053.

Mukerji, A., 2010. Post-earthquake housing recovery in Bachhau, India: The homeowner, the renter, and the squatter. Earthquake Spectra, Volume 26, pp. 1085-1100.

Myers, G., 2014. Haiti rebuilding, but land governance challenges remain. USAID Land Tenure and Property Rights Portal.

NPC, 2015. Government of Nepal - National Planning Commission. [Online] Available at:

https://www.npc.gov.np/images/category/PDNA volume BFinalVersion.pdf [Accessed 20 October 2017].

NRA, 2015. Recovery Platform. [Online]

Available at: https://www.recoveryplatform.org/assets/publication/PDNA/RecoveryFrameworks/ Nepal Earthquake 2016 PDRF.pdf [Accessed 20 October 2017].

OECD, 2016. Better Policies for Sustainable Development 2016: A new Framework for policy coherence. Paris, France: OECD Publishing.

Park, C., Wilding, M. \& Chung, C., 2014. The importance of feedback: Policy transfer, translation and the role of communication. Policy Studies, 35(4), pp. 397-412.

Payne, G., 2002. Land, rights and innovation: Improving tenure security for the Urban poor. London: ITDG Publishing.

Payne, G., Duran-Lasserve, A. \& Rakodi, C., 2009. The limits of land titling and home ownership. Environment and Urbanization, Volume 21, pp. 443-462.

Potts, K., 2012. Supporting Land and Property Risk Management Activities with Land Administration Systems. In: A. Rajabifard, I. Williamson \& M. Kalantari, eds. A National Infrastructure for Managing Land Information. The University of Melbourne, Australia. 
Rajabifard, A., 2002. Diffusion of Regional Spatial Data Infrastructure: with particular reference to Asia and the Pacific. PhD Thesis Department of Geomatics, The University of Melbourne, Australia.

Rajabifard, A. et al., 2018. Improving Resilience and Resilience Impact of National Land and Geospatial Systems. Washington DC, 2018 World Bank Conference on Land and Poverty.

Reason, P. \& Bradbury, H., 2008. The SAGE Handbook of Action Research. London, UK: SAGE Publications Ltd.

Roy, F. \& Ferland, Y., 2014. Land use planning for disaster risk management. Land Tenure Journal, Food and Agriculture Organization of the United Nations, Volume 1, pp. 71 102.

Schipper, L. \& Pelling, M., 2006. Disaster risk, climate change and international development: scope for, and challenges to, integration. Disasters. Volume 30, Issue 1, Special Issue: Climate change and disasters, pp. 19-38.

Sherman, R., 2015. Business Intelligence Guidebook. Elsevier.

Shrestha, R., Tuladhar, A. \& Zevenbergen, J., 2014. "Decades of Struggle for Space": About the Legitimacy of Informal Settlements in Urban Areas. FIG Publication. International Federation of Surveyors (FIG), Copenhagen, Denmark. [Online] Available at: http://www.fig.net/pub/fig2014/papers/ts01g/TS01G tuladhar zevenbergen et al 7095.pdf

[Accessed 13 October 2014].

Shrestha, R., Tuladhar, A. \& Zevenbergen, J., 2015. Exploring land governance in post disaster: a case of informal settlement. In Proceedings of International workshop on the role of land professionals and SDI in disaster risk reduction: in the context of Post $2015 \mathrm{Nepal}$ Earthquake, 25- 27 November 2015. Kathmandu, Nepal, pp. 1-16.

Shreshta, R., 2019. Understanding Urban Land Governance through "action space": Implications for access to land for low-income housing in managing informal settlements. Enschede: University Twente.

Simbizi, M. C., Bennett, R. \& Zevenbergen, J., 2014. Land tenure security: revisiting and refining the concept for Sub-Saharan Africa's rural poor. Land Use Policy, Volume 36, pp. 231238

SOLA, 2016. Solutions for Open Land Administration. [Online] Available at: http://www.flossola.org. [Accessed 6 January 2018].

Stone, D., 2004. Transfer agents and global networks in the 'transnationalization' of policy. Journal of European Public Policy, 11(3), pp. 545-566.

Stone, D., 2012. Transfer and translation of policy. Policy Studies, Volume 33:6, pp. 483-499. 
Stringer, E., 2008. Action Research and Policy Development in East Timor. In: The SAGE Handbook of Action Research. London: SAGE Publication Ltd., pp. 550-561.

Stubkjær, E. \& Cagdas, V., 2009. Doctoral research on cadastral development. Land Use Policy, 26(4), pp. 869-889.

Swantz, M. L., 2008. Participatory Action Research as Practice. In: The SAGE Handbook of Action Research. London: SAGE Publications Ltd., pp. 31-48.

Ting, L., 2002. Principles for an integrated land administration system to support sustainable development. Melbourne, Australia: The University of Melbourne.

UN, 2015. Sustainable Development Goals. [Online] Available at: $\underline{\text { https://sustainabledevelopment.un.org/?menu=1300 }}$ [Accessed 2201 2019].

UN, 2017. New Urban Agenda. Quito, Ecuador: Habitat III Secretariat, United Nations.

Undeland, A., Burn, T., Deininger, K. \& Selod, H., 2010. Moving from 'land titling' to 'land governance': the case of the Kyrgyz Republic.

UNFCCC, 2008. Kyoto protocol reference manual on accounting of emissions and assigned amount. [Online]

Available at:

https://unfccc.int/resource/docs/publications/08 unfccc kp ref manual.pdf [Accessed 2801 2019].

UNFCCC, 2019. 2019 United Nations Framework Convention on Climate Change - The Paris Agreement. [Online] Available at: https://unfccc.int/process-and-meetings/the-parisagreement/d2hhdC1pcy

UNFPA, 2013. United Nations Population Fund. [Online] Available at: http://www.unfpa.org/pds/trends.htm [Accessed 01 November 2013].

Unger, E.-M., Zevenbergen, J. \& Bennett, R., 2017. On the need for pro-poor land administration in disaster risk management. Survey Review, August, Volume 6265, pp. 1-12.

Unger, E.-M., Zevenbergen, J., Bennett, R. \& Lemmen, C., 2019a. Application of LADM for disaster prone areas and communities. Land Use Policy, 80(January), pp. 118-126.

Unger, E.-M., Chatkuli, R., Antonio, D., Lemmen, C., Zevenberge, J., Bennett, R., \& Dijkstra, P., 2019b. Creating resilience to natural disasters through FFP land administration - an application in Nepal. Washington DC, US, 2019 World Bank Conference on Land and Poverty, Washington DC. 
Unger, E.-M., Chatkuli, R., 2019c. Fit-For-Purpose Land Administration in a post disaster context. Lessons and Applications from Nepal. 04/2019. Nairobi, Kenya

UN-GGIM, 2018. 8th Session. Committee of Experts on Global Geospatial Information Management. Report on the eight session (1-3 August 2018). Economic and Social Council Official Records, 2018. Supplement No. 26. [Online] Available at: http://ggim.un.org/meetings/GGIM-committee/8thSession/documents/GGIM8-report-e.pdf [Accessed 2412 2018].

UN-GGIM, 2018. Integrated Geospatial Information Framework. [Online] Available at: http://ggim.un.org/meetings/GGIM-committee/8thSession/documents/Part\%201-IGIF-Overarching-Strategic-Framework-24July2018.pdf [Accessed 2201 2019].

UN-GGIM, 2019. Committee of Experts on Global Geospatial Information Management. [Online] Available at: $\underline{\text { http://ggim.un.org }}$ [Accessed 1002 2019].

UN-HABITAT, 2008. Secure land rights for all, Nairobi, Kenya: UN-HABITAT.

UN-HABITAT, 2010a. Count me in - surveying for tenure security and urban land management. Nairobi: UN-HABITAT.

UN-HABITAT, 2010b. Land and natural disasters - guidance for practitioners, Nairobi: UNHABITAT.

UN-HABITAT, 2010c. State of the World's Cities 2010/2011: Bridging the urban Divide. [Online] Available at: http://africacheck.org/wp- content/uploads/2014/03/State-of-the-worldcities-2010.pdf [Accessed 7 January 2015].

UNISDR, 2009. United Nations Office for Disaster Risk Reduction - Terminology on Disaster Risk Reduction. [Online] Available at: http://www.unisdr.org/files/7817 UNISDRTerminologyEnglish.pdf [Accessed 13 April 2014].

UNISDR, 2013. United Nations Office for Disaster Risk Reduction. [Online] Available at: http://www.unisdr.org [Accessed 2013 November 2013].

UNISDR, 2015. PreventionWeb. Risk Models. Understand disaster risk modelling. [Online] Available at: https://www.preventionweb.net/risk/models [Accessed 12 December 2017].

UNISDR, 2017. PreventionWeb Terminology. Terminology. [Online] Available at: https://www.preventionweb.net/english/professional/terminology/ [Accessed 12 January 2018] 
UNISDR, 2018. PreventionWeb. Risk Models. Understand disaster risk modelling. [Online] Available at: https://www.preventionweb.net/risk/models [Accessed 2 March 2018].

UNISDR, 2019. Sendai Framework voluntary commitments: Synthesis and analysis report. United Nations Office for Disaster Risk Reduction (UNDRR). 85 p. [Online] Available at: https://www.unisdr.org/we/inform/publications/65545

Usamah, M., Handmer, J., Mitchell, D. \& Ahmed, I., 2014. Can the vulnerable be resilient? Coexistence of vulnerability and disaster resilience: Informal settlements in the Philippines. International Journal of Disaster Risk Reduction, Volume 10. no. PartA. pp. 178-189.

van Asperen, P. \& Zevenbergen, J., 2007. Can lessons be learnt from improving tenure security in informal settlements?. Rotterdam, the Netherlands, ENHR 2007 International Conference on Sustainable Urban Areas.

van der Molen, P., 2006. FIG. [Online]

Available at: http://www.fig.net/ council/molen papers/rics 12 2006.pdf [Accessed 01 October 2014].

van Westen, C., 2009. Multi-hazard risk assessment. Enschede, the Netherlands: United Nations University - ITC School on Disaster Geoinformation Management.

van Westen, C. \& Montoya, L., 2011. Multi-hazard risk assessment Distance education course. Enschede, the Netherlands: ITC University Twente.

W3C, 2009. W3C, 2009. World Wide Web Consortium - Emergency Information Interoperability Frameworks. [Online]

Available at: https://www.w3.org/2005/Incubator/eiif/XGR-framework-20090220/ [Accessed January 2018].

WB and GFDRR, 2012. The sendai report - managing disaster risks for a resilient future, Sendai: World Bank and Global Facility for Disaster Reduction and Recovery.

WCDRR, 2015. Sendai Framework for Disaster Risk Reduction 2015-2030. [Online] Available at: http://www.wcdrr.org/uploads/Sendai Framework for Disaster Risk Reduction 201 5-2030.pdf [Accessed 19 February 2018].

Wehrmann, B. \& Antonio, D., 2011. Intermediate land tenure: inferior instruments for secondclass citizens. FAO's Land Tenure Journal, Volume 31, pp. 6-25.

Weichselgartner, J. \& Pigeon, P., 2015. The role of knowledge in disaster risk reduction. International Journal of Disaster Risk Science, Volume 6, pp. 107-116.

West, M. \& Fowler, J., 1999. Developing High Quality Data Models. Elsevier. 
WG GISD, 2017. Working Group on Geospatial Information and Services for Disasters. [Online] Available at: http://ggim.un.org/documents/UNGGIM Strategic Framework Disasters final.pdf [Accessed January 2018].

Williamson, I., Enemark, S., Wallace, J. \& Rajabifard, A., 2010. Land administration for sustainable development. Redlands, CA: Esri Press.

Woodward, K., 2014. Social sciences: The big issues. New York: Routledge.

Yin, R., 2014. Case study research: design and methods. California, US: SAGE Publications Inc.

Zevenbergen, J., Augustinus, C., Antonio, D. \& Bennett, R., 2013. Pro-poor land administration: Principles for recording the land rights of the underrepresented. Land Use Policy, Volume 31, pp. 595-604.

Zevenbergen, J., Augustinus, C. \& Bennett, R., 2014a. Towards a design for a pro-poor land recordation system. Washington, US, Paper presented at the Annual World Bank Conference on Land and Poverty. Washington DC, 24-27 March 2014.

Zevenbergen, J., Kerle, N. \& Tuladhar, A., 2014b. Spatial Information for Addressing and Assessing Land Issues in Disaster Risk Management. In: Land Tenure Journal. Rome, Italy: Food and Agriculture Organization of the United Nations, pp. 09-35.

Zevenbergen, J., de Vries, W. \& Bennett, R., 2015. Advances in Responsible Land Administration. Florida, US: CRC Press. 


\section{Summary}

Responsible Land Administration (LA) continuously seeks to align the technical processes of LA to dynamic local societal demands, economic conditions, and legal requirements. It is motivated by the desire to improve the land tenure security of vulnerable and marginalized groups. Disaster Risk Management (DRM) and especially community-based disaster risk management (CBDRM) aims to evaluate and manage natural disaster risks at the local level - and emphasises the role of communities when it comes to natural disasters. However, responsible LA has so far received minimal attention in Disaster Risk Management (DRM), and likewise, LA design often neglects the potential requirements of DRM. This is even though the number of natural disasters and the people affected increased significantly in recent decades.

The 2030 Agenda for Sustainable Development with its defined Sustainable Development Goals (SDGs), together with the Sendai Framework for Disaster Risk Reduction, stimulate innovative and transformative approaches to secure land and property rights for all (UN, 2015). Consequently, there is growing agreement on the need to adopt responsible LA approaches, ones that better address the needs of the poor living in disaster prone contexts. Ultimately, responsible LA should enable the poor to minimise vulnerabilities and disaster risks through an inclusive land tenure security approach that supports prevention, mitigation, preparation, respond to and recover from natural disasters.

The absence of a theoretical framework linking the LA and DRM domains, the lack of methods enabling integrated technical approaches and responses, including data capture and management, and limited evidence from local level initiatives, hampers the adoption of an integrated approach. Therefore, an integrated approach for responsible LA in DRM is needed. To this end, this thesis sought to understand and demonstrate how responsible LA can be combined with DRM, via concepts and tools, in a way that is people-serving, efficient and effective from global down to local levels. For this purpose, four specific objectives are addressed.

First, to illustrate the theoretical linkages within responsible LA in DRM, a conceptual framework is developed. The model explains the interactions between global change forces, disaster risk drivers, and foundational land administration constructs. Conceptual modelling, with knowledge acquisition and model abstraction mechanisms, is used to undertake the task. These methods are used to examine the interrelations and interactions between the three identified and fundamental global change forces (people, land and disaster) and the three disaster risk drivers (vulnerability, exposure and hazard). The results are used to develop a graphically visualised conceptual framework. The utility of the conceptual work is examined through its application to literature-based cases studies from Kenya, the Philippines, India and Haiti. These show starkly the link and the possible contributions of responsible LA to DRM. Within those, 
especially participatory approaches are identified as critical with regards to creating implementable responsible LA strategies in the context of DRM.

Second, in order to support such an integrated approach in its application at national, local and community level, a conceptual data model is developed, linking the domains of LA and DRM to support resilience to natural disasters. The LA-DRM, conceptual data model, is then developed using a design approach, with a supportive literature review, studying various tools and standards used in LA and DRM. This model supports interoperability and standardisation measures to access and share diverse information answering the basic questions regarding, 'What?' 'Where?' and 'How?' with regard to impacted individuals and communities. Hence, the supportive data model enables the integration of LA and DRM. The work shows that it is possible to further link LA and DRM, at the level of data capture, storage, and application. To emphasise the linkage, the potential of the LA-DRM model in each of the DRM phases is graphically illustrated.

Third, there is limited evidence of local initiatives testing an integrated approach to the application of responsible land tools applied in DRM post-earthquake contexts. Using a case study approach, the application of the developed conceptual data model, LADRM, together with innovative land tools, is tested in Dolakha, Nepal. Further analysis on the effects and hindrances of an incomplete LA system in a post disaster context are presented. The case study identifies that vulnerable or at-risk groups are children, elderly, persons with disabilities, women, the poor and marginalized, and especially people affected by tenure insecurity. The research highlights that DRM policies have to be redirected towards tenure security, poverty and vulnerability reduction, instead of only short-term compensation, resettlement and relief responses. It substantially proves the importance of documenting all people-to-land relationships in order to prepare, mitigate, respond to and recover from natural disasters.

Having established the fundamental link at theoretical, methodological and technical level, opportunities and limitations of policy transfer within LA and DRM are assessed. Using an action research inspired approach, the key characteristics of policy transfer for two frameworks, Framework for Effective Land Administration (FELA) and Strategic Framework for Geoinformation Services for Disaster (SFGISD), related to tenure security and natural disasters developed by the United Nations are assessed. This assessment focused on the identification of which mode, institutional or network, the two policy frameworks are following. The results show that even though the two frameworks follow conventional institutional means, network measures are also being utilised. The assessment framework which is adapted in this research could further be used for future policy transfer processes relevant for the 2030 Agenda for Sustainable Development. 
In conclusion, responsible LA can be used in DRM as a fundamental instrument to mitigate and respond to natural disasters. Further studies have to be conducted to apply a similar holistic approach on other domains/global challenges, to enhance understandings of effective LA, a term which is introduced in this research. The results of this thesis contribute to knowledge and literature, by highlighting the potential of an integrated approach for responsible LA in DRM at theoretical, methodological technical and policy diffusion levels. This is especially relevant since both disciplines are integrated and intrinsically linked with various themes reflected in the SDGs. Further for the case study area in Nepal, the results show the need for responsible land policies addressing all forms of tenure especially in a post-disaster context. The Fit-For-Purpose Land Administration (FFPLA) application in Nepal led to a wide acceptance within both the surveying community as well as the Nepalese people and government, which led to the 2019 National Land Policy recognising informal tenure and equitable access to land for the landless, small holders and informal settlers in Nepal. Finally, with regards to other societal challenges and needs, the research shows that a holistic approach strengthens the demand for, and the possibilities of, interlinkages with the 2030 Agenda for Sustainable Development and its 5Ps (People, Planet, Prosperity, Peace and Partnership) and the domain of LA. 


\section{Samenvatting}

Verantwoorde land administratie ('responsible land administration') streeft naar continue afstemming tussen technische processen van land administratie enerzijds en dynamische lokale maatschappelijke eisen, economische omstandigheden en wettelijke vereisten anderzijds. Het wordt gestimuleerd door de wens tot verbeterde bescherming van landrechten voor kwetsbare en gemarginaliseerde groepen. Rampenbestrijding, en in het bijzonder rampenbestrijding met lokale gemeenschappen ('community based disaster risk management') is gericht op het evalueren en beheren van natuurrampenrisico's op lokaal niveau. Echter, verantwoorde land administratie heeft tot nu toe minimale aandacht gekregen bij rampenbestrijding en, omgekeerd, wordt er bij het ontwerp van land administratie vaak weinig rekening gehouden met de potentiële vereisten van rampenbestrijding. Dit ondanks het feit dat het aantal natuurrampen en het aantal getroffen personen de afgelopen decennia aanzienlijk is toegenomen.

De Agenda 2030 voor duurzame ontwikkeling met de daarin geformuleerde duurzame ontwikkelingsdoelen samen met het zogenaamde 'Sendai-Kader' voor rampenbestrijding, stimuleren innovatieve en transformatieve benaderingen om landen eigendomsrechten voor iedereen te beschermen (UN, 2015). Daarom bestaat er steeds meer consensus over de noodzaak om verantwoorde benaderingen in land administratie te hanteren, die beter tegemoetkomen aan de behoeften van de armen die in een rampgevoelige omgeving leven. Uiteindelijk zal verantwoorde land administratie de armen in staat stellen om de kwetsbaarheid en ramp risico's te beperken door middel van een benadering waarin landrechten voor iedereen beschermd worden mede ter ondersteuning van preventie, mitigatie, reactie en herstel bij natuurlijke rampen.

Het ontbreken van een theoretisch kader dat de kennisgebieden land administratie en rampenbestrijding met elkaar verbindt, het ontbreken van methoden die geïntegreerde technische benaderingen en reacties mogelijk maken (waaronder het verzamelen en beheren van gegevens), alsmede beperkt bewijs vanuit initiatieven op lokaal niveau, belemmeren de invoering van een geïntegreerde aanpak. Invullen van deze leemten is nodig voor een geïntegreerde aanpak van verantwoorde land administratie en rampenbestrijding. Te dien einde is in dit proefschrift getracht te begrijpen en te laten zien hoe verantwoorde land administratie kan worden gecombineerd met rampenbestrijding, via concepten en instrumenten, op een wijze die mensen dient en die tevens efficiënt en effectief is van globale tot lokale niveaus. Voor dit doel worden vier specifieke doelstellingen behandeld.

In de eerste plaats is een conceptueel kader ontwikkeld om de theoretische verbanden te leggen tussen verantwoorde land administratie en rampenbestrijding. Het model beschrijft de interacties tussen veranderingen op wereldniveau, risico's voor rampen en fundamentele land administratie constructies. Modellering op conceptueel niveau, gecombineerd met kennisverwerving en model abstracties, wordt gehanteerd om de 
taak te verwezenlijken. Deze methoden worden gebruikt voor het onderzoeken van de onderlinge relaties en de interacties tussen drie geïdentificeerde en fundamentele wereldwijde krachten van verandering (mensen, land en de rampen) en de drie risico's voor rampen (kwetsbaarheid, blootstelling en gevaar). De resultaten zijn gebruikt om een grafisch gevisualiseerd conceptueel kader te ontwikkelen. De bruikbaarheid van dit conceptuele werk is onderzocht door middel van de toepassing ervan op (op de literatuur gebaseerde) casestudies uit Kenia, de Filippijnen, India en Haïti. De resultaten tonen een sterk verband tussen, en tevens de mogelijke bijdragen van, verantwoorde land administratie en rampenbestrijding. Binnen dit kader is vooral een participatieve aanpak geïdentificeerd als cruciaal met betrekking tot implementatie van uitvoerbare verantwoorde land administratie strategieën in het kader van rampenbestrijding.

Ten tweede, om een dergelijke geïntegreerde aanpak bij de toepassing ervan op nationaal, lokaal en gemeenschapsniveau te ondersteunen, is een conceptueel datamodel ontwikkeld dat de kennisgebieden land administratie en rampenbestrijding koppelt om meer veerkracht bij natuurrampen te ondersteunen. Het 'LA-DRM' conceptueel datamodel is vervolgens ontwikkeld met behulp van een ontwerpbenadering (met een ondersteunende literatuurstudie) waarin verschillende hulpmiddelen en standaarden worden onderzocht die worden toegepast in land administratie en rampenbestrijding. Dit model ondersteunt interoperabiliteit en standaardisatie maatregelen om toegang te kunnen krijgen en informatie te kunnen delen voor het beantwoorden van fundamentele vragen over, 'wat?' 'waar?' en 'hoe?' met betrekking tot getroffen individuen en gemeenschappen. Het ondersteunende datamodel maakt de integratie van land administratie en rampenbestrijding mogelijk. Het werk laat zien dat het mogelijk is om land administratie en rampenbestrijding verder te koppelen - op het niveau van gegevens inwinning, opslag en gebruik. Om de potentie van deze koppeling te benadrukken is het LA-DRM model in alle fasen van rampenbestrijding grafisch weergegeven.

Ten derde is er beperkt bewijs van lokale initiatieven met het testen van een geïntegreerde aanpak van de toepassing van verantwoorde land gereedschappen toegepast in de context van rampenbestrijding bij aardbevingen. Met behulp van een case study benadering, is de toepassing van het ontwikkelde conceptuele LA-DRM model met innovatieve land administratie gereedschappen, is in het veld getest in Dolakha, Nepal. Nadere analyse van de effecten en de belemmeringen van een onvolledig land administratie systeem in een post ramp context zijn gepresenteerd. De case study maakt duidelijk dat de kwetsbare groepen in deze context, kinderen, ouderen, personen met een handicap, vrouwen, armen en gemarginaliseerden, en in het bijzonder mensen met slecht beschermde landrechten zijn. Het onderzoek maakt 
verder duidelijk dat beleid in het kader van rampenbestrijding moet worden omgebogen naar bescherming van landrechten, armoedebestrijding en verlagen van kwetsbaarheid, in plaats van alleen op korte termijn compensatie, herhuisvestiging en redding. Het bewijst de wezenlijke noodzaak van het documenteren van alle mensen-to-land relaties bij de fases preventie, mitigatie, reactie en herstel bij bestrijding van natuurrampen.

Nadat er de fundamentele koppeling op theoretisch, methodologisch en technisch niveau is gevestigd zijn de mogelijkheden en beperkingen van de overdracht van goed beleid in land administratie en rampenbestrijding beoordeeld. Gebruikmakend van een op actie onderzoek geïnspireerde benadering, zijn de belangrijkste kenmerken van beleidsoverdracht beoordeeld bij twee beleidskaders, te weten het beleidskader voor effectieve land administratie en het strategisch beleidskader voor geo-informatie services bij rampen (ontwikkeld door de Verenigde naties), gerelateerd aan bescherming van landrechten en natuurrampen. Deze beoordeling is gericht op de identificatie van welke wijze, te weten institutioneel of netwerk, bij deze beleidskaders is gevolgd. De resultaten laten zien dat ondanks binnen deze beleidskaders conventionele institutionele middelen worden gevolgd, als ook netwerkmaatregelen worden gebruikt. Het beoordelingskader dat in dit onderzoek is toegepast, kan in de toekomst worden gebruikt voor beleidsoverdrachtsprocessen die relevant zijn voor de 2030 Agenda voor duurzame ontwikkeling.

In conclusie, kan verantwoorde land administratie worden gebruikt bij land administratie als een fundamenteel instrument bij het verlichten en te reageren op natuurrampen. Verdere studies moeten worden uitgevoerd om een soortgelijke holistische benadering toe te passen op andere kennisgebieden en mondiale uitdagingen, om begrip van effectieve land administratie, een term die is geïntroduceerd in dit onderzoek, te verbeteren. De resultaten van dit proefschrift leveren een bijdrage aan kennis en literatuur, door te wijzen op de mogelijkheden van een geïntegreerde aanpak voor verantwoorde land administratie en rampenbestrijding op theoretische, methodologische technische en beleidsmatige niveaus. Dit is vooral relevant omdat beide disciplines zijn geïntegreerd en intrinsieke aan elkaar verbonden binnen diverse thema's in de beschrijving van de duurzame ontwikkelings doelstelling. Dit onderzoek is verder relevant voor het casestudiegebied in Nepal, met aantonen van de noodzaak aan van een verantwoord grondbeleid dat alle vormen van landrechten erkent, met name in een context een post ramp context. De toepassing Fit-For-Purpose Land Administration in Nepal is nu breed geaccepteerd bij zowel de landmeetkundige gemeenschap als bij de Nepalese bevolking en bij de overheid, wat heeft geleid tot de erkenning van informele landrechten en gelijke toegang tot land voor landlozen, kleine houders en informele land bezitters in het Nationale Landbeleid 2019 van Nepal. Ten slotte toont 
het onderzoek met betrekking tot andere maatschappelijke uitdagingen en behoeften aan dat een holistische aanpak de vraag naar en de mogelijkheden van koppelingen met de Agenda 2030 voor duurzame ontwikkeling en zijn 5P's (People, Planet, Prosperity, Peace and Partnership) versterkt, alsmede het kennisgebied land administratie. 


\section{Zusammenfassung}

Responsible Land Administration (RLA) versucht kontinuierlich die formellen Prozesse der Landadministration mit den lokalen, wechselnden gesellschaftlichen Anforderungen, wirtschaftlichen Bedingungen und gesetzlichen Erfordernissen in Einklang zu bringen. Die Motivation ist durch den Wunsch geprägt, die Landrechte der schutzbedürftigen und marginalisierten Gruppen zu verbessern und abzusichern. Disaster Risk Management (DRM) und im Besonderen Community-basiertes Katastrophenmanagement (CBDRM) hat zum Ziel Gefahren durch Naturkatastrophen auf lokaler Ebene einzuschätzen und zu bewältigen - es wird die Wichtigkeit der Community im Falle von Naturkatastrophen betont. Jedoch wurde der LA im Rahmen des DRM bislang nur minimale Aufmerksamkeit geschenkt, sowie oft potentielle Anforderungen des DRM durch LA vernachlässigt. Und das obwohl die Anzahl der Naturkatastrophen und der davon betroffenen Menschen in den letzten Jahrzehnten erheblich gestiegen sind.

Die Agenda 2030 für nachhaltige Entwicklung - mit ihren festgelegten Zielen (SDGs) zusammen mit dem Sendai Framework for Disaster Risk Reduction fördert innovative und transformative Ansätze zur Sicherung von Land- und Eigentumsrechten für alle (UN, 2015). Es besteht Konsens über die Notwendigkeit, Ansätze der LA zu integrieren und anzuwenden, um somit besser auf die Bedürfnisse der benachteiligten Menschen, welche in katastrophengefährdeten Gebieten leben, einzugehen. Letztlich sollte LA durch einen umfassenden Ansatz hinsichtlich Grundbesitzes und Landrechte, benachteiligten Menschen dazu verhelfen, Schäden und Gefahren durch Katastrophen möglichst gering zu halten. Dieser Ansatz sollte die Prävention, die Abschwächung, die Vorbereitung sowie die Reaktion auf Naturkatastrophen und die Rehabilitation nach solch einer zum Ziel haben.

Ein integrierter Ansatz wird durch das Fehlen eines theoretischen Rahmens, welcher die Gebiete der LA und DRM vereint, erschwert. Es fehlen Methoden mit integrierten, fachspezifischen Herangehensweisen und mangelndes Wissen über lokale Initiativen. Genau deshalb bedarf es jedoch eines integrierten Ansatzes für Responsible LA (RLA) in Bezug auf Katastrophenmanagement (DRM). Diese wissenschaftliche Arbeit mit all seinen Konzepten und Werkzeugen stellt einen Leitfaden dar wie RLA und DRM einhergehen können. Hierfür wurden vier spezifische Zielsetzungen ausgearbeitet.

Erstens, wird ein konzeptioneller Rahmen erarbeitet, welcher die theoretischen Verknüpfungen zwischen RLA und DRM darstellt. Dieser Rahmen erläutert, wie sich die Kräfte des globalen Wandels, Risikofaktoren von Katastrophen und grundlegende LA Modelle gegenseitig beeinflussen. Dafür wird der konzeptionelle Rahmen durch 
Abstraktionsmechanismen und weiteres fachspezifische Wissen von Modellen erarbeitet. Mit Hilfe dieser Methoden werden die Zusammenhänge und Wechselwirkungen zwischen den drei identifizierten grundlegenden Kräften des globalen Wandels (Menschen, Land, Naturkatastrophen) und den drei Risikofaktoren für Katastrophen (Vulnerabilität, Gefährdung, Risiko) erforscht. Auf den Ergebnissen basierend, wird eine graphische Darstellung des konzeptionellen Rahmens erarbeitet. Die theoretische Anwendung dieses konzeptionellen Rahmens wird auf literaturbasierten Fallstudien aus Kenia, den Philippinen, Indien und Haiti untersucht. Diese zeigen deutlich den Zusammenhang und die möglichen Beiträge von RLA zu DRM.

Zweitens, zur Umsetzung eines solch integrierten Ansatzes ist die Entwicklung eines konzeptionellen Datenmodells, um die zwei Bereiche von LA und DRM auf Datenebene zu verknüpfen, notwendig. Das konzeptuelle Datenmodell LA-DRM, wird nach einer umfangreichen Literaturstudie über themenbezogene Werkzeuge und Standards entwickelt. Dieses Modell unterstützt Interoperabilitäts- und Standardisierungsmaßnahmen um verschiedene Antworten auf die grundlegenden Fragen „Was?", „Wo?" und „Wie?“ in Bezug auf betroffene Personen und Communities zu liefern. Deshalb erlaubt das Datenmodell die Integration von LA und DRM gleichermaßen. Diese wissenschaftliche Arbeit zeigt die Möglichkeit auf, LA und DRM auf der Ebene der Datenerfassung, Datenspeicherung und Datenanwendung zu verknüpfen. Um diese Verknüpfung noch mehr hervorzuheben, wird das Potenzial des LA-DRM Modells in allen DRM Phasen graphisch illustriert.

Drittens, es gibt wenige lokale Initiativen, welche einen integrierten Ansatz bzgl. RLA und DRM implementiert haben. Mit Hilfe einer Fallstudie, wird das konzeptuelle Datenmodell - LA-DRM - gemeinsam mit innovativen RLA Werkzeugen in Dolakah, Nepal, getestet. Weitere Analysen zu den Auswirkungen und Hürden eines unvollständigen LA - Systems im Zusammenhang mit den Folgen von Katastrophen werden gezeigt und analysiert. Die Fallstudie identifiziert Kinder, Ältere, beeinträchtigte Personen, Frauen, Arme, und ausgegrenzte Menschen als Risikogruppen, die von nicht rechtmäßig anerkannten Besitzansprüchen betroffen sind. Die Forschungsarbeit belegt, dass der Fokus der DRM Richtlinien zu eben diesen Risikogruppen umgeleitet werden muss, anstatt kurzfristig zu kompensieren, umzusiedeln und Hilfsmaßnahmen bereitzustellen. Des Weiteren beweist die Forschungsarbeit wie wichtig es ist, alle Mensch-zu-Land Beziehungen zu dokumentieren, um Naturkatastrophen vorbereitet entgegenzutreten, und so die Folgen abzuschwächen bzw. Hilfeleistung gezielt tätigen zu können. 
Viertens, nach der Ausarbeitung des Zusammenhangs von RLA und DRM auf theoretischer, methodischer und fachlicher Ebene, werden Möglichkeiten aber auch Einschränkungen dieses integrierten Ansatzes untersucht. Hierfür werden zwei von der UN entwickelte Rahmenwerke, Framework for Effective Land Administration (FELA) und Strategic Framework for Geoinformation Services for Disaster (SFGISD), analysiert. Diese Analyse soll vor allem ermitteln, ob diese zwei Rahmenwerke dem institutionellen oder Netzwerk-basierten Methoden der Politik Transferprozessen entsprechen. Die Analyse zeigt, dass, obwohl die zwei Rahmenwerke von konventionel institutionellen Methoden ausgehen, sie durchaus auch die Anwendung von Netzwerk- basierten Methoden fördern. Der in dieser Forschungsarbeit angewendete und adaptierte Beurteilungsrahmen kann für zukünftige Politik Transferprozesse in Bezug auf die Agenda 2030 für nachhaltige Entwicklung angewendet werden.

Abschließend kann festgehalten werden, dass RLA im Rahmen von DRM ein wesentliches Instrument zur Eindämmung und Abschwächung der Auswirkungen von Naturkatastrophen fungieren kann. Es bedarf weiterer Studien, um einen ähnlichen ganzheitlichen Ansatz für andere Bereiche/ globale Herausforderungen zu untersuchen und somit das Verständnis von effektiver LA zu verbessern, ein Begriff, der im Rahmen dieser Forschungsarbeit etabliert wurde. Die Ergebnisse dieser wissenschaftlichen Arbeit heben das Potential eines integrierten Ansatzes für RLA im Rahmen von DRM auf theoretischer, methodischer- und fachlicher Ebene und in Bezug auf Politikdiffusion hervor und liefert dadurch neue Erkenntnisse. Dies ist von besonderer Bedeutung, da beide Disziplinen (LA und DRM), sich in den SDGs wiederfinden und untrennbar verknüpft sind. Für die Fallstudie von Nepal unterstreichen die Ergebnisse darüber hinaus, dass RLA sich mit allen Formen von Landbesitzrechten vor allem nach Katastrophen, befassen muss. Die Anwendung von FFPLA in Nepal wurde sowohl von den nationalen Vermessungsinstitutionen als auch von der Bevölkerung und der Regierung begrüßt. Dies führte zur National Land Policy 2019, welche den informellen Grundbesitz und einen gerechten Zugang zu Grundbesitz/ Land für kleine Landbesitzer/ Kleinbauern und informelle/ inoffizielle Siedler in Nepal anerkennt. Bezugnehmend auf andere gesellschaftliche Herausforderungen und Bedürfnisse, in Hinblick auf Landadministration und Katastrophenmanagement, wird in dieser wissenschaftlichen Arbeit darauf hingewiesen, dass ein ganzheitlicher Ansatz die Möglichkeiten zur Verknüpfung der Agenda 2030 mit ihren fünf Ps (People, Planet, Prosperity, Peace and Partnership) und RLA verstärkt. 
About the author

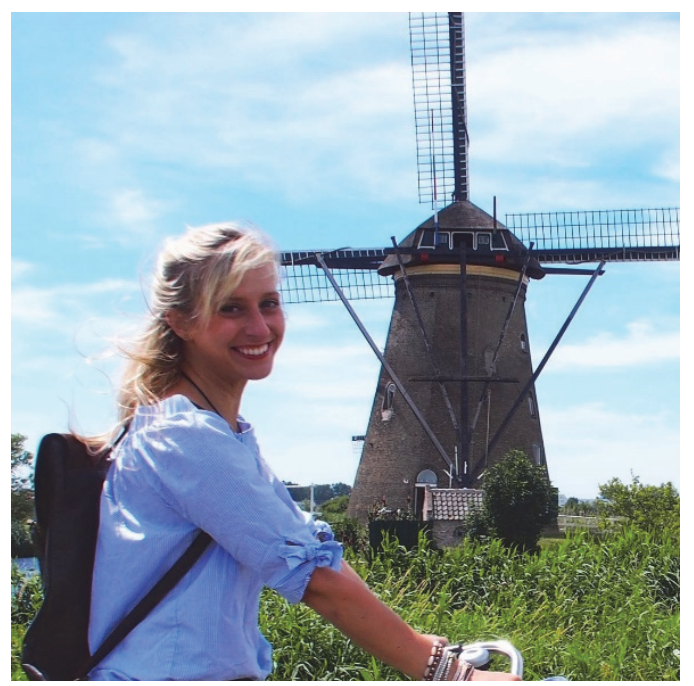

Eva-Maria Unger was born on the $17^{\text {th }}$ of March, 1986 in Oberwart, Austria. She completed her Master's degree in Geodesy and Surveying (Msc/Dipl.Ing.) at the Vienna University of Technology (TU Wien) in 2011 with her thesis on 'Semantic Transformation in the context of INSPIRE'. After obtaining her master's degree, she joined the Federal Office of Metrology and Surveying (BEV) as Surveying Engineer in the Information Management Department. She worked on national and international projects investigating, adapting, and applying engineering techniques and developing geodata products and web-based applications. Eva-Maria was a representative of the Federal Office in the national address register council. She was the project manager for the development of geocoding applications and web services to enhance the address system of Austria (GeoGIP). From 2014-2016 she was the chair of the Federal Office for Metrology and Surveying Admission Commission. During her time at BEV she enrolled as a PhD candidate at the Faculty of Geo-Information Science and Earth Observation (ITC) of the University of Twente. She also became heavily involved the International Federation of Surveyors (FIG) becoming Chair of the FIG Young Surveyors Network (YSN) from 2015-2018. Through her continuous engagement with the UN-Habitat Global Land Tool Network (GLTN) she became advisory board member of the Social Tenure Domain Model (STDM). Under her FIG YSN leadership, the Volunteer Community Surveyors Program (VCSP) was established in a cooperation with UN-Habitat GLTN, and the FIG Foundation and various Training of Trainers programmes were conducted worldwide resulting in an STDM Ambassador Network. In 2017 EvaMaria joined the Netherlands Cadastre, Land Registry and Mapping Agency, Kadaster where she works as a Geodetic Advisor at Kadaster International. She is working on projects in Mozambique, Indonesia and Nepal. Eva-Maria is one of the principal authors of the UN-Habitat GLTN publication 'Fit-For-Purpose Land Administration (FFP LA) in a post disaster context - Lessons and Applications from Nepal'. She is heavily involved the United Nations Committee of Experts on Global Geospatial Information Management (UN-GGIM) Expert Group on Land Administration and Management (EG-LAM) supporting the development of the Framework for Effective Land Administration.

As a PhD candidate, Eva-Maria was involved in teaching and supervising MSc students and she organised a SENSE writing week for other PhD candidates on Terschelling, the Netherlands. Eva-Maria's research interests focus on geo-spatial technological advances and innovative developments to tackle societal needs and challenges (SDGs). She is 
result-driven, with a strong capacity to inspire her colleagues with innovative solutions and to push for high quality results, in both technical and societal aspects. In her leisure time she has a very active and creative mind which she expresses either through running, surfing or yoga, where she is a certified teacher.

Unger, E.-M., Zevenbergen, J. \& Bennett, R., 2017. On the need for pro-poor land administration in disaster risk management. Survey Review, August, Volume 6265, pp. 1-12.

Unger, E.-M., Zevenbergen, J., Bennett, R. \& Lemmen, C., 2019a. Application of LADM for disaster prone areas and communities. Land Use Policy, 80(January), pp. 118-126.

Unger, E.-M., Chatkuli, R., Antonio, D., Lemmen, C., Zevenberge, J., Bennett, R., \& Dijkstra, P., 2019b. Creating resilience to natural disasters through FFP land administration - an application in Nepal. Washington DC, US, 2019 World Bank Conference on Land and Poverty, Washington DC.

Unger, E.-M., Chatkuli, R., 2019c. Fit-For-Purpose Land Administration in a post disaster context. Lessons and Applications from Nepal. 04/2019. Nairobi, Kenya

Unger, E.-M., Bennett, R., Lemmen, C., de Zeeuw, C., Teo., C., \& Zevenbergen, J., (2019). Global Policy Transfer for Land Administration and Disaster Risk Management. (Undergoing revision)

Unger, E.-M., Bennett, R., Lemmen, C., Zevenbergen, J., Dijkstra., P., \& de Zeeuw, C., (2019). LADM based models for Sustainable Development. 8th Land Administration Domain Model Workshop, 1-3 October 2019. Kuala Lumpur, Malaysia. 